FERNANDO TSUDA

\title{
UTILIZAÇÃO DE TÉCNICAS DE GPGPU EM SISTEMA DE VÍDEO-AVATAR
}

Dissertação apresentada à Escola Politécnica da Universidade de São Paulo para obtenção do Título de Mestre em Ciências. 


\title{
FERNANDO TSUDA
}

\section{UTILIZAÇÃO DE TÉCNICAS DE GPGPU EM SISTEMA DE VÍDEO-AVATAR}

\author{
Dissertação apresentada à Escola \\ Politécnica da Universidade de São \\ Paulo para obtenção do Título de Mestre \\ em Ciências.
}

Área de Concentração:

Sistemas Digitais

Orientador:

Prof. Dr. Ricardo Nakamura 
Este exemplar foi revisado e alterado em relação à versão original, sob responsabilidade única do autor e com a anuência de seu orientador.

São Paulo, 23 de janeiro de 2012.

Assinatura do autor

Assinatura do orientador

FICHA CATALOGRÁFICA

Tsuda, Fernando

Utilização de Técnicas de GPGPU em Sistema de Vídeo-Avatar/

F. Tsuda. - ed. rev. - São Paulo, 2012.

$91 \mathrm{p}$.

Dissertação (Mestrado) - Escola Politécnica da Universidade de São Paulo. Departamento de Engenharia de Computação e Sistemas Digitais (PCS).

1.Realidade virtual \#1. I. Universidade de São Paulo. Escola Politécnica. Departamento de Engenharia de Computação e Sistemas Digitais (PCS). II. t. 
Este trabalho é dedicado aos meus pais, familiares e amigos. 


\section{AGRADECIMENTOS}

Agradeço ao Prof. Dr. Ricardo Nakamura pela orientação e apoio durante o desenvolvimento deste trabalho e pela confiança depositada.

Aos meus pais Sigeki Tsuda e Keica Fulukawa Tsuda, e meus irmãos Renato e Marcos.

Aos colegas e amigos do Interlab: Prof. Dr. Romero Tori (com quem iniciei este trabalho), Mariza Ushijima Leone, Daniel Makoto Tokunaga, Silvio Ricardo Sanches, Cleber Gimenez Correa, Daniel Lemeszenski, Lucas Padovani Trias, Valdinei Silva, Alexandre Nascimento Tomoyose, João Luiz Bernardes Jr., Fabio Carmo, Ana Cláudia e a todos os demais que conheci durante o período de desenvolvimento deste trabalho.

Aos colegas e amigos da Scopus Tecnologia Ltda.: Prof. Reginaldo Arakaki, Marcos Anzai, George Marcel Smetana, Cristina Pinna e a todos os membros que fazem ou fizeram parte do Canal Internet e demais departamentos.

Aos colegas e amigos do LME: Prof. Dr. Marcelo Carreño, Prof. Dr. Marco Alayo Chávez e a todos os demais membros.

Aos amigos Marcelo Shiba, Mario Minatogawa, Evelyn Murasaki, Reinaldo Matushima, Kleber Luiz Delgado, turma da Engenharia Elétrica (Computação 2006) e a todos os amigos não citados nominalmente. 


\section{RESUMO}

Este trabalho apresenta os resultados da pesquisa e da aplicação de técnicas de GPGPU (General-Purpose computation on Graphics Processing Units) sobre o sistema de vídeo-avatar com realidade aumentada denominado AVMix. Com o aumento da demanda por gráficos tridimensionais interativos em tempo real cada vez mais próximos da realidade, as GPUs (Graphics Processing Units) evoluíram até o estado atual, como um hardware com alto poder computacional que permite o processamento paralelo de algoritmos sobre um grande volume de dados. Desta forma, é possível usar esta capacidade para aumentar o desempenho de algoritmos usados em diversas áreas, tais como a área de processamento de imagens e visão computacional. A partir das pesquisas de trabalhos semelhantes, definiu-se o uso da arquitetura CUDA (Computer Unified Device Architecture) da Nvidia, que facilita a implementação dos programas executados na GPU e ao mesmo tempo flexibiliza o seu uso, expondo ao programador o detalhamento de alguns recursos de hardware, como por exemplo a quantidade de processadores alocados e os diferentes tipos de memória. Após a reimplementação das rotinas críticas ao desempenho do sistema AVMix (mapa de profundidade, segmentação e interação), os resultados mostram a viabilidade do uso da GPU para o processamento de algoritmos paralelos nesta aplicação e a importância da avaliação do algoritmo a ser implementado em relação a complexidade do cálculo e ao volume de dados transferidos entre a GPU e a memória principal do computador.

Palavras-chave: GPGPU. Processamento paralelo. Vídeo-avatar. Realidade aumentada. Mapa de profundidade. CUDA. 


\section{ABSTRACT}

This work presents the results of research and application of GPGPU (General-Purpose computation on Graphics Processing Units) techniques on the video-avatar system with augmented reality called AVMix. With increasing demand for interactive three-dimensional graphics rendered in real-time and closer to reality, GPUs (Graphics Processing Units) evolved to the present state as a high-powered computing hardware enabled to process parallel algorithms over a large data set. This way, it is possible to use this capability to increase the performance of algorithms used in several areas, such as image processing and computer vision. From the research of similar work, it is possible to define the use of CUDA (Computer Unified Device Architecture) from Nvidia, which facilitates the implementation of the programs that run on GPU and at the same time flexibilize its use, exposing to the programmer some details of hardware such as the number of processors allocated and the different types of memory. Following the reimplementation of critical performance routines of AVMix system (depth map, segmentation and interaction), the results show the viability of using the GPU to process parallel algorithms in this application and the importance of evaluating the algorithm to be implemented, considering the complexity of the calculation and the volume of data transferred between the GPU and the computer's main memory.

Keywords: GPGPU. Parallel processing. Video-avatar. Augmented reality. Depth map. CUDA. 


\section{SUMÁRIO}

\section{Lista de Ilustrações}

Lista de Tabelas

Lista de Abreviaturas e Siglas

1 Introdução 14

1.1 Objetivo ............................ 16

1.2 Organização do Texto . . . . . . . . . . . . . . 16

2 Fundamentação Teórica 18

2.1 Processamento Paralelo de Algoritmos . . . . . . . . . . . 18

2.2 Realidade Aumentada . . . . . . . . . . . . . . . . . . 20

2.3 Visão Computacional e Processamento de Imagens . . . . . . . 22

2.4 GPU . . . . . . . . . . . . . . . . . . . 24

2.4.1 Pipeline Gráfico . . . . . . . . . . . . . . . . . . . 25

2.4 .2 Shaders...................... . . 28

2.5 GPGPU . . . . . . . . . . . . . . . . . . . 29

2.5.1 Modelo Tradicional . . . . . . . . . . . . . . . . . 30

2.5.2 APIs para Desenvolvimento GPGPU . . . . . . . . . . . . 31 
3.1 Aquisição . . . . . . . . . . . . . . . . . 35

3.2 Segmentação . . . . . . . . . . . . . . . . . . 36

3.3 Mapa de Profundidade . . . . . . . . . . . . . . . . . . . . . 37

3.4 Composição . . . . . . . . . . . . . . . . . . . . . . . . . . 39

3.5 Interação . . . . . . . . . . . . . . . . . . . . 39

4 Revisão da Literatura 43

4.1 Áreas de Aplicação . . . . . . . . . . . . . . . . . . . . . . . . . 43

4.1 .1 Processamento de Imagens . . . . . . . . . . . . 44

4.1 .2 Visão Computacional . . . . . . . . . . . . . . . . . . . 44

4.1 .3 Simulação de Física . . . . . . . . . . . . . . . . . 46

4.1 .4 Outras Áreas . . . . . . . . . . . . . . . . . . . . 47

4.2 Consolidação . . . . . . . . . . . . . . . . . . . 4 48

5 Desenvolvimento dos Módulos do AVMix com GPGPU 55

5.1 Avaliação do Sistema AVMix . . . . . . . . . . . . . . . 55

5.2 Implementação com CUDA . . . . . . . . . . . . 58

5.2.1 Organização Hierárquica das Threads . . . . . . . . . . 61

5.2.2 Organização Hierárquica da Memória . . . . . . . . . . 61

5.3 Considerações Gerais da Implementação . . . . . . . . . . . . 65

5.4 Implementação do Mapa de Profundidade . . . . . . . . . . . 66

5.5 Implementação da Segmentação . . . . . . . . . . . . . . . 68

5.6 Implementação da Interação . . . . . . . . . . . . . . 69 
6.1 Critérios de Avaliação . . . . . . . . . . . . . . . . . . . 72

6.2 Mapa de Profundidade . . . . . . . . . . . . . . . 73

6.3 Segmentação . . . . . . . . . . . . . . . . . 78

6.4 Interação . . . . . . . . . . . . . . . . . . . . . 79

6.5 Considerações Finais . . . . . . . . . . . . . . . . . . . . . . . 81

7 Conclusões $\quad 83$

$\begin{array}{lr}\text { Referências } & 87\end{array}$ 


\section{LISTA DE ILUSTRAÇÕES}

1.1 Evolução da capacidade de processamento em ponto flutuante e da largura de banda entre o processador e a memória das GPUs e CPUs (NVIDIA, 2011a). . . . . . . . . . . . . . 15

2.1 Espaço contínuo da virtualidade (MILGRAM; KISHINO, 1994). . . . 21

2.2 Conceito de um jogo de pôquer em realidade aumentada, onde os usuários reais estão imersos em um ambiente virtual (TOKUNAGA, 2010). . . . . . . . . . . . . . . . . . 22

2.3 Organização das áreas de processamento de dados, computação gráfica, processamento de imagens e visão computacional conforme os domínios de entrada e saída (VELHO; FRERY; GOMES, 2008). . . . . . . . . . . . . . . . . . . 23

2.4 Ilustração da diferença arquitetural entre a CPU e GPU. (NVIDIA, 2011a).

2.5 Pipeline gráfico adotado pelos hardwares gráficos atualmente. As fases do processamento de vértices, de primitivas e de fragmentos podem ser programados pelo usuário. Baseado em (FATAHALIAN; HOUSTON, 2008).

3.1 Tela da aplicação de testes do sistema AVMix (NAKAMURA, 2008). 34

3.2 Visão geral do sistema AVMix e sua divisão nos módulos de aquisição, segmentação, mapa de profundidade, composição e interação (NAKAMURA, 2008) 
3.3 Diagrama que mostra a configuração usada para a aquisição das imagens de entrada através de câmeras de vídeo (NAKAMURA, 2008). . . . . . . . . . . . . . . . . 36

3.4 Algoritmo de segmentação usado no AVMix: (a) imagem de referência do fundo; (b) imagem capturada pela câmera; (c) máscara obtida por subtração e limiarização das duas imagens anteriores; (d) imagem final resultante (NAKAMURA, 2008). . . . . . 37

3.5 Exemplo de obtenção do mapa de profundidade; (a) visão esquerda; (b) visão direita; (c) mapa de profundidade ideal resultante (MIDDLEBURY, 2002) . . . . . . . . . . . . . . 38

5.1 Tempo de processamento da aplicação AVMix com o uso do hardware especificado na tabela $5.1 \ldots \ldots$. . . . . . . . 58

5.2 Comparação de um algoritmo de soma de matrizes quadradas implementados na CPU com linguagem $\mathrm{C}$ e na GPU usando a CUDA. Os trechos destacados mostram a substituição dos laços pelos kernels, executados implicitamente pelas várias threads paralelas alocadas a partir do programa principal. . . . . . 60

5.3 Organização hierárquica das threads, blocos e grids computacionais na arquitetura CUDA. Baseado em (NVIDIA, 2010). . . . . . 62

5.4 Tipos de memória e relação com os elementos lógicos da GPU (FUNG; MANN, 2008). . . . . . . . . . . . . . . . . 63

5.5 Fluxo geral de um programa executado na GPU. . . . . . . . . 64

5.6 Mapeamento de threads em uma região bidimensional da memória (SANDERS; KANDROT, 2010). . . . . . . . . . . . . 65

5.7 Diagramas de classes do módulo mapa de profundidade. . . . . 67 
5.8 Diagramas de classes do módulo segmentação. . . . . . . . . . 69

5.9 Diagramas de classes do módulo integração. . . . . . . . . . . . 70

6.1 Tempo de processamento em milissegundos dos módulos do AVMix usando um conjunto de dados sintético. . . . . . . . . . . 74

6.2 Taxa de quadros por segundo obtida usando um conjunto de dados sintético. . . . . . . . . . . . . . . . 75

6.3 Tempo de processamento em milissegundos dos módulos do AVMix usando um conjunto de dados reais. . . . . . . . . . . . 76

6.4 Taxa de quadros por segundo obtida usando um conjunto de dados reais. . . . . . . . . . . . . . . . . . . 77

6.5 Comparação do tempo de processamento em milissegundos entre as implementações usando a memória global e memória de textura. . . . . . . . . . . . . . . . 78

6.6 Tempo de processamento em milissegundos do módulo de segmentação do AVMix usando um conjunto de dados reais. . . . . . 79

6.7 Tempo de processamento do módulo de integração do AVMix considerando a profundidade máxima de 6 níveis. (a) Tempo de processamento em milissegundos obtido em cada nível; (b) Detalhamento do resultado anterior, com os tempos obtidos a partir do nível 5

6.8 Tempo de processamento total, em milissegundos para a criação da octree inteira com 6 níveis. 


\section{LISTA DE TABELAS}

4.1 Implementações de algoritmos feitas usando-se técnicas de GPU, mostrando a linguagem de programação usada e o ganho obtido. . . . . . . . . . . . . . . . . . . . . 49 49

5.1 Especificação do sistema usado no trabalho . . . . . . . . . . 56

5.2 Porcentagem de tempo médio gasto no processamento de 1 quadro, considerando a execução com 8 threads. . . . . . . . . 57

5.3 Tipos de memória disponibilizadas pela GPU. . . . . . . . . . . . 64

6.1 Ocupação da GPU durante o processamento do mapa de profundidade. . . . . . . . . . . . . . . 76

6.2 Ocupação da GPU durante processamento da segmentação. . . 78

6.3 Resultados consolidados, mostrando valor de quadros processados por segundo (referência e alterado), o ganho calculado sobre o valor das taxas obtidas e o ganho obtido isoladamente pelo módulo alterado. . . . . . . . . . . . . . . . . . . . . . 82 


\section{LISTA DE ABREVIATURAS E SIGLAS}

GPU Graphics Processing Unit

CPU Central Processing Unit

GPGPU General-Purpose computation on Graphics Processing Units

API Application Programming Interface

IDE Integrated Development Environment

CUDA Computer Unified Device Architecture

GLSL OpenGL Shading Language

HLSL (DirectX) High-Level Shader Language

SGM Semi-global matching

SRAD Speckle reducing anisotropic diffusion

DCT Discrete cosine transform

BFV Bitwise fast voting

DES Data Encryption Standard

SFC Space filling curves

VLSI Very-large scale integration

SISD Single Instruction Single Data

SIMD Single Instruction Multiple Data

SIMT Single Instruction Multiple Threads

MISD Multiple Instruction Single Data 
MIMD Multiple Instruction Multiple Data

RA Realidade Aumentada

ULA Unidade Lógica Aritmética

RAM Random Access Memory 


\section{INTRODUÇÃO}

O presente trabalho dá continuidade ao sistema denominado AVMix, apresentado em Nakamura (2008). O AVMix é um sistema de interação com realidade aumentada responsável pelas atividades de identificação, exibição e interação de um vídeo-avatar em um ambiente tridimensional. Este sistema, que será detalhado adiante, implementa alguns algoritmos de visão computacional e processamento de imagens que possuem requisitos críticos em termos de tempo de execução. Propõe-se a resolução deste problema através de técnicas que permitem a execução paralela de algoritmos usando-se placas aceleradoras gráficas.

Nos últimos anos, a arquitetura das placas aceleradoras gráficas para computadores pessoais, comumente conhecidas como Graphics Processing Units (Unidades de Processamento Gráfico) ou GPUs evoluiu para um hardware flexível e programável, possibilitando o seu uso em aplicações além da Computação Gráfica. A sua arquitetura altamente paralela também possibilita que as aplicações sejam desenvolvidas dentro deste paradigma, possibilitando o aumento de desempenho. Apesar da evolução dos processadores de uso geral, neste texto referidos pela sigla CPU (do inglês Central Processing Unit, Unidade Central de Processamento) para uma arquitetura de múltiplos núcleos, pode-se verificar na figura 1.1 a maior evolução do poder de processamento e largura de banda de memória das GPUs neste mesmo período, motivada principalmente pela alta demanda do mercado por gráficos tridimensionais in- 
terativos em alta resolução e realistas, processados em tempo real, conforme levantado por Nvidia (2011a).
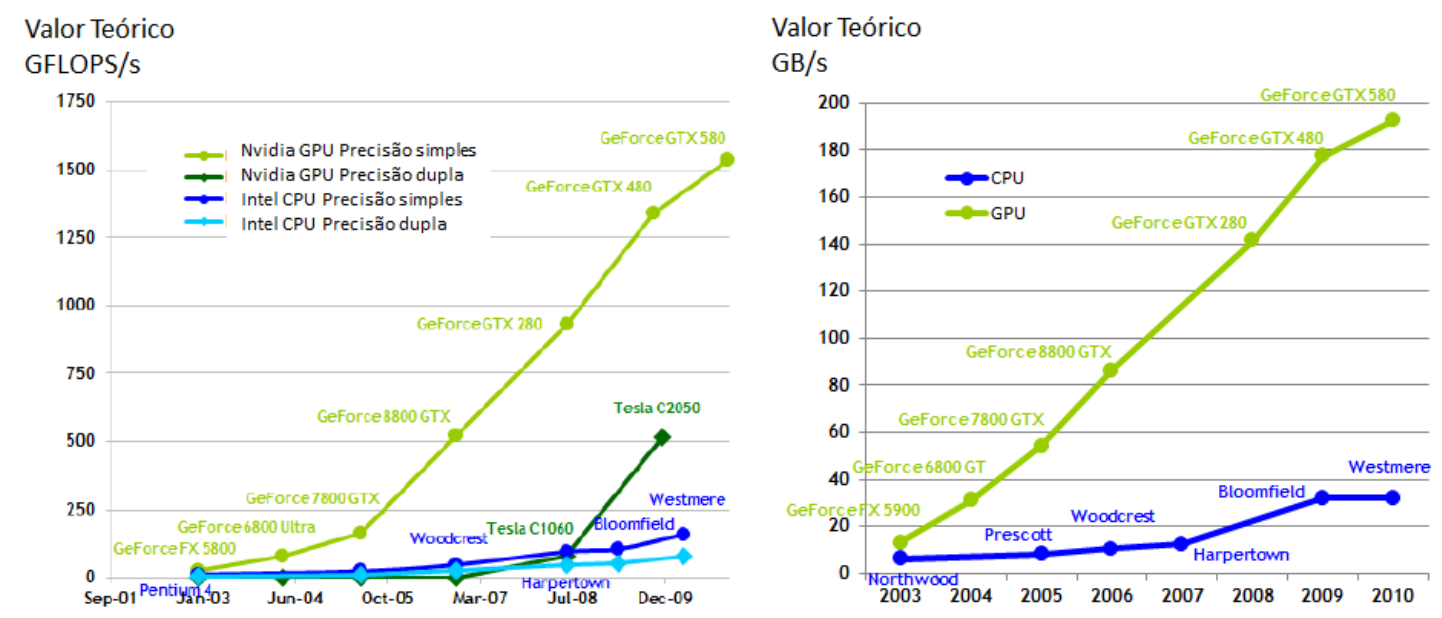

Figura 1.1: Evolução da capacidade de processamento em ponto flutuante e da largura de banda entre o processador e a memória das GPUs e CPUs (NVIDIA, 2011a).

O desenvolvimento desta arquitetura paralela possibilitou a criação de técnicas que possibilitam o uso das GPUs como um co-processador que auxilia a CPU na execução de programas, resultando em um ganho significativo de desempenho na maioria dos casos. Dentro da área de realidade aumentada e jogos eletrônicos, esta distribuição no processamento entre a CPU e GPU possibilita a liberação dos recursos computacionais para o processamento de outras tarefas, como por exemplo o processamento de sons, o cálculo de interações entre os objetos presentes dentro de um ambiente virtual e a interpretação das interações entre o usuário e o computador. As técnicas que usam a GPU para processamento de algoritmos em geral podem ser agrupadas sob o termo GPGPU (sigla criada a partir da expressão inglesa General-Purpose computation on GPUs, Computação de Propósito Geral em GPUs) (GPGPU, 2002), e o seu uso permite o desenvolvimento de aplicações de alto desempenho em várias áreas de conhecimento, como, por exemplo, a área de visão computacional, processamento de imagens, processamento de algoritmos fí- 
sicos, entre outros.

\subsection{Objetivo}

O cenário apresentado na introdução é o motivo do desenvolvimento deste trabalho, que tem o objetivo de avaliar as implementações das rotinas críticas ao desempenho do sistema AVMix e propor novas implementações utilizando técnicas atualizadas de GPGPU, visando o aumento do desempenho geral deste sistema. Ao mesmo tempo, o trabalho também avalia o processo de desenvolvimento e adaptação de algoritmos para GPGPU, através de paradigmas de desenvolvimento atualizados (como através das linguagens CUDA ou OpenCL).

\subsection{Organização do Texto}

Este texto é organizado da seguinte forma: no capítulo 2, serão apresentados os aspectos conceituais referentes ao processamento paralelo de algoritmos. Também serão mostrados alguns conceitos importantes referentes a realidade aumentada e a sua relação com as áreas de visão computacional e processamento de imagens. Em seguida, será apresentada a evolução das GPUs até o seu estado atual, representada por uma arquitetura unificada que possibilita o seu uso para processamento geral. O capítulo 3 detalha o sistema AVMix, que será utilizado para o desenvolvimento deste trabalho. Depois, o capítulo 4 mostra alguns trabalhos realizados que envolvem o uso da GPGPU, e com foco nas áreas de conhecimento usadas pelo AVMix. O capítulo 5 descreve a metodologia usada para implementação e avaliação dos algoritmos críticos do AVMix implementados com as técnicas de GPGPU. Os resultados dos testes realizados após a implementação são apresentados e discutidos 
no capítulo 6 . O capítulo 7 apresenta as conclusões e considerações finais deste trabalho. 


\section{FUNDAMENTAÇÃO TEÓRICA}

Para explicar a motivação do uso da GPU para processamento de algoritmos gerais, deve-se antes entender a evolução ocorrida nas áreas de processamento paralelo, da computação gráfica e o desenvolvimento das GPUs, possibilitando a sua transformação de uma unidade dedicada para uma unidade de processamento geral.

\subsection{Processamento Paralelo de Algoritmos}

Como apresentado em Duncan (1990), foi possível verificar a introdução de uma grande variedade de arquiteturas computacionais para o processamento paralelo e que possibilitou o aumento de desempenho dos sistemas computacionais. Culler, Gupta e Singh (1997) dizem que este aumento deve-se ao avanço da tecnologia VLSI (very-large scale integration, ou integração em escala muito grande), que permitiu alocar um número cada vez maior de transístores em um chip, e ao mesmo tempo aumentar sua frequência de relógio (clock rate). Culler, Gupta e Singh (1997) observam também um ciclo evolutivo onde este aumento de desempenho permite o aumento nas funcionalidades das aplicações computacionais, ocasionando a uma nova demanda por desempenho destas aplicações, e assim sucessivamente. Apesar destes avanços na área de hardware, tradicionalmente o software tem sido desenvolvido considerando-se um fluxo serializado de execução, o que muitas vezes 
impede o aproveitamento máximo do processador.

Para possibilitar o uso mais eficiente dos processadores atuais, compostos por múltiplos elementos de processamento, é possível desenvolver o software com o emprego de técnicas de programação paralela. Estas técnicas basicamente baseiam-se no uso de rotinas de comunicação e sincronização entre os múltiplos elementos de processamento, possibilitando a colaboração mútua para a resolução de um problema. Skillicorn e Talia (1998) mostram que o processamento paralelo é dependente de três componentes: os processadores, os módulos de memória e os elementos de comunicação.

Duncan (1990) e Culler, Gupta e Singh (1997) classificam os sistemas paralelos através da taxonomia de Flynn, que caracteriza os sistemas paralelos conforme a quantidade de instruções executadas e a quantidade de dados processados em um determinado instante de tempo. Considerando-se estes dois parâmetros, os sistemas paralelos podem ser classificados em quatro tipos:

- SISD (Single Instruction Single Data): Sistema tradicional serializado, que executa uma determinada instrução sobre um único conjunto de dados;

- SIMD (Single Instruction Multiple Data): Sistema onde uma instrução em comum é executada sobre um conjunto variado de dados em paralelo;

- MISD (Multiple Instruction Single Data): Sistema onde várias instruções são executadas em paralelo sobre um único conjunto de dados;

- MIMD (Multiple Instruction Multiple Data): Sistema onde várias instruções são executadas sobre vários conjuntos de dados em paralelo.

Skillicorn e Talia (1998) apresentam uma classificação de acordo com o modelo de comunicação adotado pela arquitetura paralela: 
- Passagem de mensagem;

- Transferência de dados através de memória compartilhada;

- Acesso direto à memória remota.

Também de acordo com Skillicorn e Talia (1998), um modelo de computação paralela é uma interface que separa as propriedades de alto e de baixo nível, definindo uma máquina abstrata que provê certas operações para o nível mais alto e requer a implementação destas funções para o nível abaixo. Este modelo foi desenvolvido visando separar os interesses da programação e da execução paralela.

\subsection{Realidade Aumentada}

A realidade aumentada (augmented reality), ou RA, é um conceito variante da realidade virtual (virtual reality) que permite a disposição de objetos virtuais dentro de um ambiente real, complementando-o. A diferença em relação a realidade virtual reside no fato de que neste último o usuário é inserido dentro de um ambiente completamente sintético, sem elementos pertencentes ao ambiente real. Milgram e Kishino (1994) expande a classificação destes conceitos, definindo o espaço contínuo da virtualidade (virtual continuum), apresentado na figura 2.1. Nesta definição, a realidade virtual é classificada como sendo uma representação completamente sintética de um ambiente e seus objetos, em oposição ao ambiente real. De forma intermediária, são definidos os conceitos de realidade aumentada e virtualidade aumentada (augmented virtuality), no qual objetos reais são inseridos dentro de um ambiente sintético. Estes dois últimos compõem a chamada realidade mista (mixed reality).

Assim como definido em Nakamura (2008), este trabalho considera o uso 


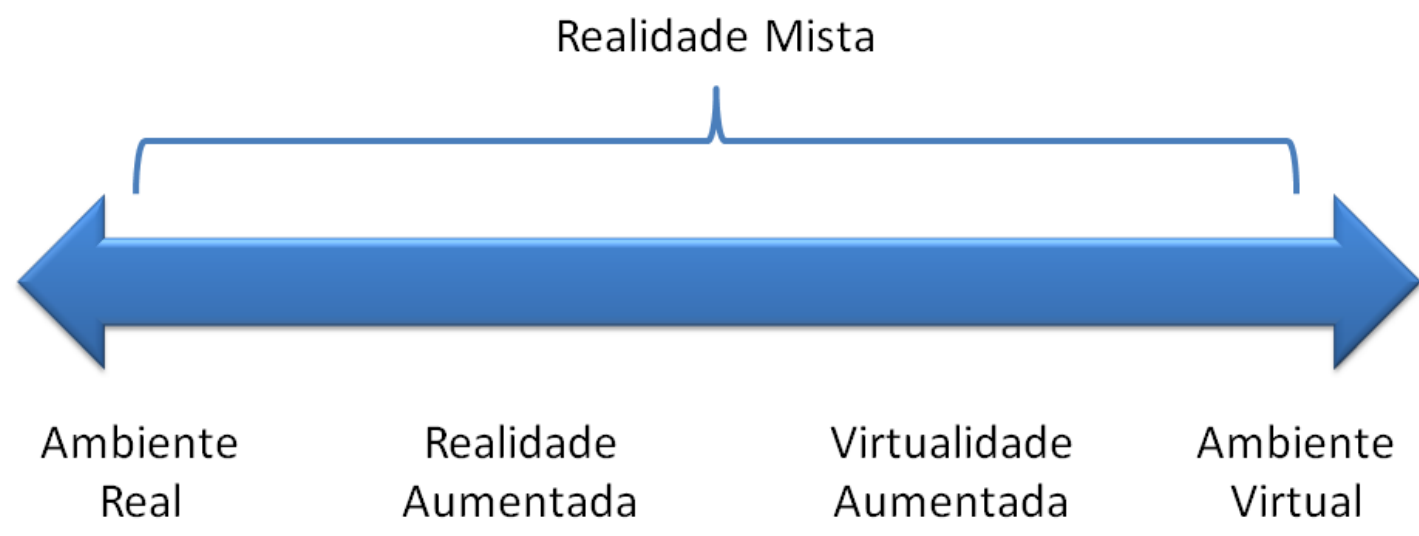

Figura 2.1: Espaço contínuo da virtualidade (MILGRAM; KISHINO, 1994).

mais abrangente do termo realidade aumentada, onde o mesmo designa os ambientes denominados como realidade mista em Milgram e Kishino (1994). A figura 2.2 mostra o conceito de um jogo de pôquer em realidade aumentada.

Para evitar a associação da realidade aumentada ao uso de dispositivos e tecnologias específicos, Azuma (1997) define as seguintes características como sendo necessárias aos sistemas de RA:

1. Combinação de real e virtual;

2. Interação em tempo real;

3. Registro em 3D.

O conceito do registro refere-se à correspondência de duas imagens distintas, porém relacionadas, como exemplificado por Gonzales e Woods (2000) em uma situação onde duas imagens de uma mesma cena podem ser obtidas de pontos de vista diferenciados. Especificamente na área de realidade aumentada, este conceito é usado para descrever os alinhamentos geométricos das entidades reais e virtuais existentes em uma cena (NAKAMURA, 2008). 


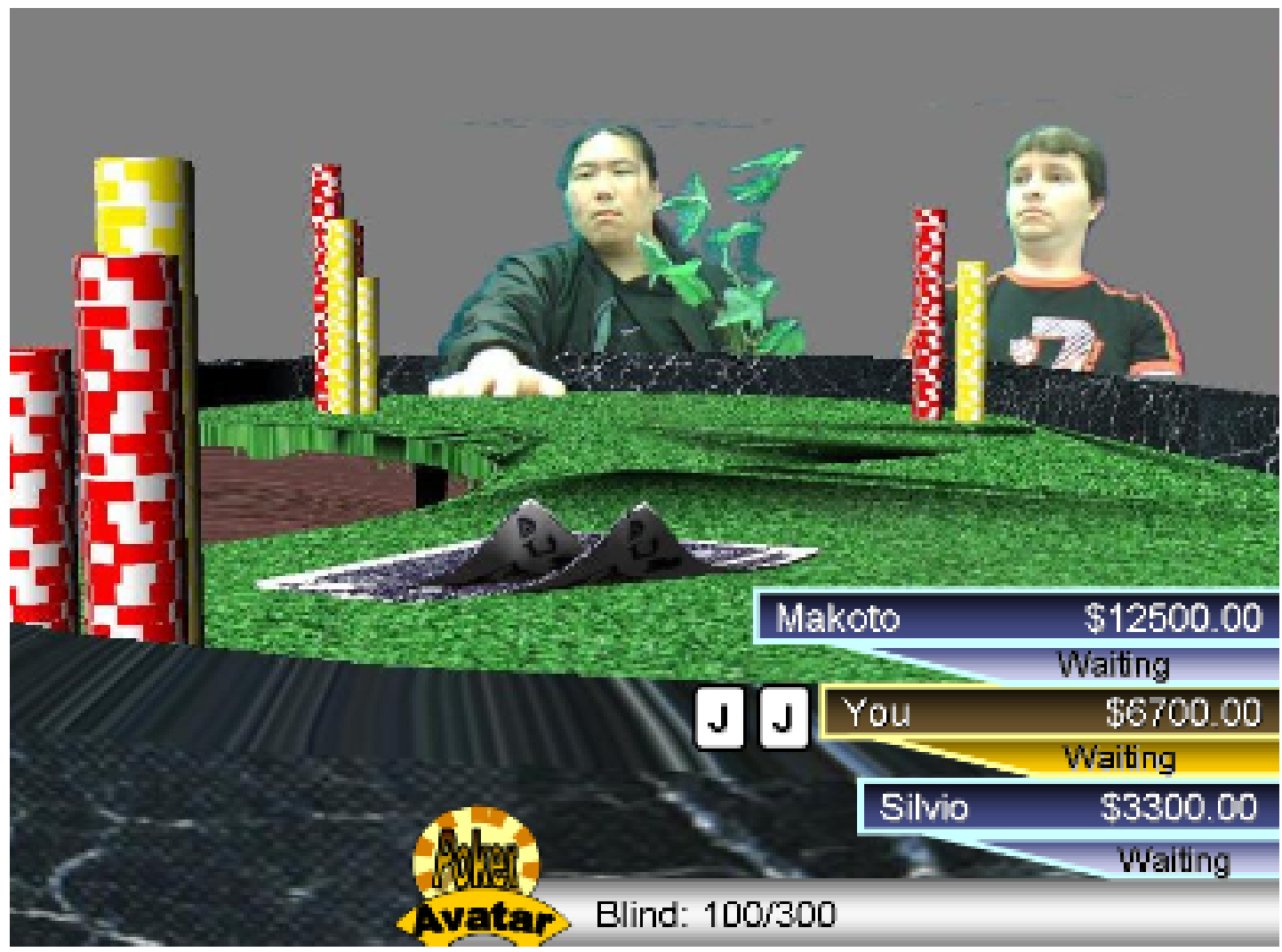

Figura 2.2: Conceito de um jogo de pôquer em realidade aumentada, onde os usuários reais estão imersos em um ambiente virtual (TOKUNAGA, 2010).

\subsection{Visão Computacional e Processamento de Imagens}

A área de imagens computacionais (computer imaging) pode ser definida como a aquisição e o processamento de informações visuais pelo computador (UMBAUGH, 1997). Esta área pode ser dividida em visão computacional e processamento de imagens. No primeiro caso, os resultados do processamento geram dados a serem usados pelo computador, enquanto que no segundo caso as imagens resultantes são processadas visando-se o uso humano. VeIho, Frery e Gomes (2008) associam ainda as áreas de computação gráfica e processamento de dados, definindo-as conforme a natureza das entradas e saídas, como mostrado na figura 2.3.

A visão computacional é um tópico importante, pois oferece as técnicas 


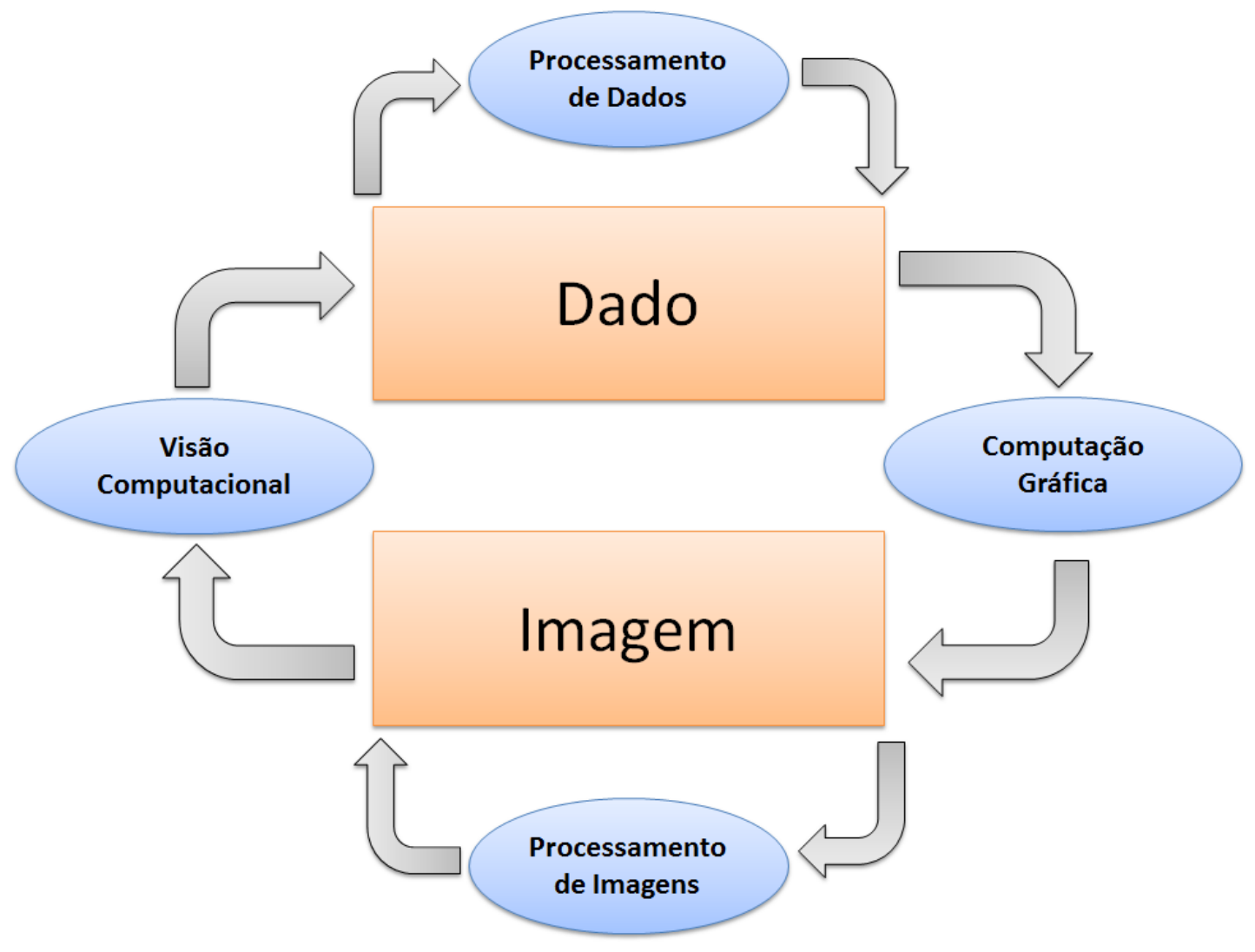

Figura 2.3: Organização das áreas de processamento de dados, computação gráfica, processamento de imagens e visão computacional conforme os domínios de entrada e saída (VELHO; FRERY; GOMES, 2008).

usadas na resolução de problemas de outras áreas, como por exemplo, a de realidade aumentada, onde a computação do registro (correspondência geométrica entre os objetos e/ou ambientes reais e virtuais) pode ser feita através de imagens obtidas por câmeras de vídeo, em uma opção de baixo custo, porém visando maximizar o aumento no desempenho, precisão, robustez e acessibilidade (BIMBER; RASKAR, 2005). Neste exemplo, é possível identificar as seguintes tarefas de visão computacional (ZITOVA; FLUSSER, 2003):

1. Detecção de características, tais como regiões fechadas, bordas, contornos, intersecções de linhas, arestas, entre outras;

2. Correspondência entre as características detectadas em uma imagem com as presentes em uma imagem de referência; 
3. Estimativa de transformação do modelo, onde os parâmetros das funções de mapeamento são obtidos através da correspondência das características detectadas com a referência;

4. Reamostragem da imagem e transformação, onde a imagem obtida é processada com o uso das funções de mapeamento, para a aplicação da técnica de interpolação adequada.

\subsection{GPU}

Como já descrito brevemente no capítulo 1, desde 2003 as GPUs tem apresentado um aumento de desempenho na execução de funções em ponto flutuante em relação às CPUs. A diferença de desempenho do primeiro chega a ser uma ordem de grandeza maior em relação ao segundo (NVIDIA, 2011a).

Tecnicamente, a diferença de desempenho entre a CPU e a GPU pode ser explicada na diferença das filosofias de projetos entre estes dois tipos de processadores: A CPU foi projetada visando a otimização de desempenho para programas sequenciais, através do uso de um sofisticado controle de lógica que permite instruções de uma thread única seja executada em paralelo ou mesmo fora de ordem, porém mantendo a impressão de que foi executado sequencialmente, e de uma grande quantidade de memória cache usada para reduzir a latência de acesso aos dados e instruções das aplicações, enquanto que a GPU prevê o cálculo de muitas operações de ponto flutuante, através da execução de várias threads, que podem executar tarefas paralelamente enquanto outras aguardam o acesso à memória, minimizando o controle de lógica requerido para thread executada. Somente uma pequena quantidade de memória cache é fornecida, visando auxiliar o requisito de banda das aplicações, evitando a necessidade de recuperação de dados através do acesso 
à memória principal. Em termos físicos, isso significa que a área de um chip será ocupada pelos processadores, e não pela memória.

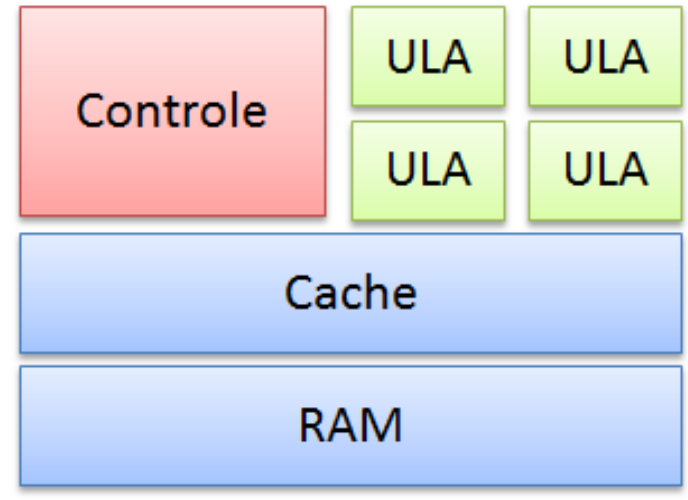

CPU

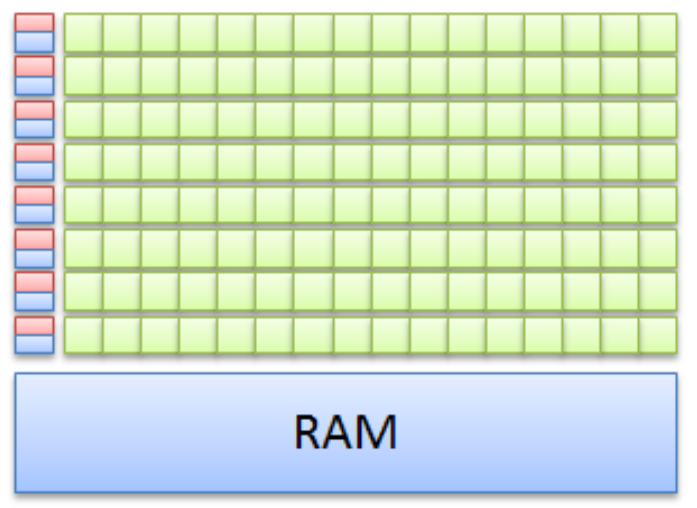

GPU

Figura 2.4: Ilustração da diferença arquitetural entre a CPU e GPU. (NVIDIA, 2011a).

As GPUs foram dimensionadas para resolver problemas possíveis de serem modelados através de computações onde os dados podem ser tratados paralelamente, ou seja, a aplicação de um algoritmo paralelamente sobre um conjunto de dados, com uma alta intensidade aritmética. Esta característica do mesmo programa ser executado em paralelo permite a diminuição da necessidade de um controle de fluxo sofisticado, e a alta intensidade aritmética faz com que a latência do acesso a memória possa ser escondida com cálculos ao invés da manutenção dos dados na memória cache.

\subsubsection{Pipeline Gráfico}

A tarefa de qualquer sistema gráfico 3D interativo é sintetizar imagens a partir de uma descrição de uma cena, com uma taxa de atualização que ofereça a sensação de movimento ao sistema de visão humano. Uma taxa desejada para o suporte de cenas animadas é algo em torno de 20 imagens, ou quadros, apresentados por segundo (KIRNER; SISCOUTTO, 2007). Esta cena 
geralmente é criada usando-se primitivas geométricas que compõem os objetos, assim como as descrições da iluminação, da reflexão da luz pelos objetos e a posição e orientação do visualizador da cena.

Os projetistas das GPUs e as APIs (Application Programming Interface) como o Direct3D e o OpenGL tradicionalmente expressam este processo de síntese da imagem como um pipeline com fases especializadas que podem ser executadas em paralelo, onde cada fase recebe como entrada o resultado obtido na fase anterior. Este pipeline, considerando sete fases, é apresentado na figura 2.5. Através desta figura, nota-se que o pipeline de processamento gráfico realiza operações sobre quatro entidades fundamentais: vértices, primitivas, fragmentos e pixels.

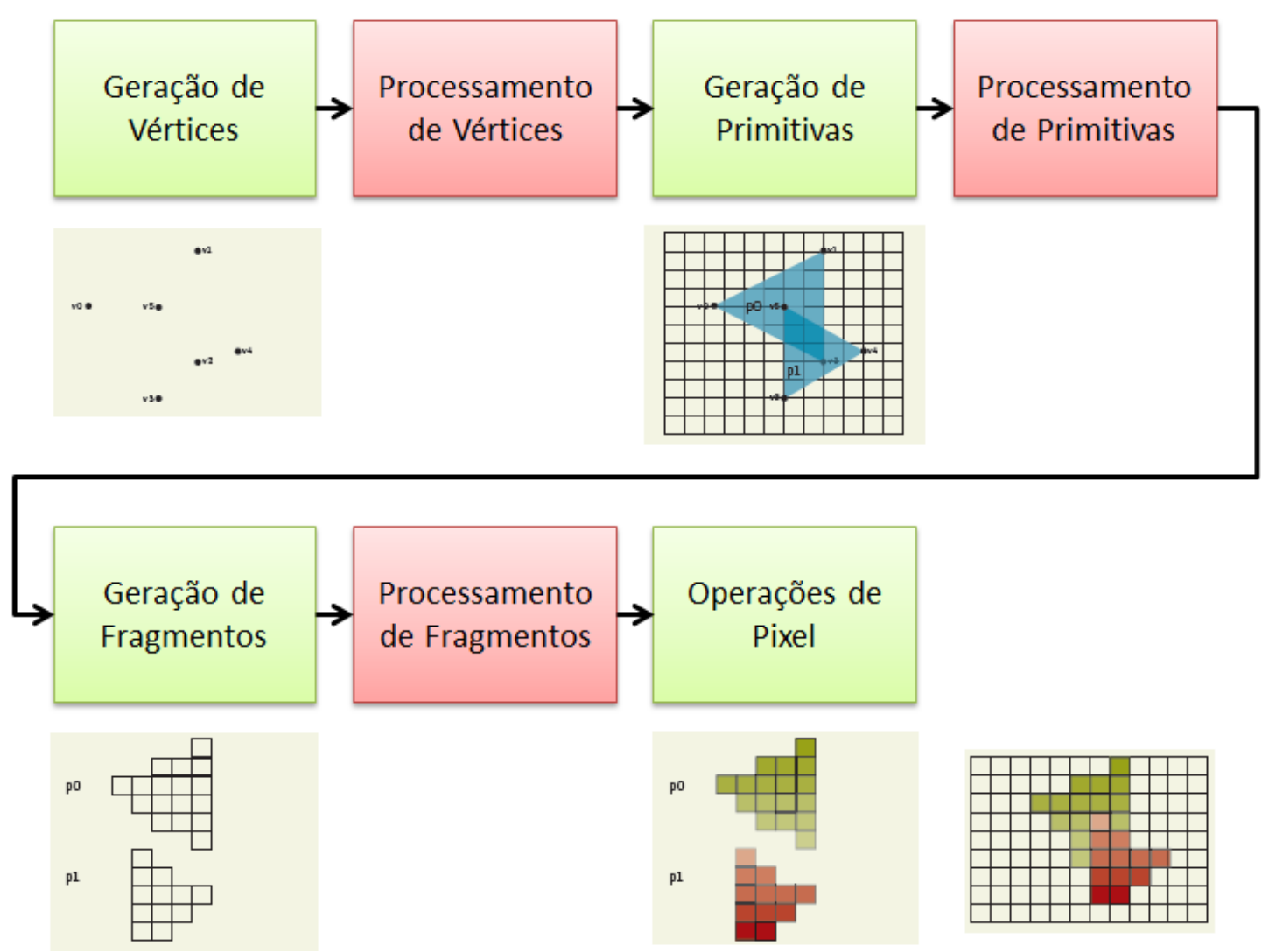

Figura 2.5: Pipeline gráfico adotado pelos hardwares gráficos atualmente. As fases do processamento de vértices, de primitivas e de fragmentos podem ser programados pelo usuário. Baseado em (FATAHALIAN; HOUSTON, 2008).

As APIs gráficas representam as superfícies como um conjunto de primiti- 
vas geométricas simples, como pontos, vetores e triângulos. Cada primitiva, por sua vez, é definida por um conjunto de vértices, onde cada registro é basicamente composto pela sua posição em um determinado sistema de coordenadas e de valores para parâmetros como cor da superfície e orientação de seu vetor normal. Uma vez que todos os vértices estejam representados em um sistema de coordenadas homogêneo, o processador de vértices pode realizar uma determinada operação em cada vértice de forma independente.

A principal função de um processador de vértices é calcular a imagem de saída bidimensional a partir da projeção do vértice.

A geração de primitivas realiza o agrupamento dos vértices obtidos da fase anterior em um fluxo de primitivas que serão ordenadas conforme a topologia dos vértices fornecida pela aplicação. O processamento de primitivas ocorre em cada primitiva para produzir um novo conjunto de primitivas, que pode ser maior ou menor que o conjunto de entrada, conforme a distância da câmera virtual.

A geração de fragmentos, ou rasterização, envolve a amostragem de cada primitiva no espaço da tela, para gerar registros contendo a posição da imagem neste espaço. O processamento dos fragmentos é responsável pela determinação de parâmetros como cor e opacidade em cada fragmento amostrado, obtida após a simulação da interação da luz com a cena. Após esta computação, são realizadas as operações por pixel, onde a posição da tela de cada fragmento é usada para calcular a contribuição nos pixels que serão exibidos na imagem de saída. Nesta fase, são consideradas a distância da câmera virtual e a oclusão entre os objetos.

Recentemente, as GPUs e as APIs substituíram o pipeline gráfico tradicional por uma arquitetura unificada na qual os processadores customizados para o processamento de vértices, primitivas e fragmentos foram substituídos 
por um grande conjunto de processadores gerais, responsáveis pelo processamento de todas estas fases. Na área de processamento gráfico, esta evolução permitiu uma melhor utilização dos processadores, uma vez que a taxa de execução dos programas de shader varia de acordo com a natureza da aplicação (LUEBKE; HUMPHREYS, 2007). Luebke e Humphreys (2007) apresentam um exemplo onde são citadas as situações do processamento de ambiente contendo um céu e terrenos distantes, através de triângulos grandes, que satura o processamento de fragmentos e mantém os processadores de vértices sem tarefas; por outro lado, esta mesma aplicação pode usar uma geometria detaIhada para representar personagens e objetos; neste caso, os processadores de vértices são usados, enquanto que os processadores de fragmentos ficam sem tarefas. A arquitetura unificada permite, desta maneira, alocar de forma mais adequada a quantidade de processadores conforme a necessidade de cada uma destas situações.

\subsubsection{Shaders}

Pela descrição do processamento realizado pelo pipeline gráfico, nota-se que as fases de processamento de vértices, primitivas e fragmentos envolvem a execução de programas sobre os dados de entrada. Conforme apresentado por Owens et al. (2007), historicamente, estes programas eram representados por rotinas fixas, onde o número limitado de operações disponíveis em cada estágio fazia com que tarefas específicas ficassem restritas a estas operações. Baseado no sucesso de sistemas de renderização offline, como o RenderMan da Pixar (APODACA; MANTLE, 1990), estas fases do pipeline ganharam flexibilidade, permitindo ao desenvolvedor programá-los com a função a ser executada.

Para isto, foram criadas as funções de shader, que possibilitam a pro- 
gramação do comportamento da aplicação nestas fases de processamento de vértices, de primitivas e de fragmentos. Neste contexto, as funções fixas para as operações na fase do processamento de vértices são substituídas por um programa de vértices (vertex program) e as funções fixas no processador de fragmentos são substituídas por programas de fragmentos (fragment program). Para facilitar o desenvolvimento destes programas dentro da área de processamento $3 \mathrm{D}$ em tempo real, algumas linguagens de alto nível foram criadas, dentre as quais as mais usadas são as seguintes:

- OpenGL Shading Language (GLSL): Linguagem de shader desenvolvida para ser usada juntamente com o OpenGL (OPENGL, 2011);

- Cg: Linguagem de programação criada pela Nvidia, que se destaca pela independência de API (NVIDIA, 2011c);

- DirectX High-Level Shader Language (HLSL): Linguagem de shader desenvolvida pela Microsoft para ser usada com o DirectX, é similar ao Cg da Nvidia (MICROSOFT, 2011).

Os programas desenvolvidos através destas linguagens geralmente são compilados e então executados pelos drivers gráficos em tempo de execução. A capacidade de programação destes estágios do pipeline permitiu o avanço da computação de propósito geral na GPU.

\subsection{GPGPU}

O aumento do desempenho juntamente com a possibilidade de programação nas fases de processamento de vértices e de fragmentos possibilitou aos desenvolvedores moverem as rotinas computacionais mais intensas de um 
software para a GPU. Como será detalhada nas seções subsequentes, inicialmente a programação destas rotinas era realizada através da programação usando as APIs gráficas, evoluindo para a possibilidade do uso dos shaders, e somente recentemente surgiram iniciativas para facilitar a programação de funções gerais na GPU (WU; LIU, 2008).

\subsubsection{Modelo Tradicional}

O modelo de programação na GPU tradicional é baseado no modelo de programação por fluxo de dados (stream programming model), onde o paralelismo e a comunicação dentro da aplicação são definidos pela estruturação dos dados dentro destes fluxos, que serão computados por kernels que executam operações aritméticas. As cenas renderizadas pelas placas gráficas geralmente possuem mais fragmentos que vértices; desta forma, um programa típico de GPGPU usa o processador de fragmentos como unidade de processamento paralelo. O programa deve ser estruturado da seguinte maneira (OWENS et al., 2007):

1. O programador deve determinar a porção do programa que possui dados que podem ser processados em paralelo. A aplicação deve então ser segmentada em seções paralelas independentes. Cada uma dessas seções pode ser considerada um kernel e deve ser implementado como um programa de fragmento. Os dados de entrada e saída de cada kernel devem ser tratados como um conjunto de dados e armazenados na memória de textura da GPU;

2. Para executar um kernel, a faixa que será computada deve ser especificada. O programador pode fazer isso passando informações dos vértices para a GPU. Uma chamada típica é um quadrilátero orientado para- 
lelamente ao plano da imagem, e dimensionado para cobrir uma região retangular de pixels que cubra o tamanho desejado do conjunto de dados de saída;

3. O rasterizador gera um fragmento para cada pixel contido no quadrilátero, podendo produzir até milhões de fragmentos;

4. Cada fragmento gerado é então processado pelo programa de fragmento ativo. Deve-se notar que cada fragmento é processado pelo mesmo programa. O programa pode ler posições arbitrárias da memória, porém só pode gravar em posições correspondentes a localização do fragmento no buffer do frame;

5. A saída do programa de fragmento são valores gerados para cada fragmento, que podem representar o resultado final da computação ou pode ser armazenado como textura e então ser usado em outra computação, como é comum acontecer em aplicações complexas, que podem necessitar de múltiplas passagens pelo pipeline.

Deve-se ressaltar que a programação destes programas deviam ser feitas através do uso de uma API gráfica que permitisse o acesso aos núcleos do processador gráfico, gerando a necessidade de se utilizar o OpenGL ou DirectX. Esta abordagem evoluiu para possibilitar o uso das linguagens de shaders.

\subsubsection{APIs para Desenvolvimento GPGPU}

Como foi possível perceber, a abordagem inicial para o uso de técnicas de GPGPU está muito ligada ao funcionamento do pipeline gráfico, na qual um algoritmo geral deve ser apresentado na forma de um algoritmo gráfico, dificultando sua utilização por desenvolvedores leigos na área de computação 
gráfica. Desta maneira, é desejável a utilização de um modelo de programação mais próxima à programação geral. Um dos primeiros trabalhos visando esta facilidade foi apresentado por Buck et al. (2004), através do Brook, que é um ambiente de programação que oferece uma API que expõe a GPU como um co-processador de fluxo de dados, possibilitando o seu processamento de forma paralela. A API minimiza a necessidade de conhecer profundamente as linguagens de shader para a programação. Esta abordagem evoluiu para as ferramentas existentes atualmente e apresentadas brevemente abaixo:

\section{CUDA}

A arquitetura CUDA (Computer Unified Device Architecture) oferece um modelo de processamento e programação paralela, através de um ambiente de software que estende a linguagem $\mathrm{C}$, e foi projetado para facilitar a transposição do desafio de criar softwares que aproveitem o poder dos múltiplos processadores de uma GPU. Desenvolvido pela Nvidia, o uso desta arquitetura implica na necessidade que a GPU a ser usada seja desta empresa e com os recursos habilitados para o uso da CUDA, a partir da arquitetura unificada denominada "Tesla" (também conhecida pelo código G80) e disponível a partir das placas gráficas da série GeForce 8, lançada no mercado consumidor em 2006 (NICKOLLS; DALLY, 2010). As ferramentas de desenvolvimento foram disponibilizadas em 2007.

Por ser a tecnologia usada para o desenvolvimento deste trabalho, as particularidades desta arquitetura serão detalhadas na seção 5.2.

\section{Open CL}

O OpenCL é um framework que visa padronizar a programação paralela em diversos processadores modernos. Este padrão é mantido pelo Khronos Group (o mesmo grupo que mantém as especificações do OpenGL) e possui 
o suporte de diversas empresas e instituições associadas (OPENCL, 2011).

As abstrações apresentadas por este padrão definem funcionalidades principais que são suportadas por diversos dispositivos, como as GPUs, as CPUs, processadores digitais de sinais (STONE; GOHARA; SHI, 2010). Porém, assim como ocorre com o OpenGL, a especificação permite que cada fabricante disponibilize características exclusivas de seu hardware e interfaces de programação experimentais, para benefício dos programadores.

\section{Direct Compute}

Assim como a CUDA e o OpenCL, o DirectCompute é uma API fornecida pela Microsoft que possibilita o desenvolvimento de rotinas em GPGPU juntamente com o DirectX, sem a necessidade de usar uma segunda API para a execução destas funções (MICROSOFT, 2010). 


\section{CONTEXTO: SISTEMA AVMIX}

O AVMix é um sistema de software para a geração de vídeo-avatar com interação tridimensional, apresentado originalmente por Nakamura (2008). Este mesmo trabalho apresenta a definição de vídeo-avatar como uma representação virtual baseada na imagem de um usuário humano, obtida através de um dispositivo de aquisição de vídeo e atualizada em tempo real. A figura 3.1 apresenta a tela da aplicação de testes do sistema.

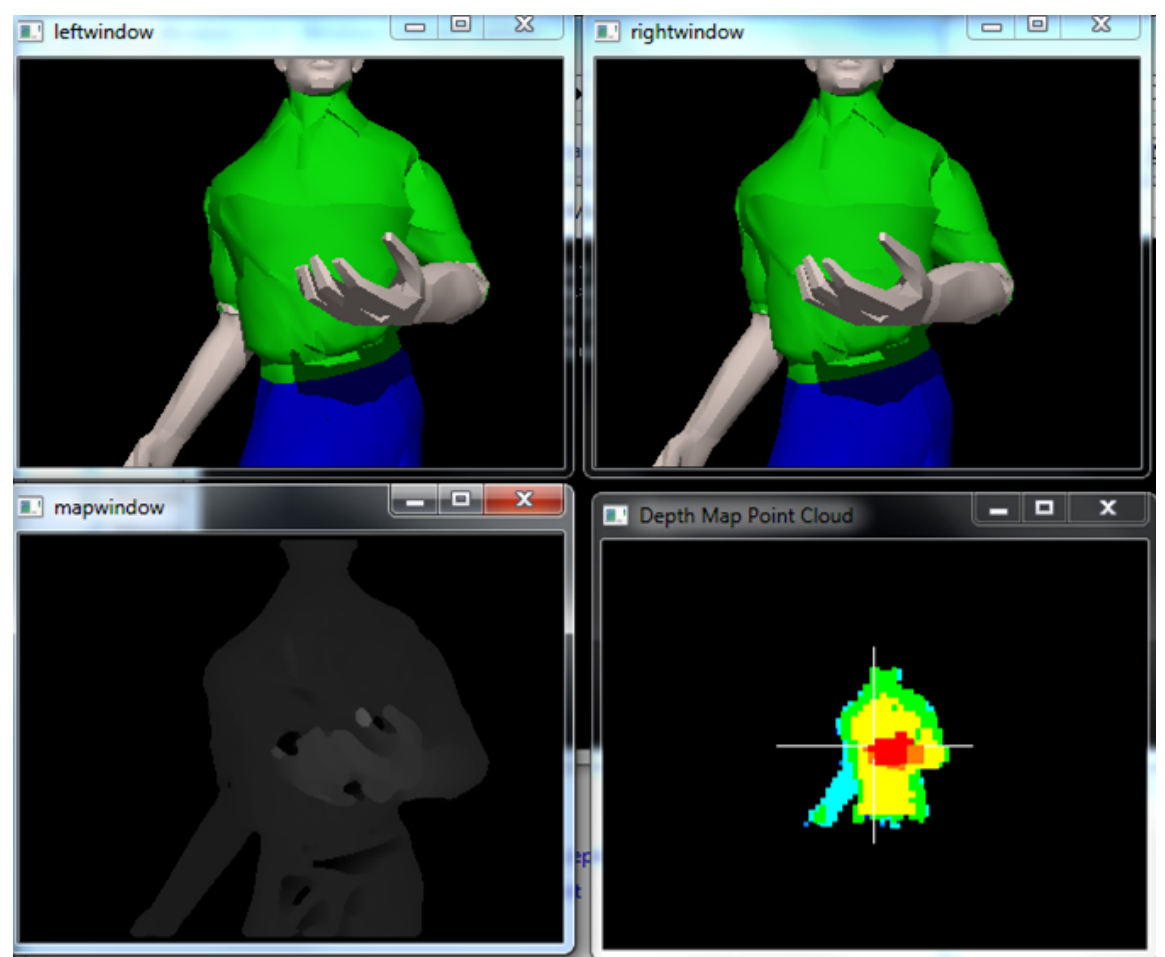

Figura 3.1: Tela da aplicação de testes do sistema AVMix (NAKAMURA, 2008).

Este sistema pode ser dividido em cinco módulos, ilustrados na figura 3.2 e detalhados adiante. 


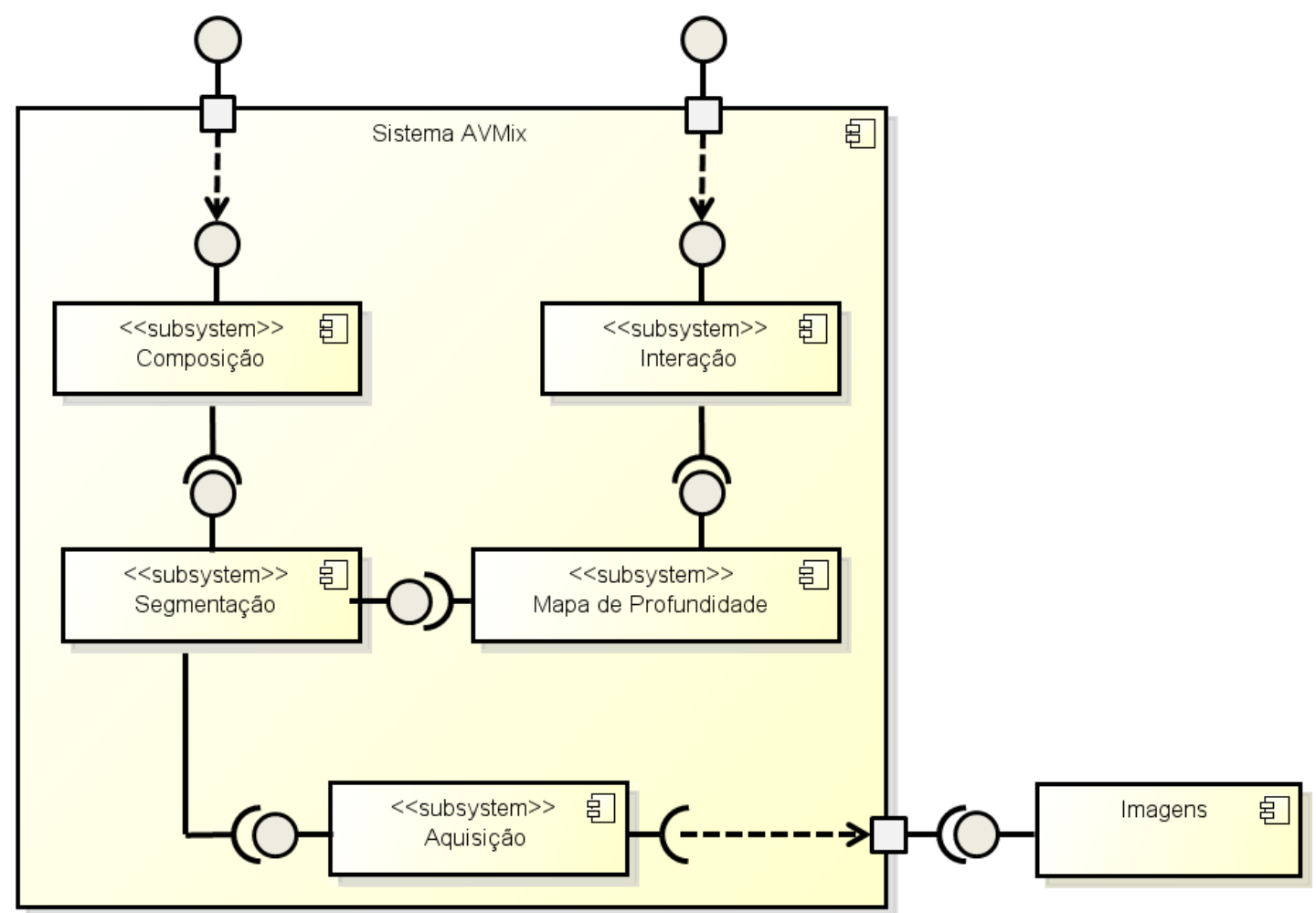

Figura 3.2: Visão geral do sistema AVMix e sua divisão nos módulos de aquisição, segmentação, mapa de profundidade, composição e interação (NAKAMURA, 2008).

\subsection{Aquisição}

Sistema responsável pela obtenção dos quadros de vídeo que serão processados pelo sistema, de duas formas principais: a partir de um par de câmeras, ou através de quadro de vídeos capturados previamente e gravadas como imagens em disco. A configuração usada no sistema é ilustrada na figura 3.3.

Este módulo também é responsável pela calibração das câmeras e pela realização da operação de retificação sobre as imagens. Este processo consiste em determinar um novo plano de imagem $\gamma$ correspondente a uma configuração de câmeras com suas lentes alinhadas e eixos ópticos paralelos. 


\section{Câmeras \\ Computador de Vídeo Usuário

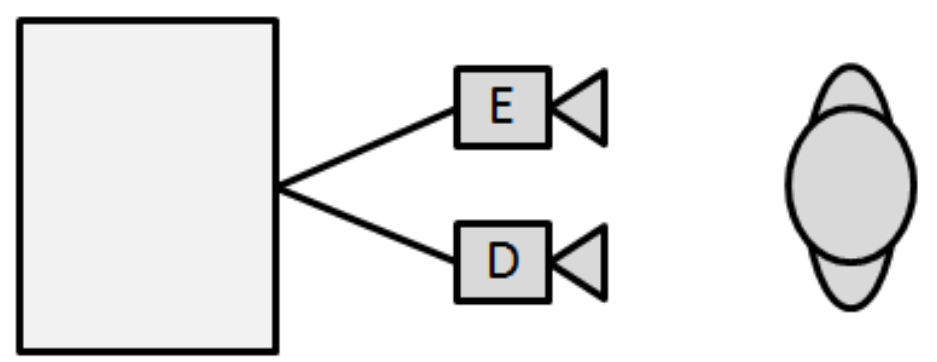

Figura 3.3: Diagrama que mostra a configuração usada para a aquisição das imagens de entrada através de câmeras de vídeo (NAKAMURA, 2008).

\subsection{Segmentação}

Sistema responsável pelo processamento das imagens obtidas no módulo de aquisição. No AVMix, a segmentação faz a subtração de fundo a partir de uma imagem de referência estática. Esta configuração é possível devido ao arranjo das câmeras de vídeo, que são fixas, e a premissa de que a imagem do fundo não sofre grandes alterações durante a obtenção do vídeo.

A subtração do fundo é feita pixel a pixel entre o quadro capturado e a imagem de referência. Depois, é realizada a limiarização sobre a imagem resultante, através da equação 3.1 , gerando uma máscara binária que pode ser usada para segmentar o fundo. Na equação, o valor $O(i, j)$ corresponde ao valor da máscara na posição $(i, j)$ da imagem, definido pela diferença do valor de $I(i, j)$ da imagem capturada com o valor $R(i, j)$ da imagem de referência. O limite indica um valor de corte que permite definir se determinado pixel é considerado ou não pertencente ao fundo a ser removido. Os ruídos são minimizados através das operações de dilatação e erosão sobre a máscara 
obtida. Este processo é ilustrado na figura 3.4.

$$
O(i, j)= \begin{cases}I(i, j) & \text { se }|I(i, j)-R(i, j)|>\text { limite } \\ 0 & \text { se }|I(i, j)-R(i, j)| \leq \text { limite }\end{cases}
$$

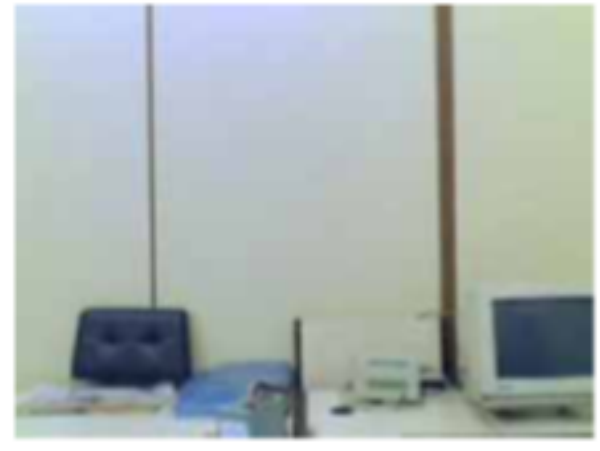

(a)

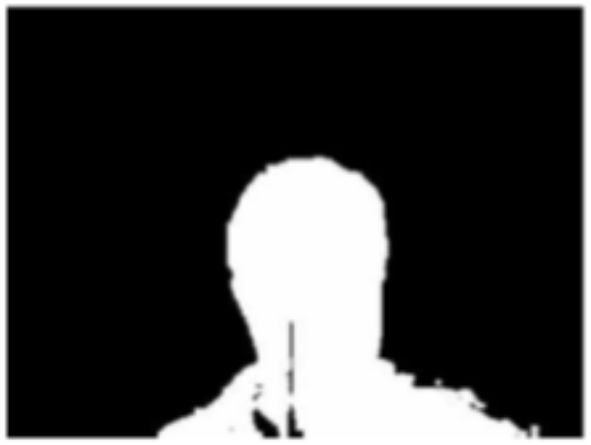

(c)

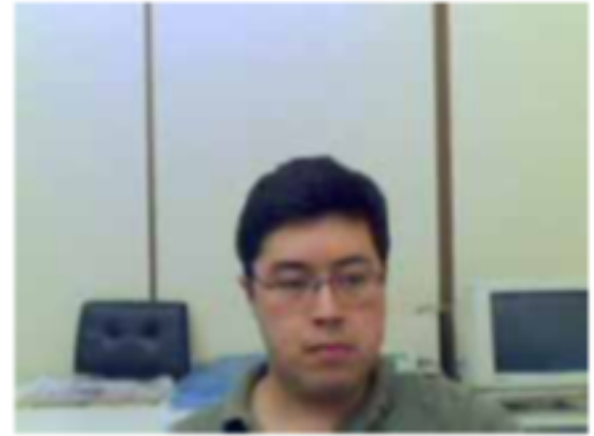

(b)

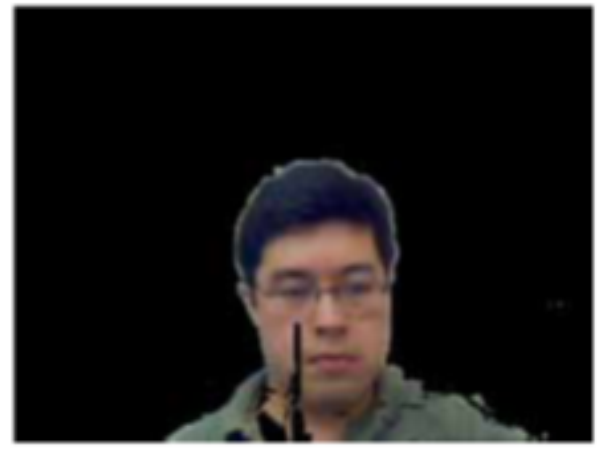

(d)

Figura 3.4: Algoritmo de segmentação usado no AVMix: (a) imagem de referência do fundo; (b) imagem capturada pela câmera; (c) máscara obtida por subtração e limiarização das duas imagens anteriores; (d) imagem final resultante (NAKAMURA, 2008).

\subsection{Mapa de Profundidade}

Sistema responsável pela geração de um mapa de profundidade a partir do par de imagens segmentados e retificados, após a aplicação de uma transformação de projeção nas imagens para que as mesmas fiquem situadas no mesmo plano. Originalmente, este módulo suporta a execução com o uso de múltiplas threads, para o aumento do desempenho. A figura 3.5 ilustra um 
exemplo de mapa resultante da análise do par de imagens.

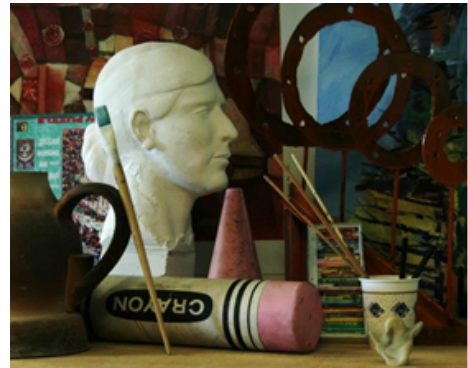

(a)

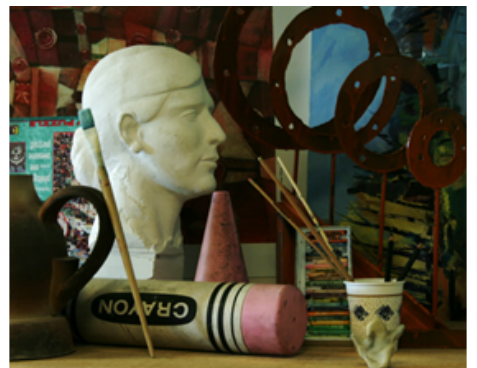

(b)

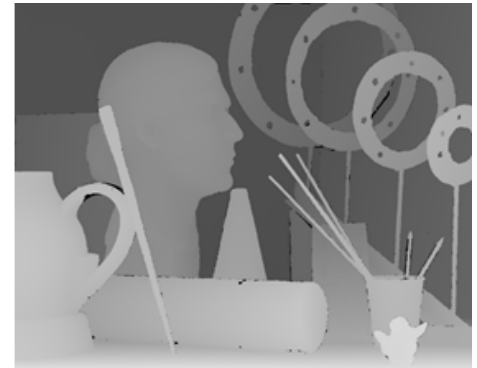

(c)

Figura 3.5: Exemplo de obtenção do mapa de profundidade; (a) visão esquerda; (b) visão direita; (c) mapa de profundidade ideal resultante (MIDDLEBURY, 2002).

A partir das imagens retificadas com o fundo removido, é possível calcular a disparidade entre as mesmas. Para o cálculo da disparidade entre as duas imagens, foi adotado um algoritmo local que analisa uma vizinhança finita de cada ponto no par de imagens para calcular uma estimativa de similaridade entre elas. A discrepância mínima entre as imagens é calculada através do quadrado da diferença entre os pontos correspondentes dela. Scharstein e Szeliski (2002) propõem que esta função de discrepância seja executada sobre uma janela retangular de tamanho pré-definido. Isso resulta na equação 3.2, onde $E$ é a discrepância entre um pixel $(r, s)$ da imagem esquerda e um pixel $(t, u)$ da imagem direita, $N$ e o tamanho fixo da janela avaliada, $C$ é o número de canais de cor da imagem (3 para imagens coloridas RGB e 1 para escala de cinza). $Q_{E}(r, s, i)$ corresponde ao i-ésimo canal de cor de um pixel da imagem esquerda e $Q_{D}(t, u, i)$ corresponde ao i-ésimo canal de cor de um pixel da imagem direita.

$$
E\left(I_{E}, I_{D}\right)=E(r, s, t, u)=\sum_{i=-N / 2}^{N / 2} \sum_{j=-N / 2}^{N / 2} \sum_{k=1}^{C}\left[Q_{E}(r+j, s+i, k)-Q_{D}(t+j, u+i, k)\right]^{2}
$$




\subsection{Composição}

Sistema responsável pela construção de uma representação visual do vídeo-avatar, a ser fornecida para as aplicações usuárias. A abordagem para a representação é a mesma apresentado por Siscoutto (2003), com o uso de um modelo geométrico plano com a imagem segmentada do vídeo-avatar aplicada como textura sobre o mesmo.

\subsection{Interação}

Sistema responsável pelos serviços de interação do usuário com os outros objetos virtuais do ambiente no qual ele está inserido. Permite detectar a colisão entre o modelo do vídeo-avatar e outros objetos do ambiente virtual no qual ele está inserido. O modelo de colisão usado pelo avatar é baseado na octree.

A octree é uma estrutura de dados organizada na forma de uma árvore, cuja raiz representa um volume finito em um espaço 3D que pode ser subdividido em três planos perpendiculares que geram oito novos volumes, representados como seus filhos e que são chamados octantes. Este processo de subdivisão ocorre recursivamente para cada um dos filhos até que algum critério de parada da recursão seja atendido. Usualmente a profundidade da octree é limitada entre 5 ou 6 níveis, devido a grande quantidade de nós necessários para representar níveis de profundidade maiores (ERICSSON, 2005).

O processo da construção da octree é feita a partir de um mapa de profundidade representado em escala de cinza, onde pixels mais claros representam objetos mais próximos. Inicialmente, os pixels do mapa de profundidade são convertidos em coordenadas tridimensionais, usando as equações 3.3, 3.4 e 
3.5, onde $\alpha$ e $\beta$ são parâmetros usados para a calibração da câmera de vídeo e $W$ e $H$ são as dimensões da imagem capturada em pixels (CHEN et al., 2002).

$$
\begin{gathered}
x_{i j}=d_{i j} \cdot \tan \alpha \cdot \frac{i-\frac{W}{2}}{\frac{W}{2}} \\
y_{i j}=d_{i j} \cdot \tan \beta \cdot \frac{\frac{H}{2}-j}{\frac{H}{2}} \\
z_{i j}=d_{i j}
\end{gathered}
$$

Após a conversão, cada ponto $\left(x_{i j}, y_{i j}, z_{i j}\right)$ é classificado dentro do volume representado pelos nós da octree para a obtenção de um modelo que represente este objeto. Visando o uso eficiente da memória, a octree é representada linearmente através de um vetor, onde cada nó em cada nível é alocado previamente. Através da equação 3.6, que calcula o número de nós para uma octree de profundidade $D$, é possível notar o crescimento exponencial do número de nós conforme o aumento do nível de profundidade. Nesta abordagem, caso o nó ocupe a posição $P$ do vetor, seus filhos irão ocupar as posições $8 P+1$ até a $8 P+8$. A partir destas relações, é possível a iteração sobre os nós da octree dentro do vetor.

$$
N=\sum_{i=0}^{D} 8^{i}
$$

O acesso as folhas da octree pode ser feito usando-se uma técnica baseada em hash chamada códigos de Morton, que convertem um ponto $(x, y, z)$ de um espaço tridimensional em um índice do vetor responsável pelo armazenamento da octree, desde que os seus filhos sejam armazenados em uma ordem coerente em relação ao código obtido. 
O código de Morton pode ser calculado usando-se as equações 3.7, 3.8 e 3.9 e os valores $(x, y, z)_{\min } \mathrm{e}(x, y, z)_{\max }$ correspondem aos limites volumétricos da octree no espaço 3D. Nestas equações, $N$ é um número inteiro igual ou maior que a profundidade da octree. A função $\operatorname{trunc}(x)$ retorna um número inteiro correspondente a $x$ sem a parte fracionaria. A função intercalar $(A, B, C)$ retorna um numero obtido pela composição dos bits de $A, B$ e $C$ intercalados sucessivamente. Ou seja, se $A=\left(a_{1} a_{2} a_{3} \ldots\right)_{2}, B=\left(b_{1} b_{2} b_{3} \ldots\right)_{2}$ e $C=\left(c_{1} c_{2} c_{3} \ldots\right)_{2}$, o retorno desta função é $\left(a_{1} b_{1} c_{1} a_{2} b_{2} c_{2} a_{3} b_{3} c_{3} \ldots\right)_{2}$.

$$
\begin{aligned}
& M_{x}=\operatorname{trunc}\left(\frac{x-x_{\min }}{x_{\max }-x_{\min }} \cdot 2^{N}\right) \\
& M_{y}=\operatorname{trunc}\left(\frac{y-y_{\min }}{y_{\max }-y_{\min }} \cdot 2^{N}\right) \\
& M_{z}=\operatorname{trunc}\left(\frac{z-z_{\min }}{z_{\max }-z_{\min }} \cdot 2^{N}\right) \\
& M=\operatorname{intercalar}\left(M_{x}, M_{y}, M_{z}\right)
\end{aligned}
$$

A utilização dos códigos de posição de Morton permite que a classificação dos pontos do vídeo-avatar na estrutura da octree seja feita da seguinte forma: primeiramente, calcula-se o código de Morton correspondente à posição de um ponto. Em seguida, altera-se o valor da folha indexada por aquele código, indicando que aquele volume do espaço está preenchido pelo vídeo-avatar. Depois que todos os pontos foram classificados, a informação presente nas folhas deve ser propagada recursivamente para os demais nós da árvore. $O$ número de operações necessário para construir a octree segundo esta abordagem é dado pela eq. 3.11, onde $P$ é o número de pontos a serem classificados. 
A segunda parcela da equação corresponde ao número de nós da árvore, que precisam ser acessados para propagar a informação recursivamente.

$$
N_{O P}=P+\sum_{i=0}^{D} 8^{i}
$$




\section{REVISÃO DA LITERATURA}

Este capítulo apresenta uma revisão de trabalhos relacionados com implementações de algoritmos usando técnicas de GPGPU, dentro das áreas de aplicação nas quais o sistema AVMix pode ser classificado.

\section{1 Áreas de Aplicação}

Com o advento do uso da GPU para processamento de aplicações gerais, várias pesquisas e implementações tem sido feitas nas mais diversas áreas de atuação. Nesta seção, serão apresentados alguns trabalhos que usam a GPU em suas implementações, com destaque aos que envolvem as áreas de Visão Computacional e Processamento de Imagens. Owens et al. (2007) apresentam um levantamento de pesquisas e implementações que fazem uso do modelo GPGPU, anterior ao advento de ferramentas que facilitam a programação na GPU; desta forma, muitas das limitações e das técnicas apresentadas envolvem o uso de linguagens de shaders para a o processamento dos dados. Mesmo assim, fica evidente a relação entre a alta capacidade computacional apresentada pela GPU e o seu baixo custo. Outro ponto interessante do artigo é que o levantamento foi feito segmentando-se os trabalhos por área de atuação, que serão replicadas para facilitar a classificação de trabalhos posteriores, com prioridade a trabalhos relacionados às áreas de visão computacional e processamento de imagens. 


\subsubsection{Processamento de Imagens}

$\mathrm{Na}$ área de processamento de imagens e sinais, Owens et al. (2007) comentam os ganhos nas seguintes técnicas: segmentação de imagens, limiarização de imagens e obtenção do mapa de profundidade. Implementações que utilizam a CUDA são demonstradas por Yang, Zhu e Pu (2008), através de algoritmos para equalização de histogramas, algoritmo de remoção de nuvens e transformada discreta de cossenos (DCT). Zhang, Chen e Wang (2010) mostram uma implementação do algoritmo de Sobel usado, por exemplo, na detecção de bordas, com ganho de 25,3x para imagens de 2048x2048 pixels de resolução, e um filtro homomórfico usado na remoção de efeitos indesejáveis na imagem, como a não uniformidade da fonte de luz, com um ganho de aproximadamente $40 x$.

\subsubsection{Visão Computacional}

Dentro da área de visão computacional, existem diversos estudos que visam portar a implementação de técnicas para a GPU. Dentre os tópicos mais estudados, como citado por Yang e Pollefeys (2005), está a pesquisa para a obtenção do mapa de profundidade a partir de um par de imagens estereoscópicas.

Rosenberg et al. (2006) e Gibson e Marques (2008) apresentam um trabalho para a obtenção de imagens estereoscópicas com a implementação, com o uso da GPGPU, do algoritmo SGM (Semi-Global Matching). Este algoritmo é detalhado em Hirschmuller (2005). No primeiro caso (ROSENBERG et al., 2006), a implementação foi feita usando-se o modelo GPGPU através da linguagem de shader Cg. No segundo (GIBSON; MARQUES, 2008), foi usado a CUDA, onde o autor indica que foi possível obter um ganho de desempenho 
de $4 x$ em relação ao algoritmo original.

Zhang et al. (2009) apresentam uma outra abordagem para a detecção de correspondência estereográfica, através do algoritmo BFV (bitwise fast voting), que identifica as disparidades confiáveis, através de uma verificação cruzada dos mapas de disparidades. O maior custo computacional se traduz em um mapa de disparidades com mais qualidade, porém ainda assim foi possível obter uma taxa de 12 quadros por segundo, com um aumento de desempenho de 52x em relação a implementação sequencial.

Humenberger et al. (2010) revisitam os trabalhos de detecção de profundidade acima e outros trabalhos, e fazem uma comparação da implementação de um algoritmo de correspondência estereográfica usando a soma das diferenças absolutas em diversas plataformas, onde além da GPU e da CPU, foi incluída uma implementação em um processador digital de sinais. No caso da GPU, foram usados dois hardwares diferentes (placas de vídeo GeForce 9800 GT, mais antiga, e a GeForce 280 GTX, mais recente), que possibilitou avaliar a escalabilidade desta arquitetura. Em relação a versão sequencial, a versão implementada com a CUDA obteve um ganho de 91x na GPU mais antiga e de 183x na mais nova; em relação a versão da CPU otimizada, o ganho foi de 4x em relação a versão executada na GPU mais antiga e de 8x em relação a GPU mais nova.

Além dos trabalhos que tratam as técnicas de forma independente, devem ser destacados os trabalhos que criam frameworks que visam facilitar a criação de aplicações de visão computacional que são executados na GPU. Os dois principais são o OpenVidia (FUNG; MANN, 2005) e o GpuCV (ALLUSSE et al., 2008), este último baseado nas rotinas implementadas pelo OpenCV, que é uma biblioteca de implementação de diversas rotinas de visão computacional (OPENCV, 2010). Neste caso, o GpuCV oferece uma alternativa à estas rotinas 
encontradas no OpenCV, e ambas são compatíveis entre si. Na última versão estável da biblioteca OpenCV, foram implementadas rotinas para execução de algumas funcionalidades na GPU, como por exemplo algumas operações básicas como operações de filtragem, morfologia, transformações geométricas, histogramas, e outras mais complexas, como a correspondência estereográfica, usando correspondência entre blocos e o algoritmo de propagação de crença (belief propagation) (OPENCV, 2010).

\subsubsection{Simulação de Física}

Um trabalho relacionado a área de simulação de física e ao AVMix para a detecção de colisões usando-se octree é apresentado por Ajmera et al. (2008), onde é proposto o uso da GPU para o cálculo nas folhas da octree, que é representada através do uso de SFCs (space filling curves). O ganho obtido neste trabalho para uma octree de 11 níveis é de $8667 x$, porém deve-se notar que este valor não é adequado em aplicações interativas em tempo real, pois o processamento sequencial cresce de forma exponencial. De certa forma, este ganho mostra que a execução na GPU de octrees com este nível de profundidade passa a ser possível. Para uma profundidade de 6 níveis, que é um valor prático indicado por Ericsson (2005), o ganho obtido foi de 2,87x. A GPU é usada também para a realização de buscas dentro desta estrutura da octree.

Madeira e Lewiner (2009) apresentam o uso de GPUs para a realização de buscas dentro de uma octree através do uso de tabelas hash, paralelizando a busca entre os níveis da octree e aproveitando-se de que a busca de cada ponto pode ser feita de maneira independente. O ganho apresentado varia de $3 x$ até $50 x$, dependendo da quantidade de pontos acessados.

Outras abordagens nesta área são apresentadas em Owens et al. (2007), 
que destaca as implementações dos motores físicos PhysX, da Nvidia e do Havok, que podem ter suas funcionalidades executadas na GPU.

\subsubsection{Outras Áreas}

Che et al. (2008) apresentam um estudo focado no ganho de desempenho apresentado na GPU, através da implementação dos seguintes algoritmos e comparando-os com as implementações feitas na CPU, usando uma execução sequencial e outra com o uso do OpenMP, o qual é uma API para o desenvolvimento de programas paralelos (OPENMP, 2012).

Filtro de difusão para redução anisotrópica (SRAD, Speckle Reducing Anisotropic Diffusion): Filtro baseado em equações diferenciais parciais usados em aplicações de imagens ultrassônicas e de radares. Os autores mostram que este tipo de problema é adequado para a execução em paralelo na GPU, uma vez que o domínio computacional pode ser tratado como uma matriz bidimensional e a computação envolve o acesso aos dados da vizinhança de um determinado ponto. Considerando uma imagem de ultrassom com resolução de 2048x2048 pixels usada como entrada, a implementação com CUDA apresentou um ganho de $17 x$ sobre a versão sequencial e de $5 x$ sobre a versão usando OpenMP.

HotSpot: Ferramenta usada para estimar a temperatura do processador a partir da planta e medidas de energia. O algoritmo usado é uma equação diferencial que calcula o transiente térmico. O ganho em relação à versão sequencial foi de aproximadamente $7 x$, e em relação a versão com OpenMP foi de 2x para o maior tamanho dos dados de entrada. Neste segundo caso, porém, foi observado que o fator de ganho diminuiu conforme o aumento do tamanho da entrada. O autor justifica dizendo que a implementação considera a execução de mais iterações do kernel para que ocorra a convergência do 
resultado, o que afeta o desempenho.

O autor também fez experimentos através da implementação de algoritmos de backpropagation, usado no aprendizado em redes neurais (com ganho de $8 x$ sobre a versão sequencial), o método DES (Data Encryption Standard), usado na criptografia de dados, com uma implementação que considera o uso de tabelas de pesquisa (lookup table) apresentando um ganho de 37x, o algoritmo de Needleman-Wunsch, usado para o alinhamento de sequências de DNA (ganho de 2,9x, porém com desempenho menor que a versão implementada com OpenMP) e o algoritmo de $k$-means usado na mineração de dados (data mining), com ganho de $72 x$.

$\mathrm{Na}$ área comercial, podemos destacar o trabalho em conjunto da Adobe e Nvidia para a aceleração do software Flash Player, para a reprodução de vídeos que usam, por exemplo, o padrão H.264/MPEG Part 10, um dos mais usados para a codificação de vídeo em alta definição (ADOBE, 2009).

Outros trabalhos acadêmicos e comerciais que usam a CUDA podem ser verificados em (NVIDIA, 2011b).

\subsection{Consolidação}

A tabela 4.1 apresenta os resultados dos trabalhos pesquisados, relacionando o algoritmo implementado, o hardware usado, a linguagem de programação usada, a metodologia para a avaliação do ganho (speed up) e o ganho obtido. 

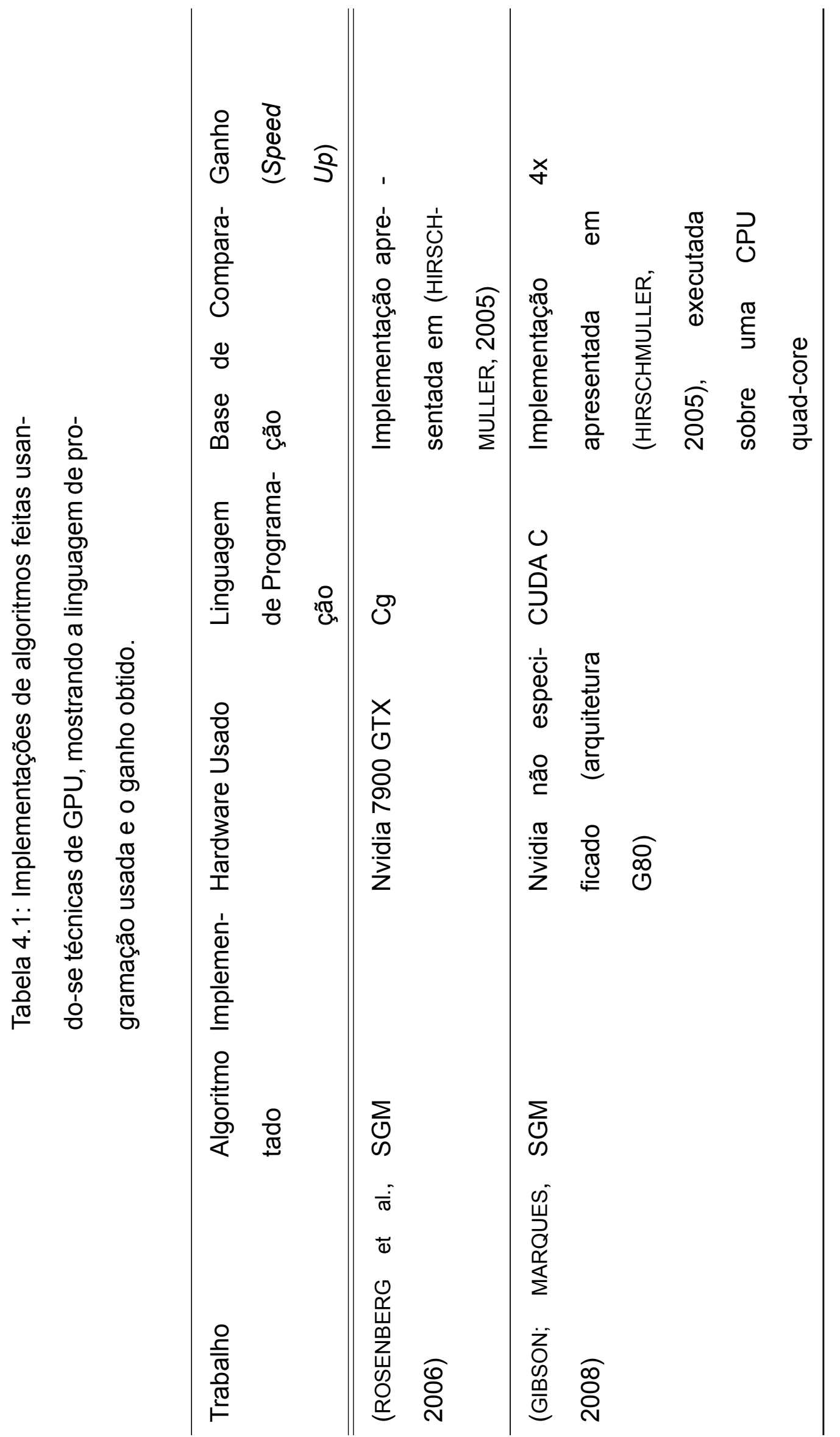

 


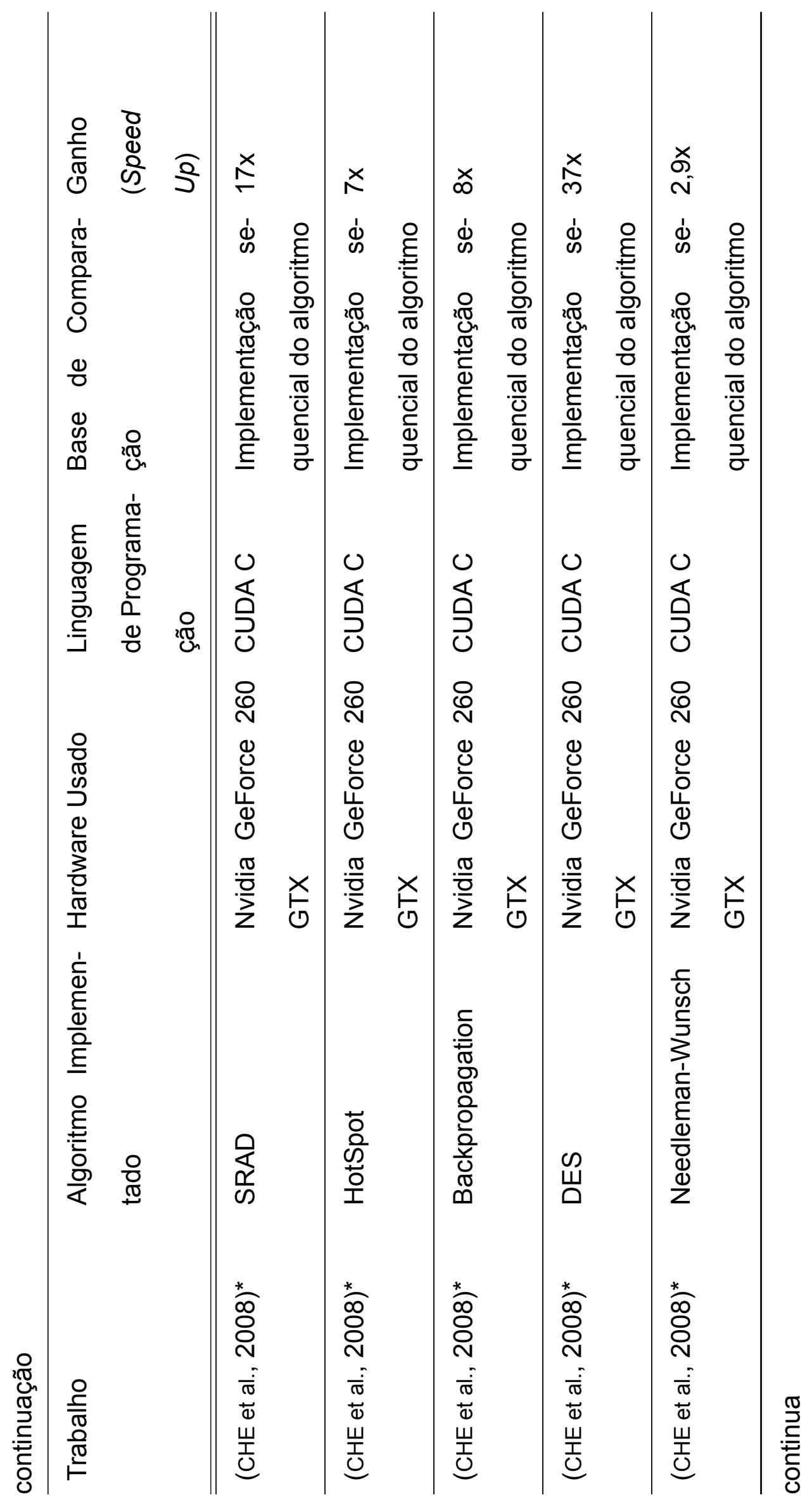




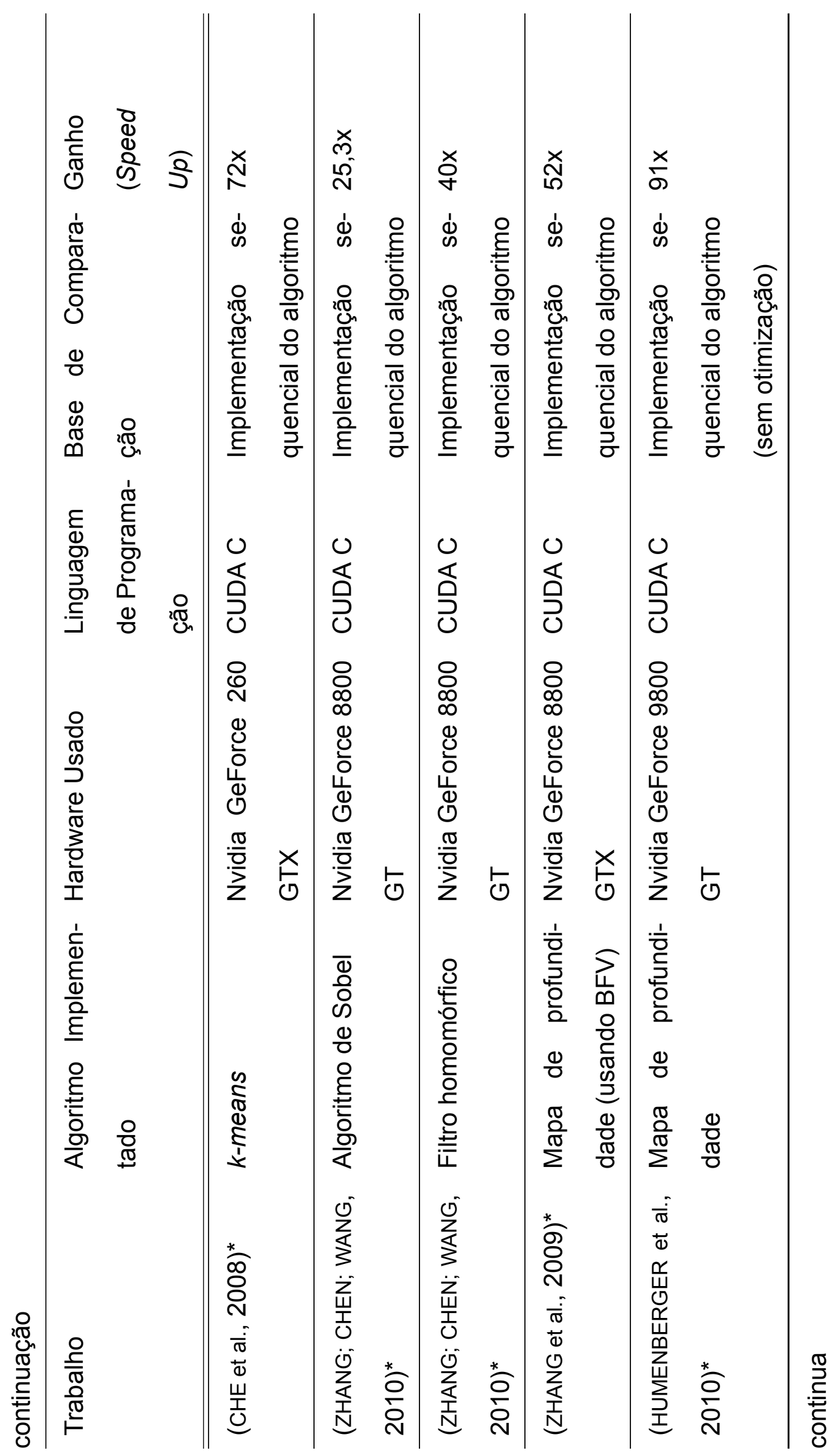




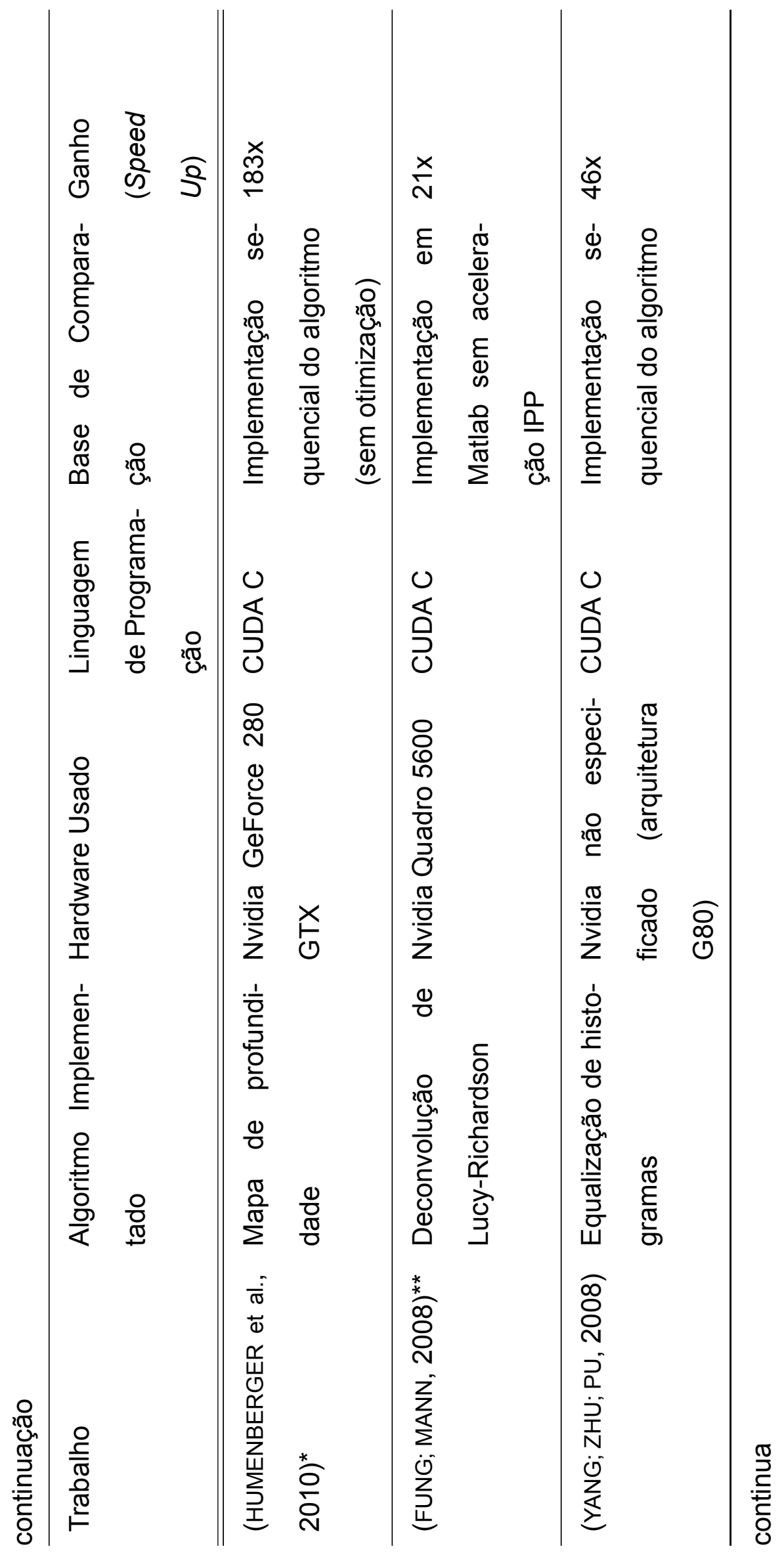




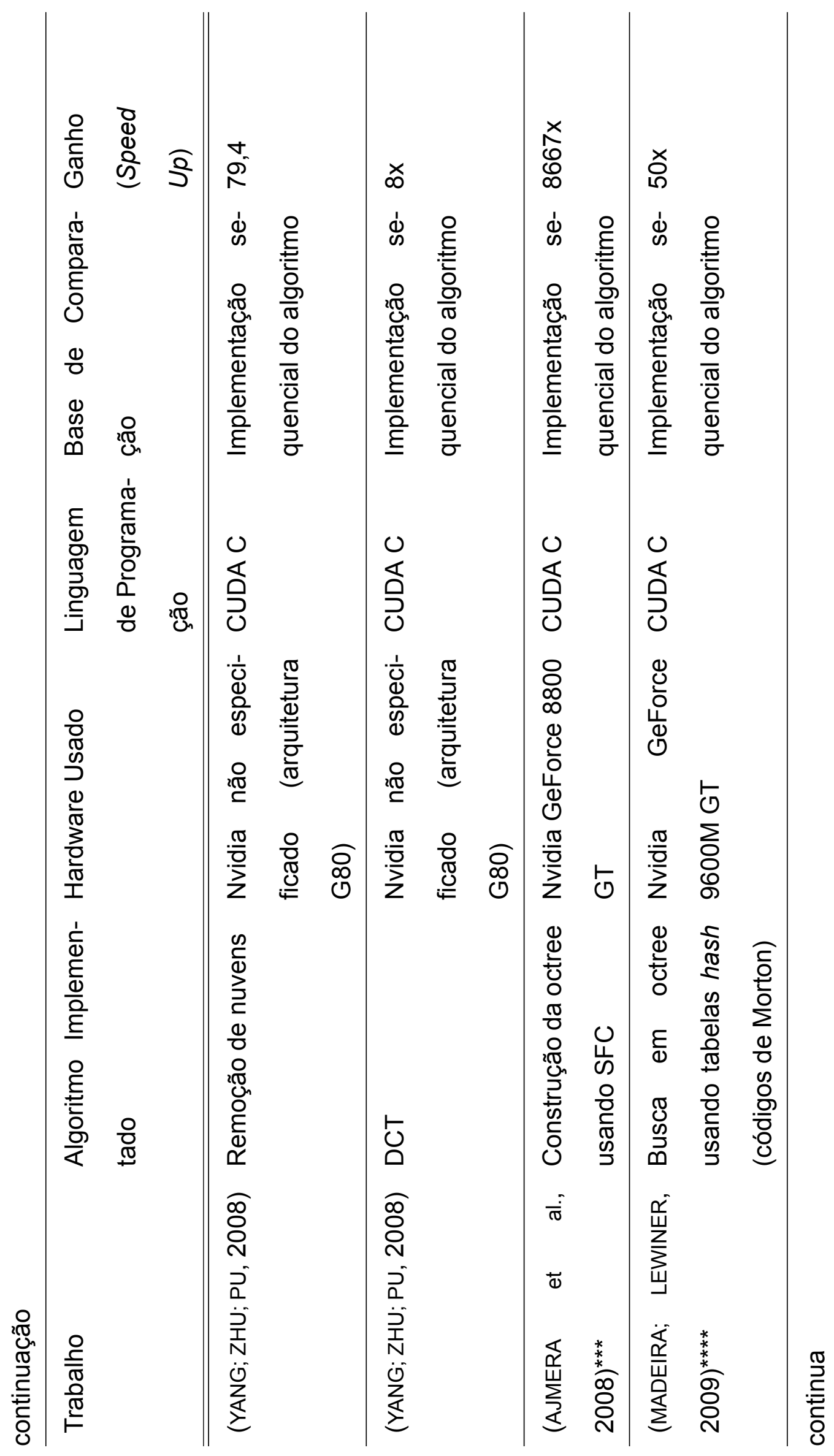




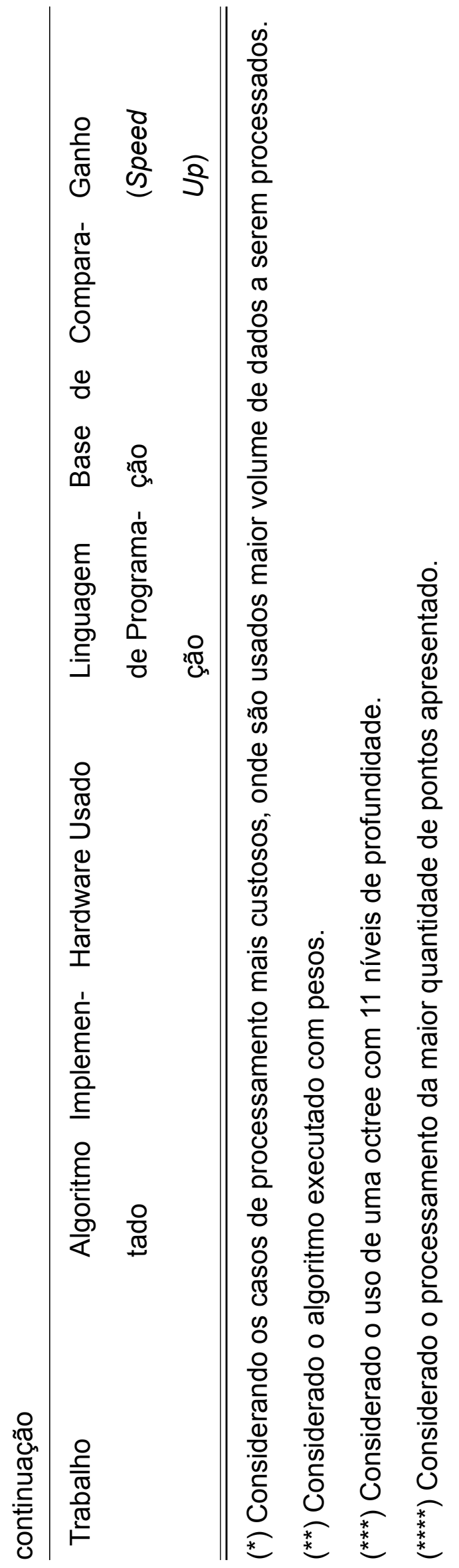




\section{DESENVOLVIMENTO DOS MÓDULOS DO AVMIX COM GPGPU}

Nesta seção, são descritas as etapas de desenvolvimento deste trabalho, considerando-se a avaliação do sistema AVMix original para a identificação dos pontos críticos, a seleção da CUDA como ferramenta de desenvolvimento, a análise e as decisões consideradas para a reimplementação dos módulos críticos de desempenho.

\subsection{Avaliação do Sistema AVMix}

Uma primeira etapa do desenvolvimento consiste na análise do sistema AVMix desenvolvido em Nakamura (2008). Inicialmente, o sistema foi preparado para ser compilado e executado usando-se hardware e bibliotecas de software atualizados. As diferenças envolvem, principalmente, as bibliotecas nativas do sistema operacional e a biblioteca OpenCV para a execução de rotinas referentes a visão computacional e processamento de imagens (foi adotada a versão 2.3 ao invés da versão 1.0 usada na versão original).

O trabalho de implementação, compilação e execução dos testes foi realizado usando as configurações apresentadas na tabela 5.1. Nesta tabela, o item capacidade computacional (compute capability) é um valor relacionado a arquitetura CUDA que possibilita identificar a versão da arquitetura da GPU utilizada e quais são os recursos de GPGPU suportados pelo hardware gráfico 
da Nvidia (NVIDIA, 2011a). No caso de hardware com capacidade computacional 1.x, significa que o mesmo implementa a arquitetura denominada "Tesla". Hardware com capacidade computacional 2.x indica o uso da arquitetura denominada "Fermi".

Tabela 5.1: Especificação do sistema usado no trabalho

\begin{tabular}{ll}
\hline Processador & Intel Core i7 860 2.8GHz (4 cores + HT) \\
\hline RAM & 4GB DDR3 667 MHz \\
\hline Placa de Vídeo & Nvidia GeForce GTX 580 1536 Mbytes \\
\hline Versão do Driver de Vídeo & 275.33 \\
\hline Sistema Operacional & Windows 7 64-bit SP1 \\
\hline IDE/Compilador & Visual C++ 2008 SP1 Professional \\
\hline Versão do CUDA Toolkit & 3.2 \\
\hline Capacidade computacional & 2.0 \\
\hline
\end{tabular}

Após a atualização e recompilação do sistema AVMix, o mesmo foi alterado para a inclusão de pontos de medição, visando a obtenção do tempo de execução de cada um dos módulos. A figura 5.1 apresenta os resultados do tempo de processamento das imagens até a construção da octree por uma aplicação de testes com o uso das rotinas implementadas no AVMix sendo executada no hardware especificado na tabela 5.1, variando-se a quantidade de threads usadas no processamento do mapa de profundidade. A tabela 5.2 mostra a distribuição do tempo médio gasto por cada módulo no processamento de um quadro do vídeo.

Este resultado inicial mostra que o módulo crítico do sistema é o processamento do mapa de profundidade, conforme já observado em Nakamura (2008) e que explica a implementação original com suporte a execução paralela. Com estes novos testes, também é possível identificar que apesar do ganho de desempenho apresentado com o uso de 8 threads (possibilitado pelo uso de um processador hyperthread ou HT, que considera cada núcleo físico como 2), ainda assim este módulo consome mais de $95 \%$ do tempo usado para o processamento de um quadro. Com os tempos de processamento obtidos com o 
uso de 8 threads, o sistema processa uma taxa média de aproximadamente 15 quadros por segundo. Apesar deste valor estar próximo da taxa desejada de 20 quadros por segundo e possibilitar ao usuário ter a impressão de uma cena animada, conforme indicado por Kirner e Siscoutto (2007), deve-se ressaltar que o programa de testes usado tem como objetivo criar um vídeo-avatar usando-se os módulos implementados do AVMix, desde as imagens capturadas até a sua exibição em tela. Em uma aplicação mais complexa de realidade aumentada, normalmente é necessário a inclusão de outros elementos, como por exemplos os sons, o cenário virtual, os objetos virtuais e implementar as interações do usuário com estes elementos, os quais consomem tempo de processamento tanto da CPU quanto da GPU. Consequentemente, a necessidade de processamento destes elementos pode afetar a taxa de quadros gerados por segundo, que por sua vez pode diminuir a sensação de animação fornecida ao usuário. Considerando-se esta situação e o peso do módulo do mapa de profundidade dentro do sistema, definiu-se a prioridade deste módulo para ser reimplementado para possibilitar a sua execução na GPU.

Tabela 5.2: Porcentagem de tempo médio gasto no processamento de 1 quadro, considerando a execução com 8 threads.

\begin{tabular}{lc}
\hline Módulo & $\%$ do tempo médio de 1 quadro \\
\hline \hline Aquisição (imagens em disco) & $1,30 \%$ \\
\hline Segmentação & $1,59 \%$ \\
\hline Mapa de Profundidade & $95,72 \%$ \\
\hline Interação (octree) & $1,38 \%$ \\
\hline
\end{tabular}

Os demais módulos selecionados para reimplementação foram o de segmentação e a interação. Esta escolha foi motivada devido ao fato destes utilizarem técnicas de processamento de imagens, e que, conforme observado no capítulo 4, é uma das áreas onde é possível obter ganho no desempenho através de implementações paralelas. 


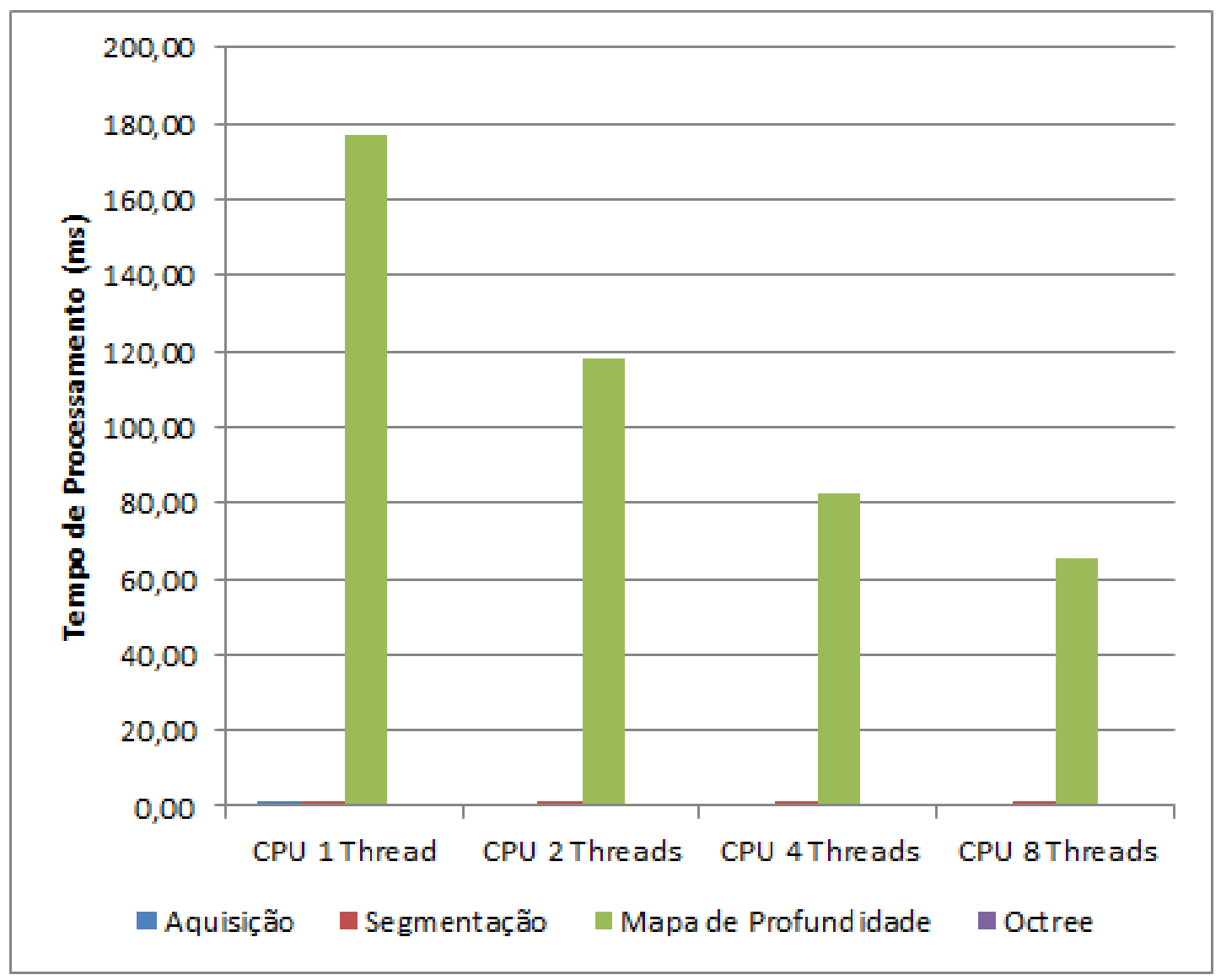

Figura 5.1: Tempo de processamento da aplicação AVMix com o uso do hardware especificado na tabela 5.1.

O módulo de aquisição não será tratado neste trabalho, pois como envolve a captura de imagens por câmeras de vídeo (ou o uso de imagens previamente capturadas armazenadas no disco rígido), o seu desempenho é definido pela velocidade da via de transmissão de dados da imagem da câmera de (ou leitura em disco para a abertura da mesma) para a memória principal do computador, limitando, desta forma, a possibilidade do aumento de desempenho através do uso da GPU.

\subsection{Implementação com CUDA}

Como apresentado no capítulo 4, existe uma grande quantidade de trabalhos desenvolvidos com o uso da arquitetura CUDA. Por este motivo, este 
ferramental foi adotado para o desenvolvimento do trabalho, sendo que, desta forma, foi possível identificar as observações e dificuldades enfrentadas pelos autores de outros trabalhos e agregá-los. Um ponto fraco desta decisão é a necessidade que a GPU a ser usada seja da empresa Nvidia e com os recursos habilitados para o uso da CUDA, a partir da chamada arquitetura "Tesla" e disponível a partir das placas gráficas da série GeForce 8. Boyd (2008) apresenta um conjunto básico de passos que podem ser usados para converter um trecho de código em um modelo paralelo:

1. Identificar uma tarefa principal apresenta dados que podem ser tratados paralelamente;

2. Identificar um algoritmo que trate esta tarefa paralelamente;

3. Selecionar um ambiente de programação paralelo;

4. Implementar o código;

5. Repetir o passo 1.

Seguindo estes passos, uma abordagem geral para a conversão de algoritmos a serem executados na GPU consiste em identificar laços, que deverão ser decompostos para que possam ser executadas paralelamente pelas threads da GPU. Para exemplificar, a figura 5.2 mostra um exemplo simplificado de conversão de um algoritmo de soma de matrizes da linguagem $\mathrm{C}$ usual para a CUDA. Pela comparação destas abordagens, é possível notar que o processamento do laço fica implicito dentro da execução paralela, onde cada iteração da implementação usual é processada por um thread individualmente.

Alguns autores dos trabalhos estudados, como por exemplo Che et al. (2008), afirmam que o ganho de desempenho com o uso da CUDA só é possível com o aproveitamento da hierarquia de memória disponibilizada e 


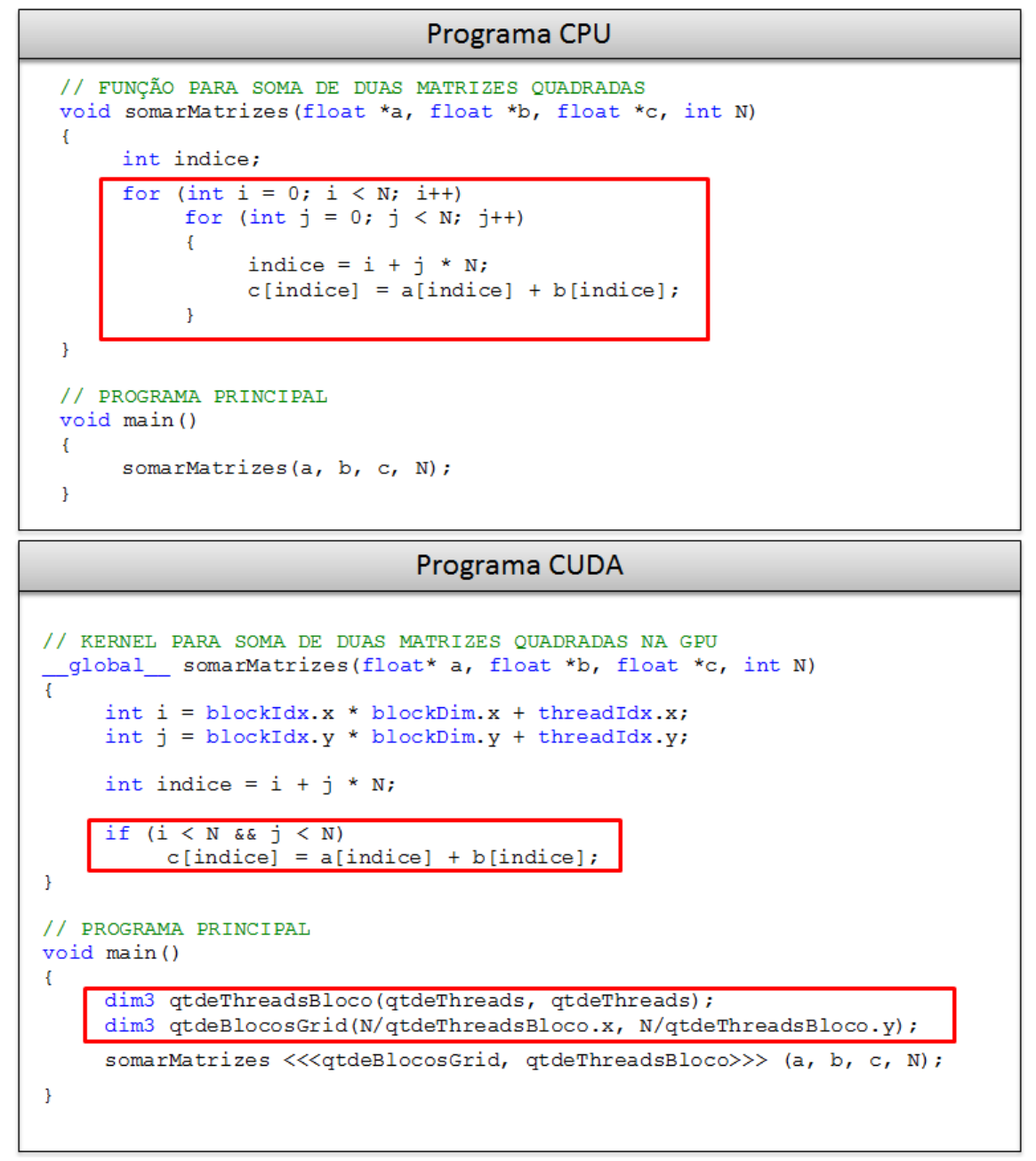

Figura 5.2: Comparação de um algoritmo de soma de matrizes quadradas implementados na CPU com linguagem $C$ e na GPU usando a CUDA. Os trechos destacados mostram a substituição dos laços pelos kernels, executados implicitamente pelas várias threads paralelas alocadas a partir do programa principal.

o conhecimento prévio do programador sobre a localização dos dados na memória. Outros fatores que também prejudicam o ganho de desempenho são: o uso da sincronização global em cálculos intermediários, o desenvolvimento de kernels contendo muita lógica condicional, a elevada quantidade de dados transferidos entre o sistema e a GPU. 


\subsubsection{Organização Hierárquica das Threads}

A partir do exemplo ilustrado na figura 5.2, é possível entender a organização hierárquica dos elementos processadores da GPU. Como mencionado, cada thread é responsável pelo processamento do kernel, que neste contexto é a função desenvolvida usando as extensões da linguagem $\mathrm{C}$ fornecidas pela CUDA, e executado na GPU orientado pela arquitetura chamada de SIMT (Single Instruction Multiple Thread, Instrução Simples em Múltiplas Threads), uma variação do SIMD, onde o mesmo programa é executado usando dados diferentes, visando o aproveitamento do paralelismo dos dados.

Estas threads podem ser organizadas sob os chamados blocos computacionais. Cada bloco pode conter até no máximo 512 threads, cuja identificação pode ser feita em 1, 2 ou 3 dimensões.

Os blocos, por sua vez, são organizados dentro dos grids computacionais. Dentro do grid, os blocos podem ser identificados em 1 ou 2 dimensões, até um limite de 65.636 blocos por grid. A figura 5.3 ilustra esta organização hierárquica.

A quantidade de blocos e threads é definida através de programação, durante a chamada para o processamento do kernel. Porém, uma vez definido, este valor não pode ser alterado durante o tempo de execução deste kernel.

\subsubsection{Organização Hierárquica da Memória}

A organização das threads em blocos e em grid computacionais também permite definir os vários tipos de memória da GPU que podem ser usadas e a sua visibilidade pelos elementos processadores. Esta organização é ilustrada na figura 5.4, e a sua utilização é listada na tabela 5.3. Esta diferenciação das memórias oferece aos programadores uma grande flexibilidade na criação dos 


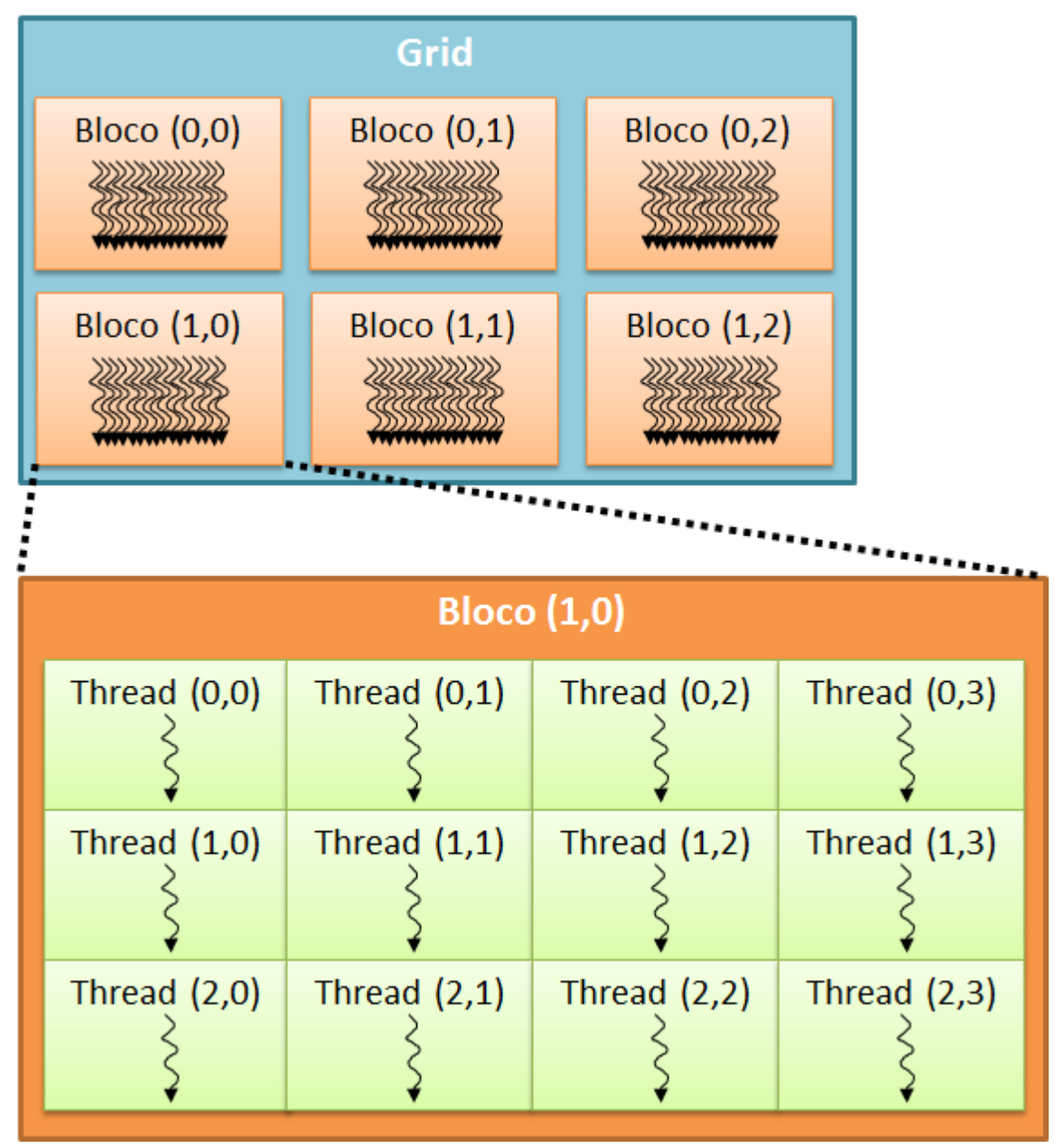

Figura 5.3: Organização hierárquica das threads, blocos e grids computacionais na arquitetura CUDA. Baseado em (NVIDIA, 2010).

programas e possibilita a otimização de desempenho conforme a adequação de seu uso na execução do kernel.

O tipo de memória mais usado pelos programas desenvolvidos com CUDA é a memória global. A existência de espaços de memória diferenciados para GPU e CPU torna necessária a alocação de um espaço nesta memória da GPU e a cópia dos dados da memória principal para este espaço antes da execução do kernel. Após sua execução, é necessário copiar de volta os resultados para o host. Este processo geral para a execução dos algoritmos na GPU é ilustrado na figura 5.5. Por ser um tipo geral, a memória global apresenta uma grande latência e possibilidade de acessos concorrentes ao 


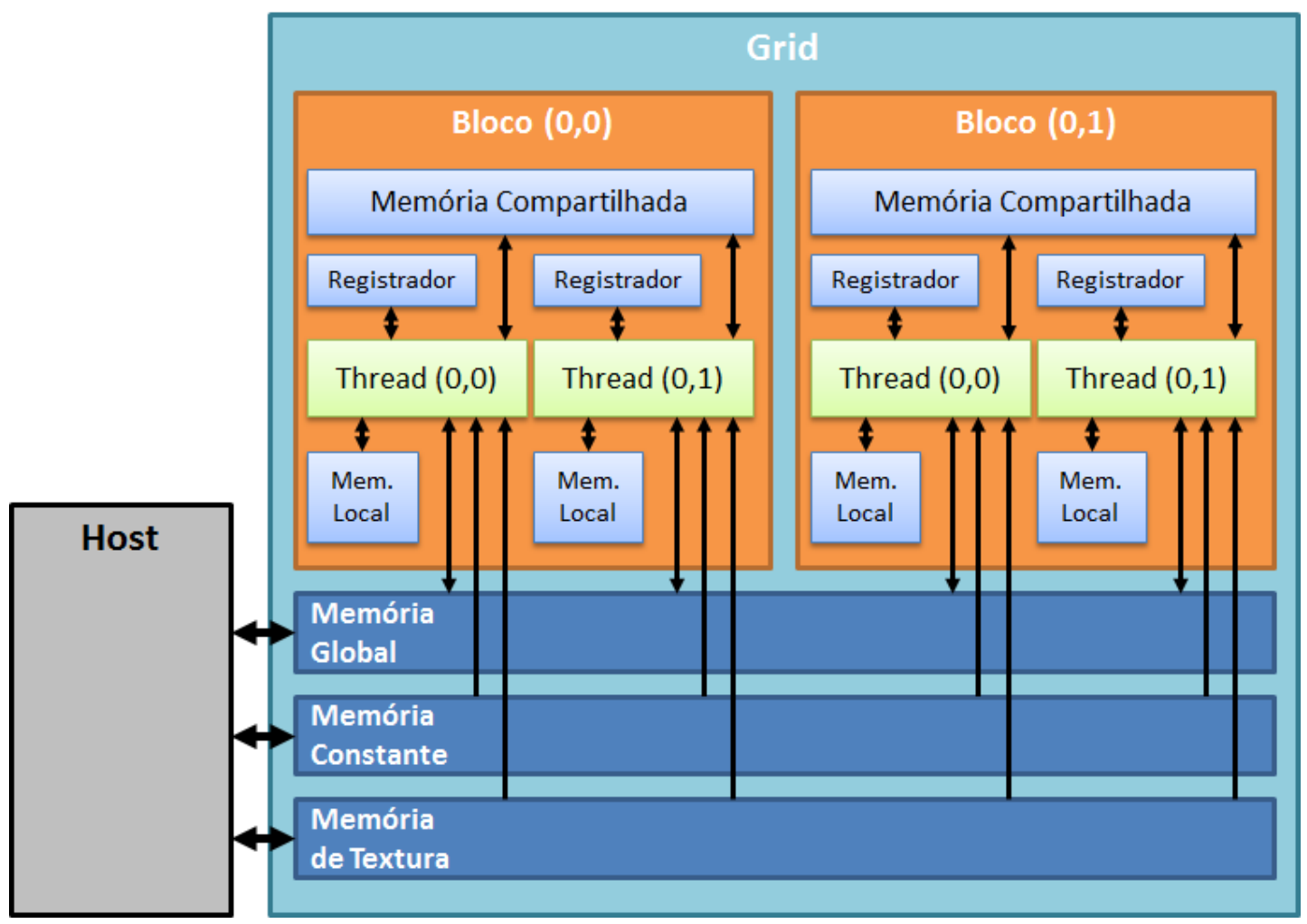

Figura 5.4: Tipos de memória e relação com os elementos lógicos da GPU (FUNG; MANN, 2008).

mesmo endereço.

Outro tipo de memória é a compartilhada (shared memory), cujo escopo envolve o bloco de threads. Ou seja, todas as threads de um mesmo bloco podem compartilhar o seu conteúdo durante o processamento do kernel. Por estar próxima aos multiprocessadores da GPU, o acesso a esta memória possui baixa latência e é altamente paralelizado, porém o seu espaço máximo é limitado em 16 kbytes em dispositivos de capacidade computacional até 1.3 e de 48 kbytes para dispositivos com capacidade computacional 2.x. Conforme a necessidade do uso desta memória pelo algoritmo executado, este limite afeta a quantidade de threads alocadas dentro do bloco. Em geral, este espaço de memória é usado para armazenar resultados intermediários dos programas executados pelo kernel, possibilitando o seu uso em cálculos subsequentes.

A memória de textura é um tipo de memória que possui um cache que, em 
Tabela 5.3: Tipos de memória disponibilizadas pela GPU.

\begin{tabular}{llc}
\hline Tipo & Uso & Acesso \\
\hline \hline Registradores & São usadas dentro de cada thread. & L/E \\
\hline Memória Local & São usadas dentro de cada thread. & L/E \\
\hline Memória Comparti- & $\begin{array}{l}\text { São usadas dentro de cada bloco, sendo } \\
\text { lhada }\end{array}$ & L/E \\
& $\begin{array}{l}\text { compartilhar os dados desta memória. } \\
\text { Memória Global }\end{array}$ & \\
\hline Usada por todo o grid computacional. & $\mathrm{L} / \mathrm{E}$ \\
\hline Memória Constante & Usada em todo o grid. & $\mathrm{L}$ \\
\hline
\end{tabular}

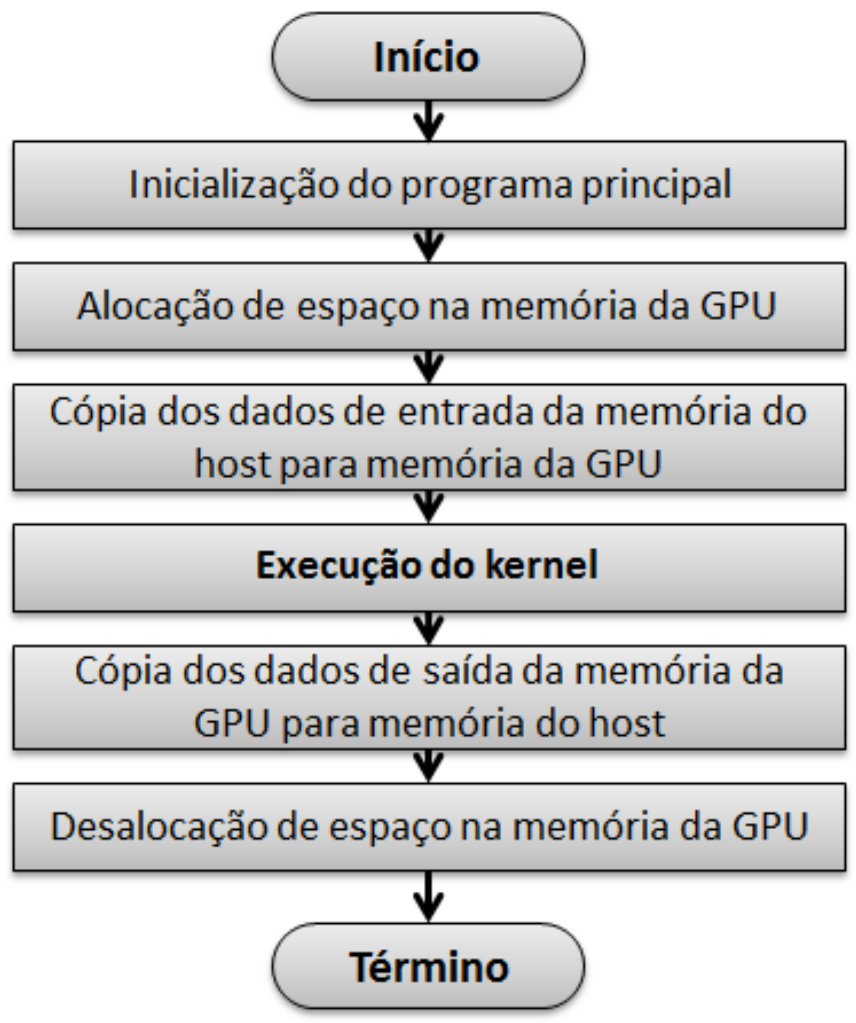

Figura 5.5: Fluxo geral de um programa executado na GPU.

algumas situações, permitem diminuir as requisições à memória global. O seu uso é adequado em aplicações que acessam a memória seguindo um determinado padrão de localização espacial, ou seja, uma thread provavelmente irá acessar um endereço de memória próximo a um endereço que outra thread vizinha acessou (SANDERS; KANDROT, 2010).

A memória constante é usada por dados que não são alterados durante a execução do kernel. Esta memória possui o tamanho máximo de 64 kbytes, e 


\section{Espaço de Memória}

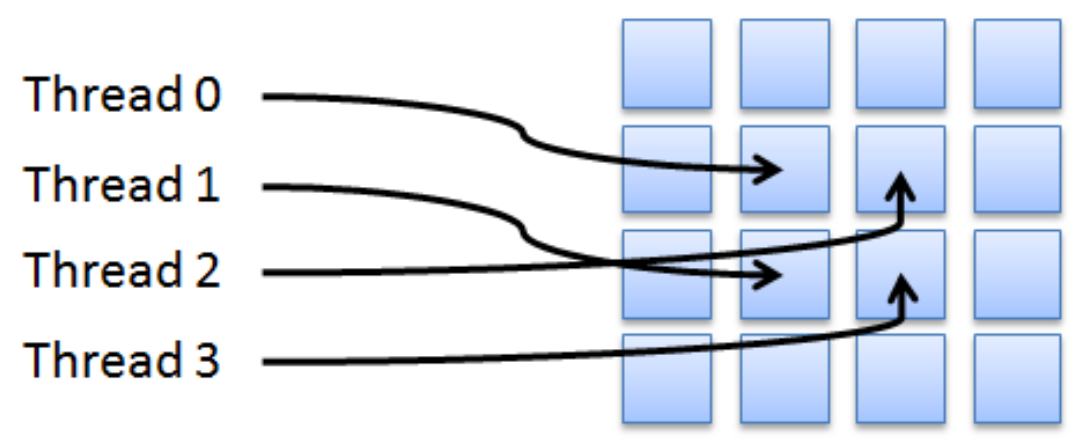

Figura 5.6: Mapeamento de threads em uma região bidimensional da memória (SANDERS; KANDROT, 2010).

em algumas situações, o seu uso em detrimento da memória global pode reduzir a largura de banda de memória requerida. Os registradores são usados por cada thread para a alocação das funções e suas variáveis.

\subsection{Considerações Gerais da Implementação}

Para a reimplementação dos módulos críticos do AVMix, as particularidades da organização dos elementos de processamento e a hierarquia da memória apresentadas anteriormente devem ser conhecidas pelo desenvolvedor para um maior aproveitamento do processamento paralelo pela GPU.

Um fator importante refere-se ao domínio e volume de dados que serão processados pela GPU, sendo necessário entender o que será processado. Como indicado em Nvidia (2010), a arquitetura SIMT, baseada na SIMD, considera que, dentro de um conjunto de dados, é possível executar o kernel sobre diferentes trechos deste conjunto de forma paralela, e para isto, é desejável que não haja dependência entre estes trechos. Em programas sequenciais, geralmente o procesamento destes dados ficam implicitos dentro dos laços de repetição; por este motivo, uma das maneiras de identificar o algoritmo candidato a ser paralelizado é analisar estes laços de programação, da mesma 
forma exemplificada na figura 5.2.

Outro item importante refere-se ao volume de dados, uma vez que a execução do kernel depende da transferência de dados da memória principal do computador para a GPU e vice-versa (conforme apresentado na figura 5.5). Neste caso, deve-se avaliar o tempo de processamento deste volume, que deve ser maior que o tempo de trasferência dos dados.

Dentro do sistema AVMix, a análise dos dados de entrada, que são as imagens tratadas por cada módulo, mostrou que eles são adequados para o processamento paralelo, pois atendem os requisitos de dados (pixels) independentes entre si e possuem um volume adequado (320x240 pixels) para serem processados em paralelo.

\subsection{Implementação do Mapa de Profundidade}

A implementação do módulo do mapa de profundidade foi feita de forma a reutilizar a interface IDepthMap definida no sistema original. Desta maneira, foi criada uma nova classe denominada DMCuda que implementa os métodos definidos nesta interface, além de ser responsável pelo gerenciamento da alocação da memória na GPU e chamadas ao kernel. A figura 5.7 mostra um diagrama de classes que ilustra o trabalho desenvolvido. O kernel implementa um algoritmo local, detalhado na seção 3.3 que avalia, a partir de um par de imagens em escala de cinza, segmentadas e retificadas, uma vizinhança finita de cada ponto entre o par de imagens, para calcular uma estimativa de similaridade entre elas. O valor da discrepância mínima, que resulta na profundidade do ponto correspondente e representado pela equação 3.2, é calculado sobre uma janela retangular, através do quadrado da diferença do valor destas áreas em cada uma das imagens de entrada. A alocação dos processadores 
consistiu no uso de blocos de tamanho 16x16 threads, referenciados em duas dimensões, onde cada thread é responsável pela análise dos pares de janelas, resultando no valor do pixel correspondente no mapa de profundidade.

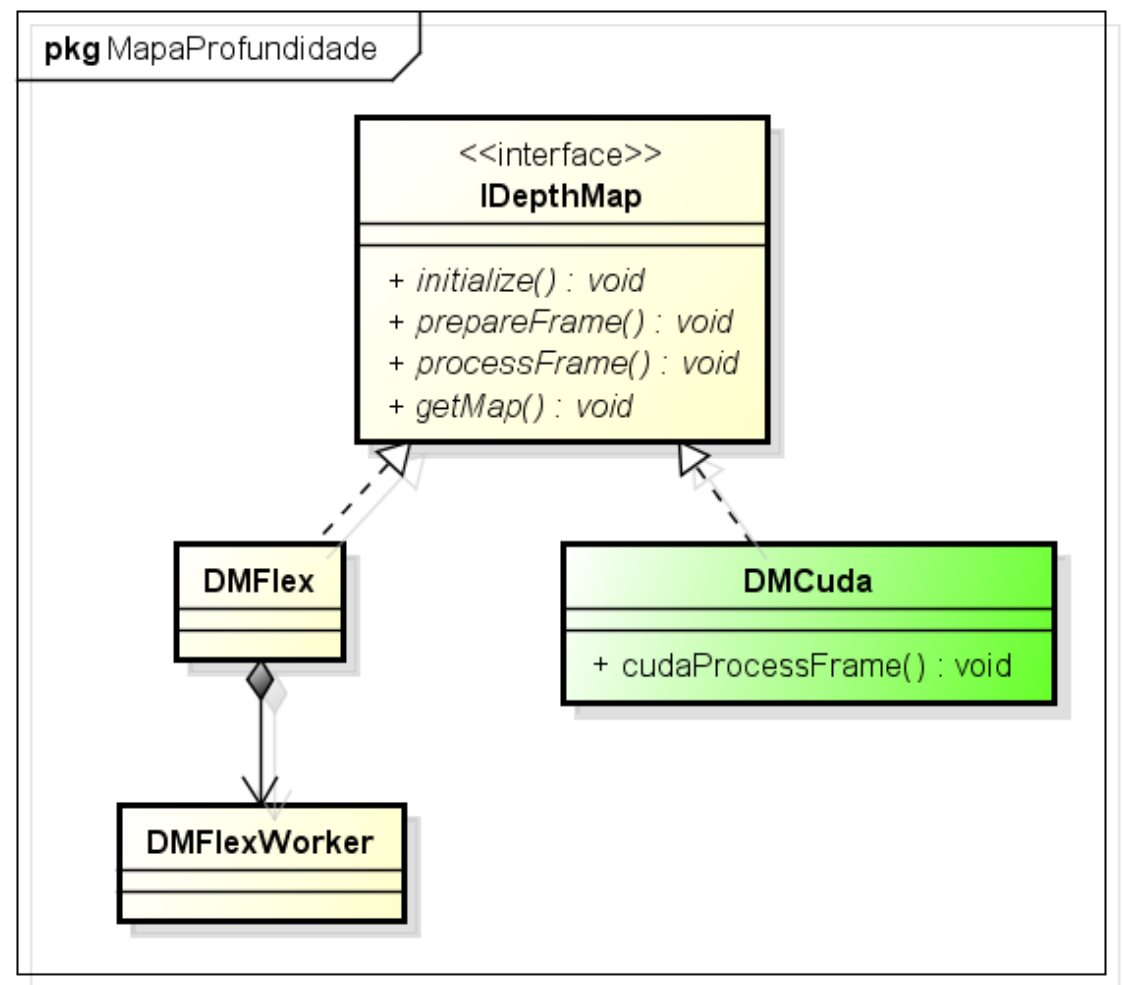

Figura 5.7: Diagramas de classes do módulo mapa de profundidade.

Para a implementação deste módulo, foram usadas duas abordagens: a primeira consistiu no uso da memória global da GPU para a transferência de dados de entrada e saída. A segunda abordagem foi usar a memória de textura para armazenar as imagens de entrada, adequada para o processamento deste algoritmo devido padrão de acesso que considera a região vizinha a determinado pixel.

O uso da memória compartilhada foi avaliada para ser usada nesta implementação, porém o seu uso não foi viabilizado, devido a inexistência de cálculos intermediários que dependam de resultados prévios e a não necessidade de cooperação destes resultados entre as threads, ou seja, os cálculos realizados para definir cada pixel do mapa de profundidade são feitos de ma- 
neira independente. Outro fator que dificultou o seu uso foi o seu tamanho limitado e necessidade de compartilhar este espaço com todas as threads dentro de um bloco. Este tamanho foi insuficiente para o armazenamento dos dados, que necessitam contemplar os pixels pertencentes a janela retangular das duas imagens de entrada e a faixa de disparidada máxima considerada para a avaliação, definida com o valor de 80 pixels.

Tsuda e Nakamura (2011a) apresentam o detalhamento da implementação deste módulo, considerando-se a aplicação de uma metodologia semelhante à apresentada na seção 5.2 e considerando a organização dos elementos de processamento e da memória da arquitetura CUDA.

\subsection{Implementação da Segmentação}

O desenvolvimento do módulo de segmentação foi feito de forma a implementar a interface IBackgroundRemover, através da criação da classe BGSubtractorCuda. A figura 5.8 apresenta o diagrama de classes que ilustra esta implementação.

O kernel desenvolvido para este módulo recebe como entrada a imagem capturada e a imagem de referência, considerando-se os três canais de cores (vermelho, verde e azul, ou RGB). A saída do módulo corresponde a imagem segmentada. Nesta situação também foram usados blocos bidimensionais de tamanho 16x16 threads, onde cada um é responsável pela avaliação e segmentação de cada pixel obtido nas duas imagens capturadas e no pixel correspondente da imagem de referência, conforme a regra apresentada na equação 3.1, e gerando como saída o pixel original do vídeo-avatar ou um pixel preto indicando a segmentação. Para este algoritmo, o desenvolvimento já considerou o uso da memória de textura, visando aproveitar a facilidade de 


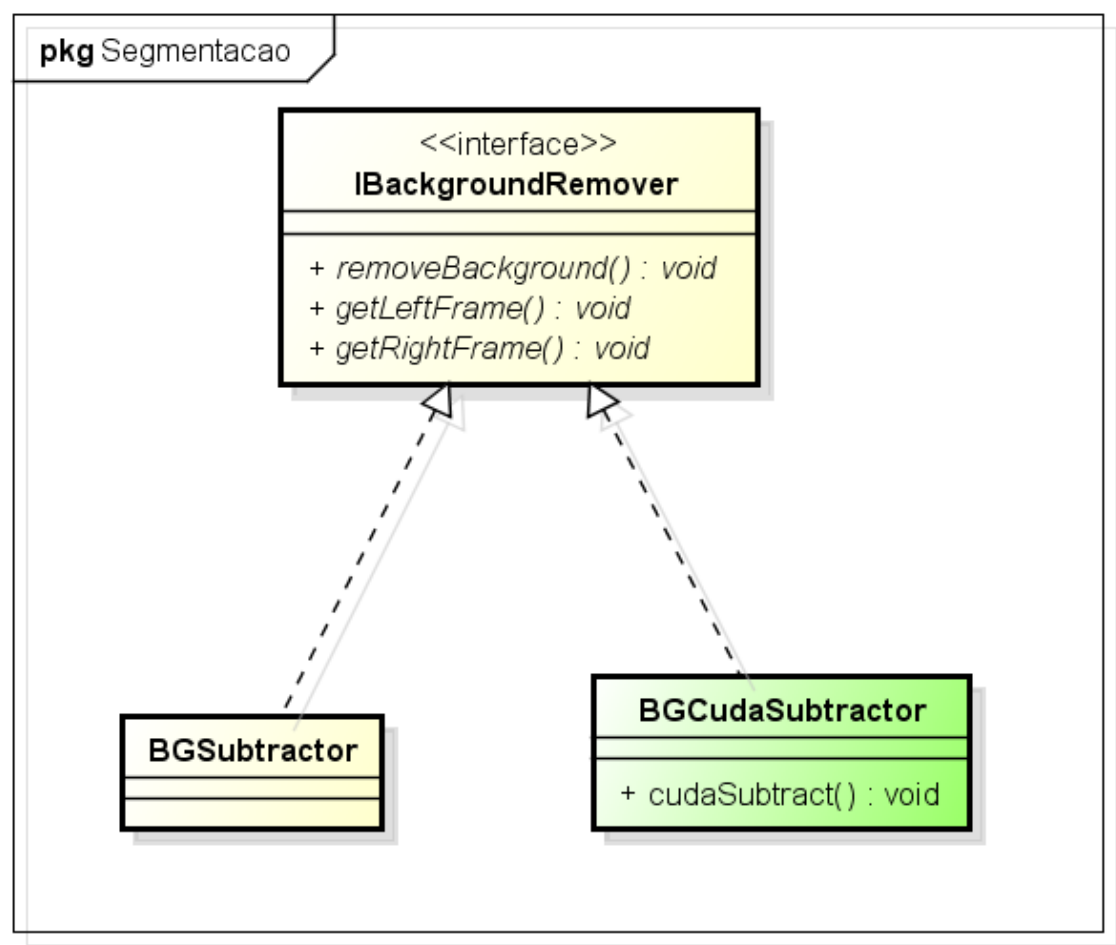

Figura 5.8: Diagramas de classes do módulo segmentação.

acesso espacial aos seus endereços.

\subsection{Implementação da Interação}

O módulo de interação, mais especificamente o algoritmo de construção da octree, foi desenvolvido implementando-se a interface ICollisionModel através da classe OctreeCollisionCuda. A figura 5.9 apresenta o diagrama de classes que ilustra esta implementação. Para este módulo, foram desenvolvidos dois kernels.

Para o primeiro kernel foram usados blocos de 16x16 threads, onde cada thread é responsável pela análise e classificação de 1 pixel, obtido a partir do mapa de profundidade fornecido na entrada, nas folhas da octree, as quais representam o menor limite volumétrico do volume total definido para o objeto, através da utilização dos códigos de Morton apresentados nas equações 3.7, 


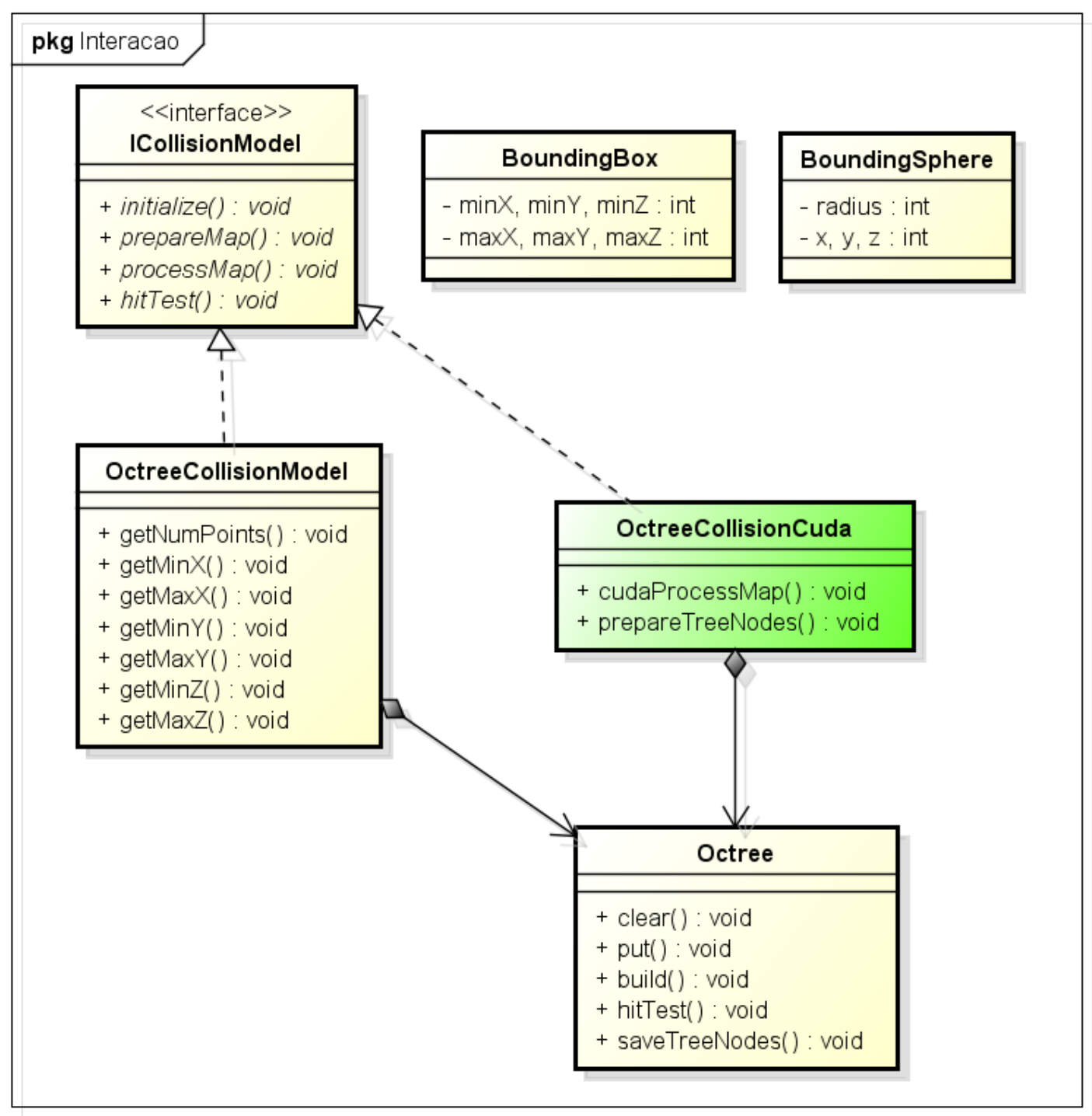

Figura 5.9: Diagramas de classes do módulo integração.

\section{8, 3.9 e 3.10 .}

O segundo kernel é responsável pela implementação do algoritmo de propagação dos resultados de dos nós filhos para o nível superior. Para este caso, foram alocados blocos contendo 512 threads organizadas em 1 dimensão, onde cada thread é responsável pela avaliação dos 8 nós filhos e a classificação do nó pai. A implementação considerou a limitação de versões antigas da CUDA de não suportar a execução de algoritmos de forma recursiva. Desta forma, o algoritmo foi implementado de forma a classificar todos os nós 
de um determinado nível antes de propagar os resultados para os nós pais. Por exemplo, para uma octree de profundidade 6, o nível 6 é analisado a partir do mapa de profundidade; após o término, todo o nível 5 é construído a partir dos resultados do nível 6 , e assim por diante, até o processamento do valor da raiz (nível 1).

Um estudo mais detalhado para este módulo e a proposta de uma implementação que utiliza a GPU e a CPU de forma a maximizar o desempenho é apresentado por Tsuda e Nakamura (2011b). 


\section{RESULTADOS E DISCUSSÃO}

Esta seção os resultados obtidos com o sistema alterado são apresentados e discutidos. Para cada módulo, são apresentados os resultados dos testes qualitativos e a contribuição do módulo reimplementado no desempenho geral do sistema AVMix.

\subsection{Critérios de Avaliação}

A avaliação dos módulos reimplementados com CUDA foi feita considerando-se os aspectos qualitativos e o desempenho do processamento. Os testes qualitativos envolvem a comparação dos resultados obtidos pela implementação nova em relação a implementação original, para garantir que o funcionamento do sistema AVMix não tenha sido afetado. Por isto, deve ser ressaltado que não houve o objetivo de melhorar a qualidade do módulo. No caso de obtenção de imagens na saída do módulo, a avaliação foi feita através de arquivos de saída que posteriormente foram comparadas.

Para cada módulo, a medição e avaliação de desempenho foi feita comparando-se a implementação original com a implementação na GPU. O programa principal da aplicação obtém, em cada etapa do fluxo de execução, o tempo antes e depois da execução do algoritmo, e registra o intervalo em um arquivo texto. A partir destes tempos, é possível obter o valor de quadros por segundo gerado pela aplicação. No caso da octree, o tempo de processa- 
mento de cada nível de profundidade foi observado.

O uso da GPU foi avaliado através da aplicação denominada CUDA Profiler. Esta aplicação monitora a execução do programa durante várias iterações e ao seu término fornece alguns valores referentes ao desempenho, como o tempo usado pela execução do kernel, o tempo consumido para transferência de dados da memória principal do sistema para a memória global da GPU, o volume de dados transferidos, entre outras informações.

A aplicação AVMix permite que a seleção do dispositivo a executar o algoritmo seja feita através de configurações em um arquivo XML (extensible markup language). Outras configurações específicas para cada dispositivo, como a quantidade de threads a serem usadas, também podem ser feitas através deste mesmo arquivo.

Em todos os testes, as imagens usadas como entrada possuem tamanho de $320 \times 240$ pixels.

\subsection{Mapa de Profundidade}

A avaliação qualitativa consiste em gravar o mapa de profundidade gerado como uma imagem após a execução do módulo. Após a comparação entre as imagens geradas pelo módulo original e o alterado, foi possível identificar que não houveram diferenças entre os resultados. Desta forma, garante-se que a funcionalidade não foi afetada.

Para os testes de desempenho do algoritmo integrado ao AVMix, foram considerados os dois cenários possíveis:

1. Uso de imagens de entrada sintéticas;

2. Uso de imagens previamente capturadas por um par de câmeras de ví- 
deo.

A diferença entre a entrada sintética e a obtida através da captura de vídeo é que a primeira não necessita de segmentação, pois as imagens de entrada não possuem fundo a ser removido. As medições do tempo foram feitas para cada um destes dois casos de teste. Em todos eles, o tamanho da janela de avaliação é de $7 \times 7$ pixels. O processamento do algoritmo na CPU, para a obtenção da referência, considera o uso de 8 threads.

As figuras 6.1 e 6.2 apresentam, respectivamente, o tempo de processamnto médio dos módulos do AVMix e a quantidade de quadros executados por segundo, alterando-se a execução do mapa de profundidade na CPU e na GPU (usando a memória global para a transferência dos dados) através do uso de um conjunto de imagens sintéticas sem fundo como entrada.

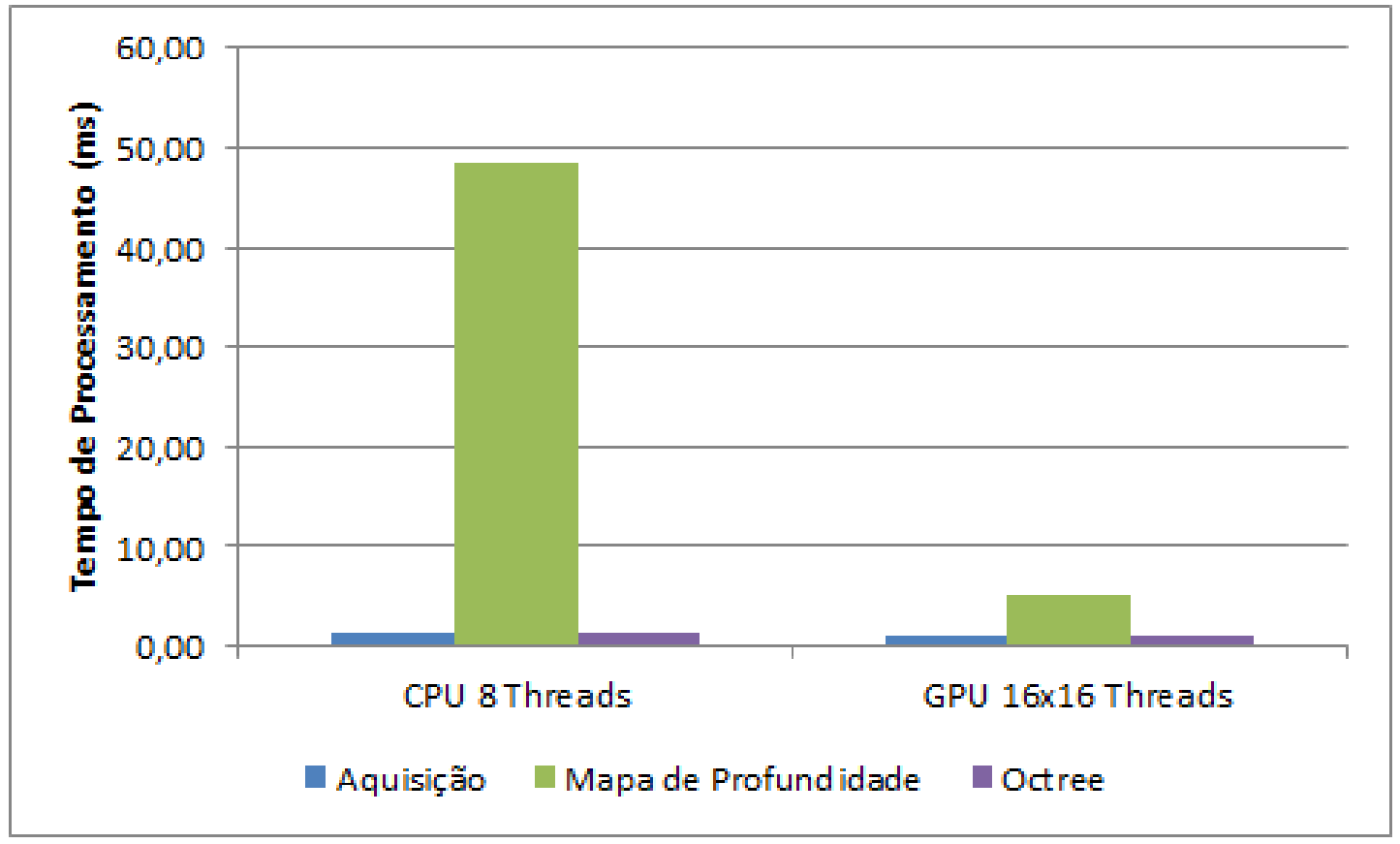

Figura 6.1: Tempo de processamento em milissegundos dos módulos do AVMix usando um conjunto de dados sintético.

Os gráficos apresentados nas figuras 6.1 e 6.2 mostram que a execução do mapa de profundidade usando as imagens sintéticas possibilita um grande 


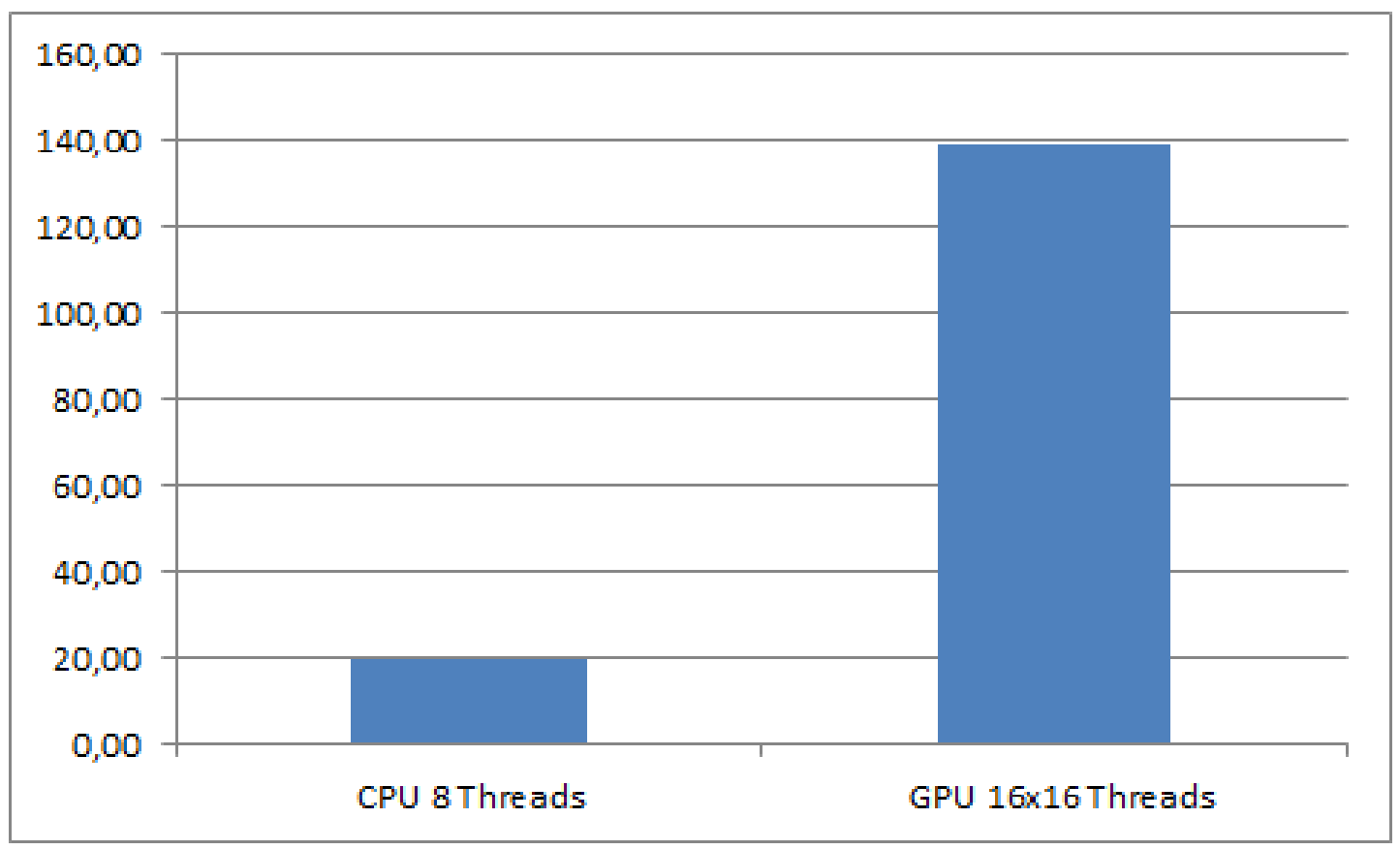

Figura 6.2: Taxa de quadros por segundo obtida usando um conjunto de dados sintético.

aumento no desempenho. Foi possível diminuir o tempo de processamento médio por quadro de aproximadamente 48 ms para 5 ms (redução de 90\%). Considerando-se o processamento de todos os módulos integrados, até a construção da octree, a taxa de quadros por segundo gerados pelo sistema aumentou de 20 para 140 .

As figuras 6.3 e 6.4 apresentam, respectivamente, o tempo de processamento médio e a quantidade de quadros executados, alterando-se a execução do mapa de profundidade na CPU e na GPU (também usando a memória global) usando-se um conjunto de imagens previamente capturadas como entrada.

Pelos gráficos apresentados nas figuras 6.3 e 6.4 , nota-se um ganho semelhante ao obtido para as imagens sintéticas. O tempo de processamento médio por quadro diminuiu de aproximadamente 63 ms para 5 ms (redução de 92\%). Considerando-se o processamento de todos os módulos, até a construção da octree, a taxa de quadros por segundo aumentou de 15 para 135. 


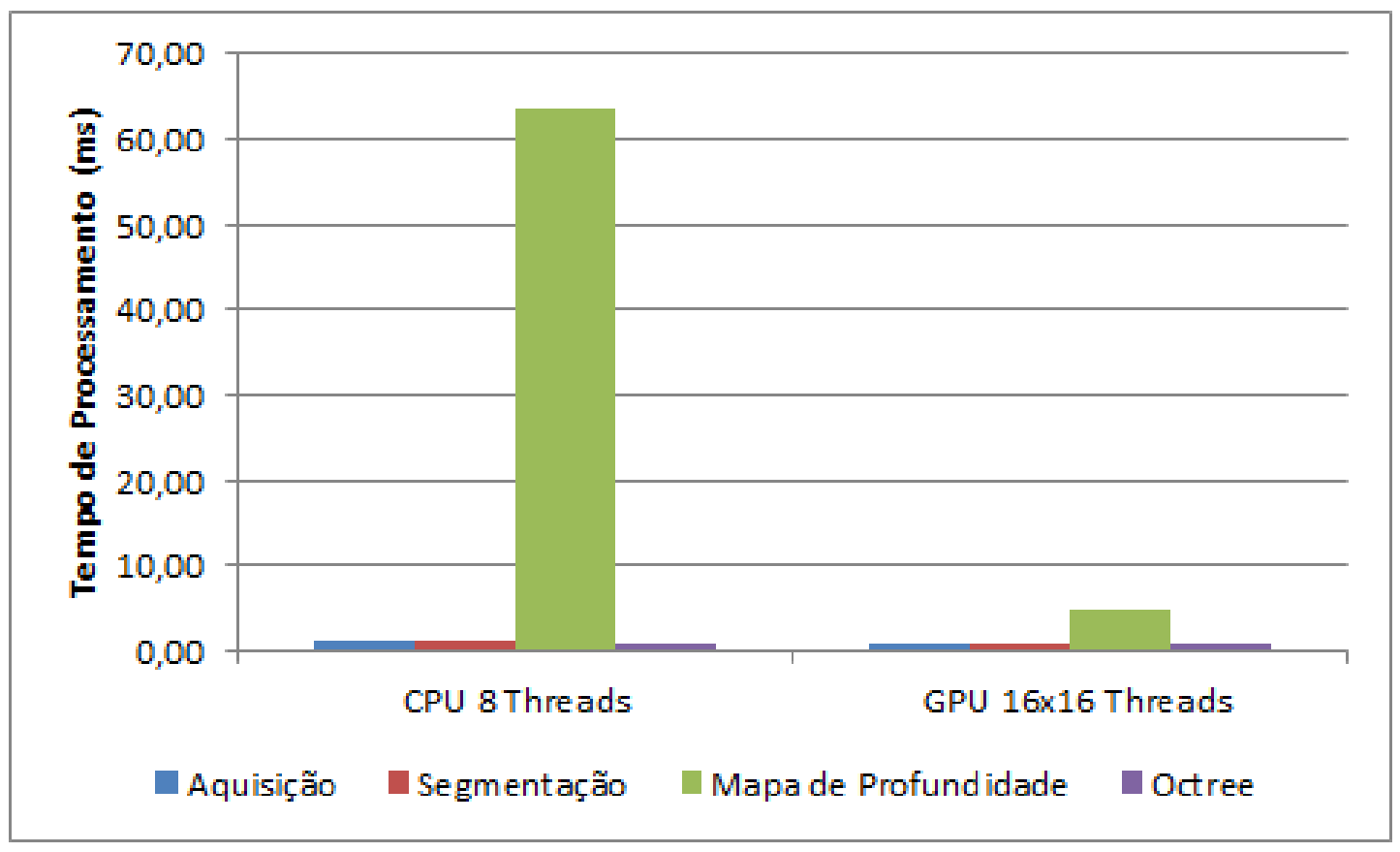

Figura 6.3: Tempo de processamento em milissegundos dos módulos do AVMix usando um conjunto de dados reais.

A tabela 6.1 apresenta o resultado sumarizado da ocupação da GPU, obtido a partir do CUDA Profiler. A ocupação da GPU para o processamento do kernel do mapa de profundidade em aproximadamente $99 \%$ do tempo indica que o algoritmo se aproveita da capacidade de processamento da GPU, e que a transferência de dados entre a RAM principal e a memória da GPU praticamente não interfere no desempenho.

Tabela 6.1: Ocupação da GPU durante o processamento do mapa de profundidade.

\begin{tabular}{lc}
\hline Tarefa & \% de Uso da GPU \\
\hline \hline Processamento do kernel & 98,87 \\
\hline Transferência dados RAM para GPU & 0,84 \\
\hline Transferência dados GPU para RAM & 0,28 \\
\hline
\end{tabular}

Outro teste realizado neste módulo refere-se à comparação do uso da memória de textura em vez da memória global. Como explicado anteriormente, esta abordagem permite o aproveitamento dos dados armazenados em cache, devido ao padrão de acesso uniforme. Os resultados desta comparação 


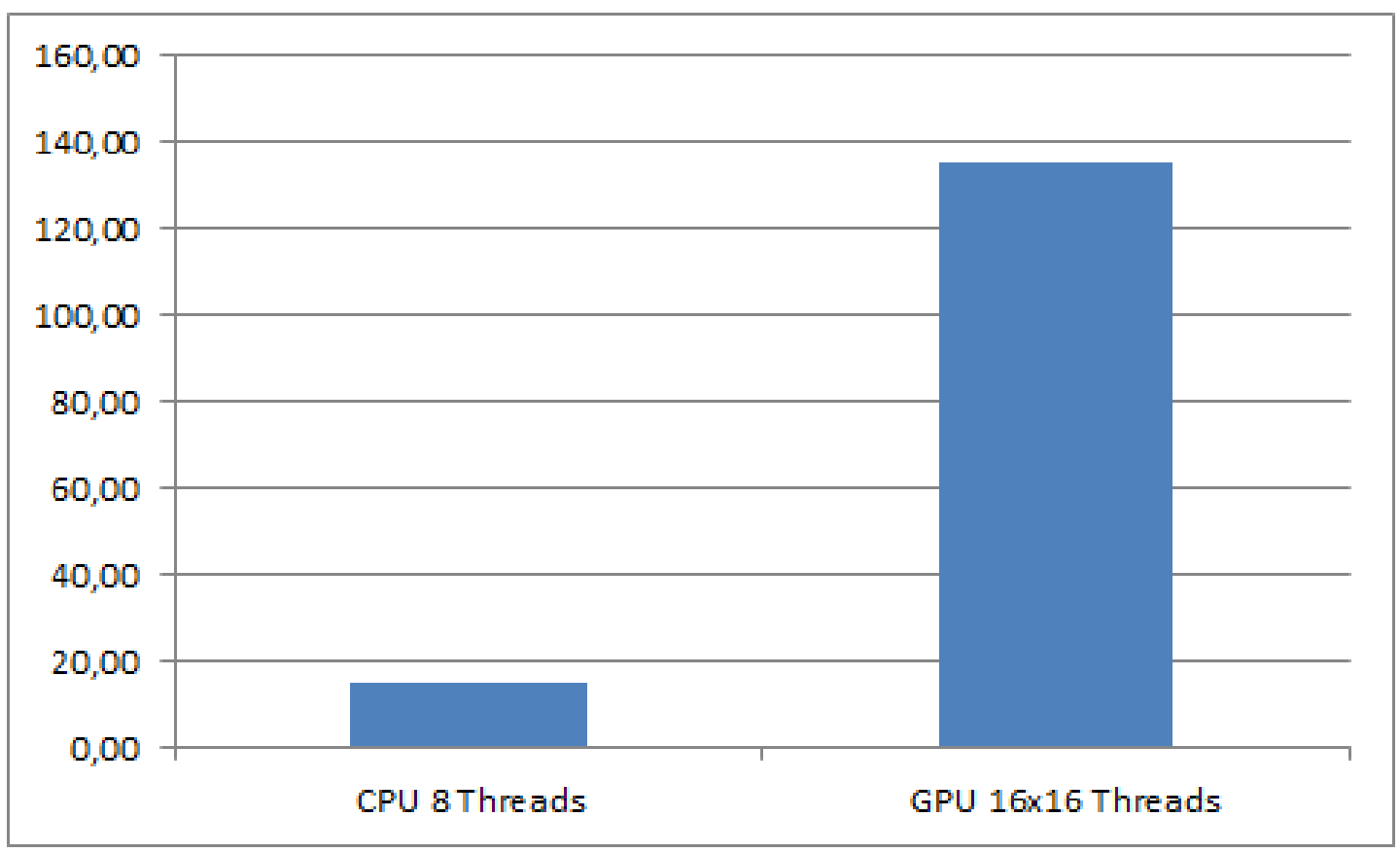

Figura 6.4: Taxa de quadros por segundo obtida usando um conjunto de dados reais.

são apresentados na figura 6.5 .

Os resultados mostram que o uso da memória de textura apresenta perda de desempenho em relação à implementação com a memória global. O resultado, que a principio contradiz a vantagem de seu uso, pode ser explicado pelo uso de uma GPU com capacidade computacional 2.0, que implementa um cache de acesso a memória global, não existente em versões anteriores. Esta característica da arquitetura denominada "Fermi" pode ser vista em Nvidia (2011a), Nickolls e Dally (2010) e Dobb's (2010).

A partir dos resultados obtidos, é possível concluir que este módulo é bastante adequado para ser executado paralelamente na GPU, pois o kernel responsável pelo cálculo da discrepância mínima entre as duas imagens de entrada consegue executar um algoritmo de avaliação sobre um conjunto único de dados de forma paralela, uma vez que os resultados gerado por cada thread são independentes entre si; desta forma, pode-se dizer que este módulo está aderente aos requisitos apresentados na seção 5.3. 


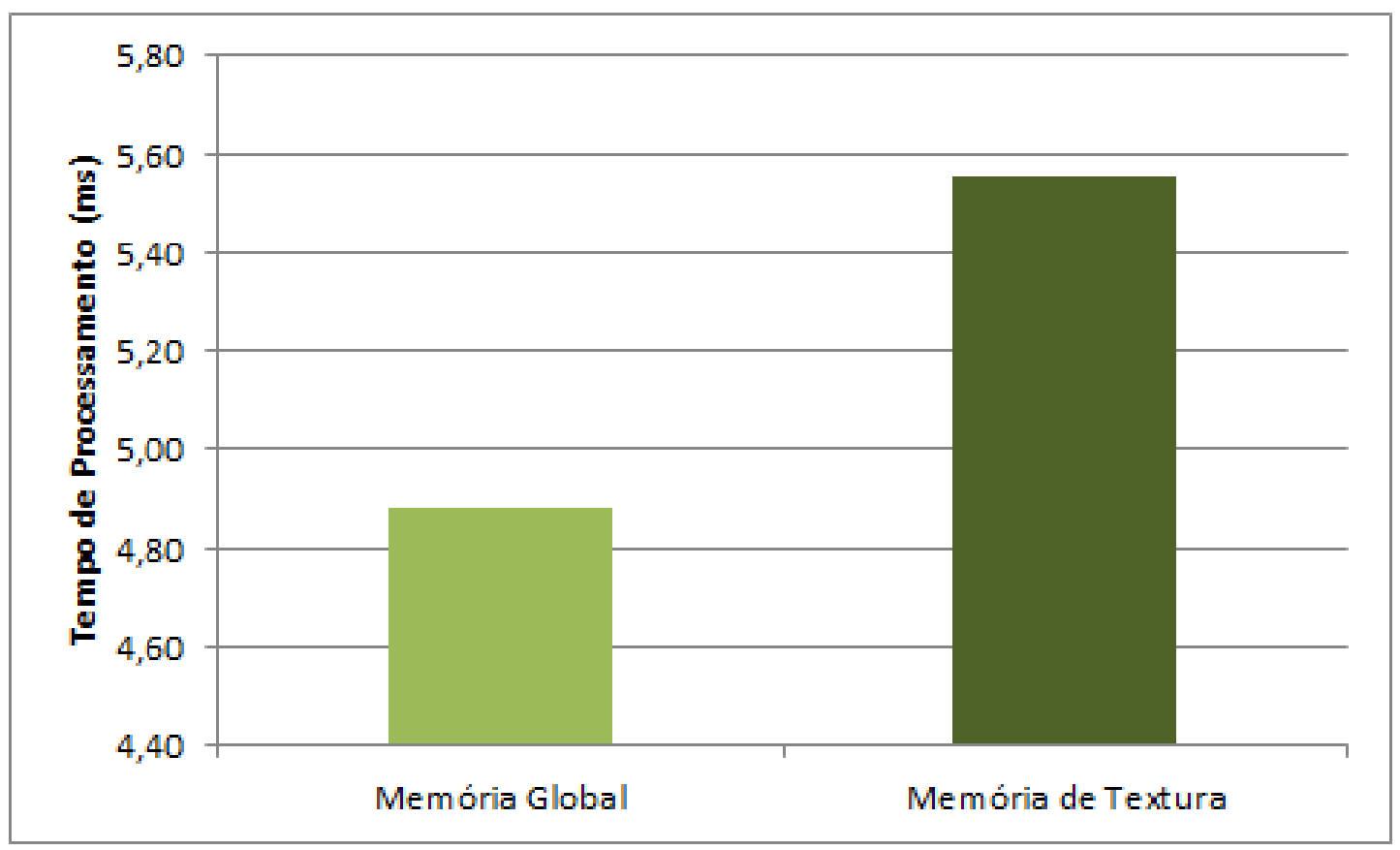

Figura 6.5: Comparação do tempo de processamento em milissegundos entre as implementações usando a memória global e memória de textura.

\subsection{Segmentação}

Para a avaliação qualitativa, adotou-se o mesmo critério usado no mapa de profundidade, ou seja, foi gerado um arquivo contendo a imagem segmentada após a execução do módulo. A comparação entre os resultados do módulo originais e do alterado mostrou que a alteração não afetou a funcionalidade, pois as imagens comparadas apresentaram-se idênticas.

Os resultados comparativos de desempenho entre a implementação original e a implementação na GPU são apresentados na figura 6.6 A tabela 6.2 apresenta o resultado sumarizado da ocupação da GPU.

Tabela 6.2: Ocupação da GPU durante processamento da segmentação.

\begin{tabular}{lc}
\hline Tarefa & $\%$ de Uso da GPU \\
\hline \hline Processamento do kernel & 12,42 \\
\hline Transferência dados RAM para GPU & 58,48 \\
\hline Transferência dados GPU para RAM & 29,09 \\
\hline
\end{tabular}

Nesta situação, a implementação na GPU apresentou perda de desem- 


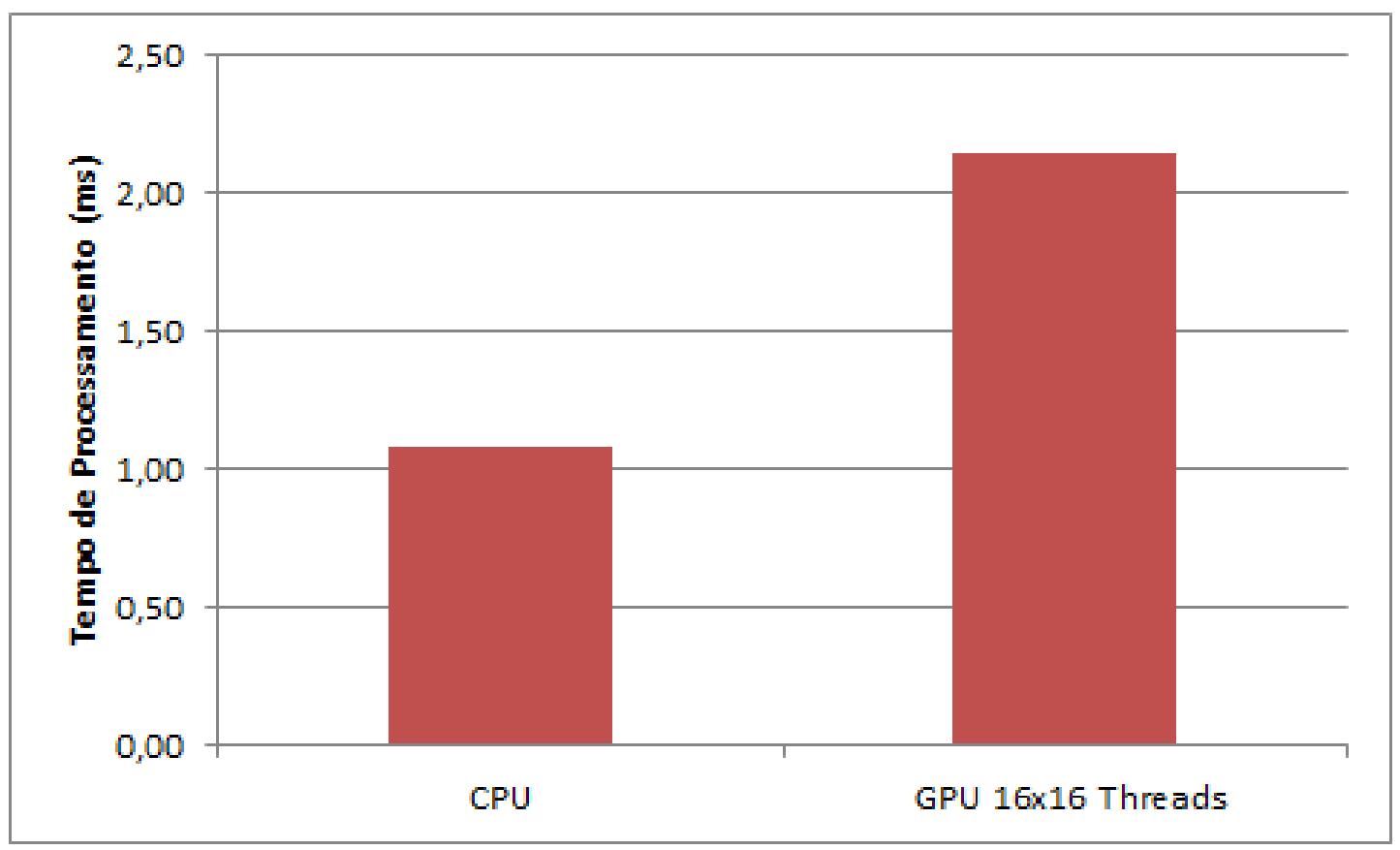

Figura 6.6: Tempo de processamento em milissegundos do módulo de segmentação do AVMix usando um conjunto de dados reais.

penho, com o tempo de processamento do algoritmo aumentando de 1,0 ms para 2,1 ms. Os resultados da ocupação da GPU mostram que, para o processamento deste módulo, a transferência de dados entre a RAM e a memória da GPU é um fator crítico de desempenho, pois totaliza quase $88 \%$ do tempo de uso da GPU, enquanto que o kernel usa somente 12\%. Nesta situação, pode-se afirmar que o processamento da avaliação e subtração de pixels, considerando-se os três canais de cores (RBG), não é uma rotina intensa, e que o tempo de transferência dos dados entre a CPU e GPU anula o ganho que poderia ser obtido com o processamento paralelo na GPU.

\subsection{Interação}

A avaliação qualitativa do algoritmo consistiu em gerar em arquivo os valores dos nós da octree de 6 níveis. Os resultados da comparação mostraram que as duas implementações (CPU e GPU) geraram octrees idênticas. Desta 
forma, foi realizado um teste para a obtenção do tempo de processamento de cada nível da octree. Os resultados são mostrados nas figuras 6.7 e 6.8 .

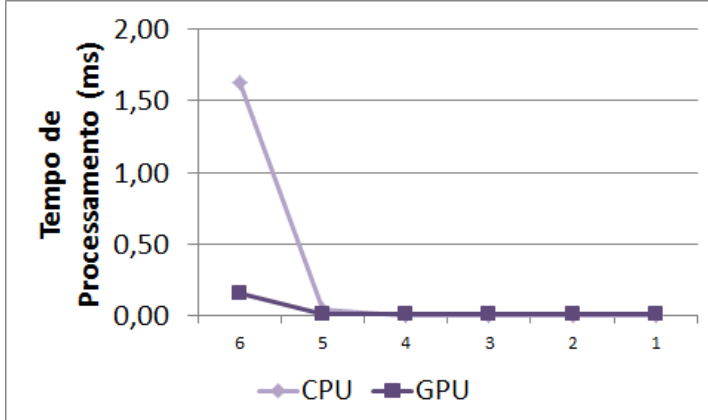

(a)

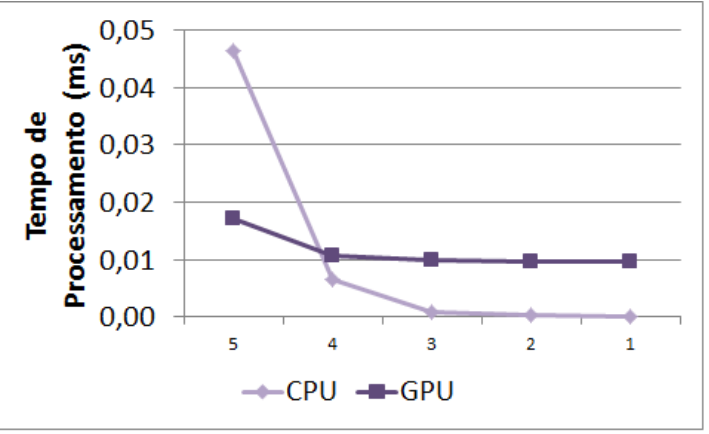

(b)

Figura 6.7: Tempo de processamento do módulo de integração do AVMix considerando a profundidade máxima de 6 níveis. (a) Tempo de processamento em milissegundos obtido em cada nível; (b) Detalhamento do resultado anterior, com os tempos obtidos a partir do nível 5.

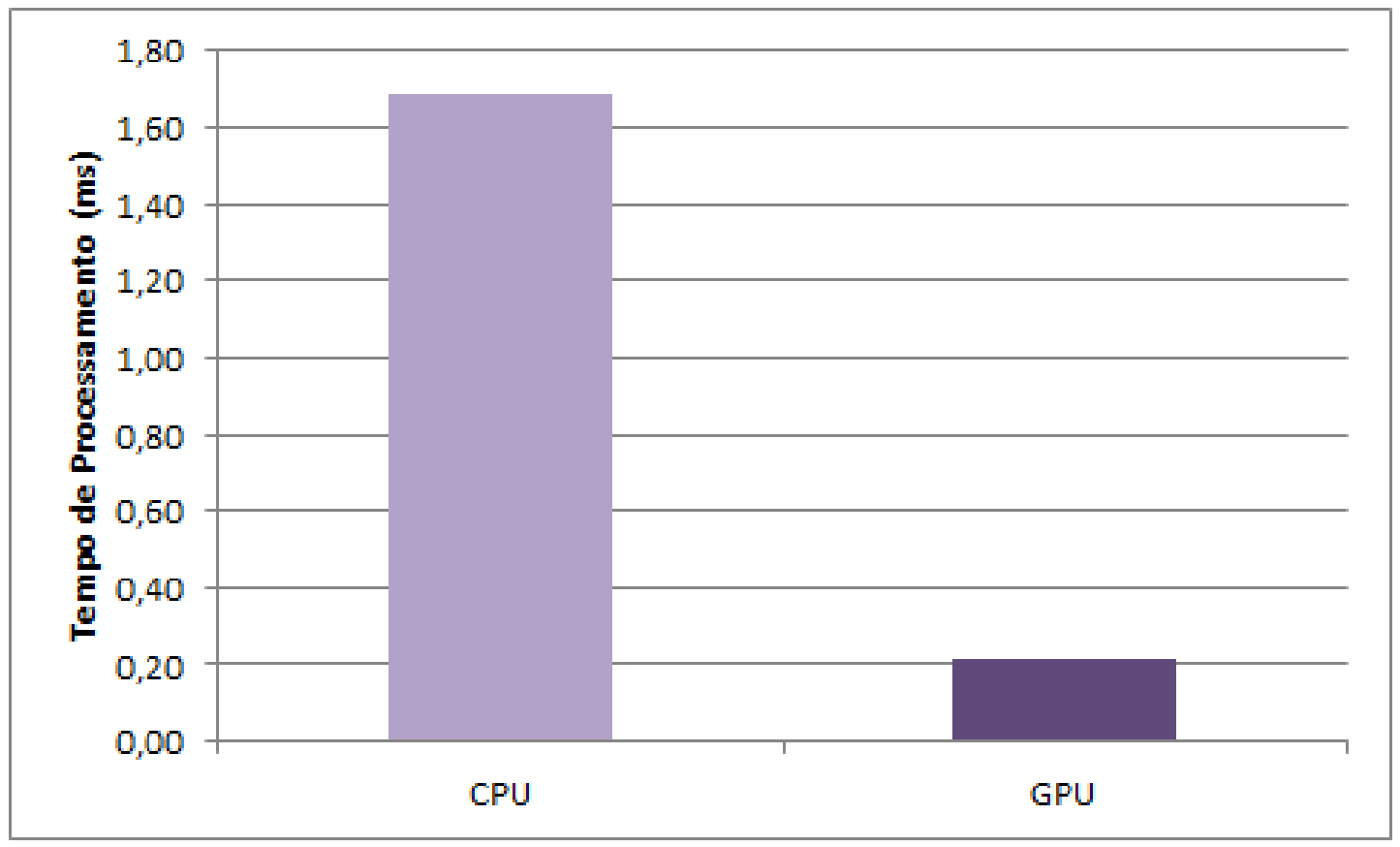

Figura 6.8: Tempo de processamento total, em milissegundos para a criação da octree inteira com 6 níveis.

Os resultados mostram que o uso da GPU para a construção da octree é vantajoso. É possível perceber que o processamento do mapa de profundidade e classificação das folhas é a etapa que mais se beneficia do processamento paralelo, uma vez que os seus pixels estão sendo tratados de maneira 
paralela por diferentes threads, ao contrário da execução na CPU, onde os pixels são tratados individualmente um de cada vez, através do uso de um laço que percorre a imagem. O fato da propagação dos resultados ter menor desempenho na GPU conforme a proximidade da raiz pode ser explicada principalmente pelo fato da GPU sempre alocar uma quantidade mínima de blocos de execução, independentemente da quantidade de threads que serão usadas. Ou seja, para o processamento do nível 1, mesmo que somente uma thread seja usada, todo o bloco será executado. Isso é evidenciado pela obtenção de tempos quase constantes durante a construção dos níveis mais próximos da raiz, a partir do nível 3.

Apesar de um valor alto do ganho, de 7,98x, o desempenho geral do sistema não foi alterado com o uso do novo módulo, devido a pequena participação deste no tempo total do processamento de um quadro.

\subsection{Considerações Finais}

A tabela 6.3 apresenta os valores dos quadros processados por segundo com os módulos do AVMix sendo executado na CPU e na GPU, e um valor do ganho obtido calculado a partir destes valores. Para efeito de comparação, também é apresentado o ganho obtido de forma isolada pelo módulo.

Pelos resultados apresentados, concluí-se que a reimplementação do algoritmo de mapa de profundidade com a CUDA consegue resolver a criticidade deste módulo em relação ao desempenho geral do AVMix. O resultado de aumento de desempenho através da implementação de kernels de rotinas complexas, como o cálculo da disparidade entre duas imagens e a classificação dos pontos do mapa de profundidade nas folhas da octree, mostra que, nestas situações, o uso da GPU é favorável. Comparando-se com as imple- 
Tabela 6.3: Resultados consolidados, mostrando valor de quadros processados por segundo (referência e alterado), o ganho calculado sobre o valor das taxas obtidas e o ganho obtido isoladamente pelo módulo alterado.

\begin{tabular}{llllll}
\hline Módulo & CPU & GPU & $\begin{array}{l}\text { Ganho Ge- } \\
\text { ral }\end{array}$ & $\begin{array}{l}\text { Ganho Al- } \\
\text { goritmo }\end{array}$ \\
\hline \hline $\begin{array}{l}\text { Mapa de profundidade } \\
\text { (sintético) }\end{array}$ & 20 & 140 & $7 x$ & $9,66 x$ \\
Global & & & & \\
\hline $\begin{array}{l}\text { Mapa de profundidade } \\
\text { (imagens capturadas) e }\end{array}$ & 15 & 135 & $9 x$ & $13,04 x$ \\
Memória Global & & & & \\
\hline $\begin{array}{l}\text { Mapa de profundidade } \\
\text { (imagens capturadas) e }\end{array}$ & 15 & 124 & $8,26 x$ & $11,46 x$ \\
Memória de Textura & & & & \\
\hline $\begin{array}{l}\text { Segmentação e Memória } \\
\text { de Textura }\end{array}$ & 14,97 & 14,95 & $0,99 x$ & $0,51 x$ \\
\hline $\begin{array}{l}\text { Interação (construção da } \\
\text { Octree) e Memória de Tex- } \\
\text { tura }\end{array}$ & & & & $7,98 x$ \\
\hline
\end{tabular}

mentações apresentadas no capítulo 4, a implementação dos módulos neste trabalho não apresentou valor muito elevado de ganho. Porém, considerando-se a manutenção das interfaces e funcionalidades originais do sistema AVMix, o ganho é bastante expressivo.

No processamento da octree, durante a propagação dos valores das foIhas para a raíz, fica visível o impacto da execução dos kernels usando um baixo volume de dados, fazendo com que várias threads fossem executadas, mas sem contribuir na obtenção de resultados válidos.

A perda de desempenho na execução do módulo de segmentação mostrou uma situação onde não há vantagens em usar a GPU no processamento. Esta situação reforça a necessidade da avaliação criteriosa dos algoritmos para determinar a viabilidade de sua implementação paralela na GPU. 


\section{CONCLUSÕES}

O trabalho apresentou um estudo das técnicas para a paralelização de algoritmos a serem executados em GPU, através da reimplementação de rotinas críticas do sistema AVMix.

A revisão da literatura no capítulo 4 mostrou que o uso da GPGPU é um campo bastante explorado, e que, em geral, o seu uso permite aumentar o desempenho das aplicações. Estes trabalhos apresentam uma variação do ganho de desempenho grande, dependendo da área de conhecimento. Deve ser ressaltado que o foco deste trabalho foi o entendimento e a aplicação de um processo para converter os algoritmos existentes para GPGPU. Por isto, é possível concluir que objetivo de aumentar de desempenho do AVMix foi atingido, porém sem a preocupação de fazer com que os valores dos ganhos atingissem os mesmos níveis dos demais trabalhos.

Os resultados obtidos sobre o sistema AVMix mostram a viabilidade do uso das técnicas de GPGPU neste sistema, que por sua vez se apoiam sobre as técnicas apresentadas pelas áreas de processamento de imagens e visão computacional, dois dos campos bastante explorados em outros trabaIhos. Também foi possível perceber a importância da análise de viabilidade da implementação paralela e associá-las à organização dos elementos de hardware da GPU, principalmente em relação aos elementos de processamento (threads, blocos e grids computacionais) e à hierarquia dos tipos de memória 
disponíveis. Devido a pequena barreira de aprendizado, o uso de técnicas de GPGPU deve ser estimulado em projetos que envolvam a execução de algoritmos críticos, como os usados em projetos de realidade aumentada e vídeo-avatar, visando o aumento do desempenho ou até mesmo o ganho qualitativo.

A criação de APIs que expõem os recursos das GPUs para o desenvolvimento de algoritmos não gráficos, acessadas através de linguagens de programação usuais, como a CUDA usada neste trabalho, permite a abstração e o aproveitamento da maior parte dos recursos da GPU sem a necessidade de conhecimentos específicos do pipeline gráfico e das linguagens de shader. Estas facilidades incentivam o programador a adotar estas ferramentas para o desenvolvimento de rotinas executadas na GPU. Porém, diversos autores indicam que, apesar das facilidades já existentes, ainda é necessário algum conhecimento a respeito da organização estrutural do hardware da GPU, tais como os processadores, memórias e integração com a CPU e memória principal do sistema, para que os recursos sejam melhores explorados. Esta necessidade do conhecimento dos recursos de hardware disponibilizados foi verificada no desenvolvimento deste trabalho em algumas situações, como por exemplo na diferença do valor do tempo de processamento diferenciado em relação ao tipo de memória usado na implementação do mapa de profundidade e na perda de desempenho na implementação do módulo de Segmentação do AVMix na GPU, onde o tempo de processamento do algoritmo de segmentação não era crítico em relação ao tempo de transferência dos dados entre a GPU e a CPU.

A arquitetura CUDA mostrou-se bastante adequada para a implementação deste trabalho, e o pioneirismo de seu lançamento em 2007, juntamente com a arquitetura unificada das GPUs fez com que um grande volume de traba- 
Ihos fossem desenvolvido com o seu uso. A linguagem adotada, próxima a C, e as ferramentas disponibilizadas evitaram a necessidade de uma curva de aprendizado muito grande. Porém, o seu uso naturalmente implica na necessidade de um hardware da Nvidia. Algumas alternativas a sua utilização é a adoção do OpenCL, pois a execução de programas que a utilizam independem do fabricante hardware (inclusive a arquitetura de hardware da Nvidia passou a suportar o processamento de programas criados com OpenCL (NVIDIA, 2011d)), ou através de ferramentas que permitem a execução de códigos em outros hardwares que não são da Nvidia (DOBB'S, 2011).

Como referência para trabalhos futuros em relação ao sistema AVMix, uma proposta para a continuidade deste trabalho é o estudo detalhado e aplicação dos algoritmos apresentados no capitulo 4, visando um maior aproveitamento da capacidade de processamento da GPU para a execução de algoritmos de visão computacional e processamento de imagens. Deve-se ressaltar que a execução do AVMix com o uso de câmeras de vídeo USB torna este dispositivo um limitante de desempenho, pois em geral elas fornecem 15 quadros por segundo na entrada e fazendo com que o ganho não seja aproveitado de forma adequada. Este poder computacional pode, então, ser usado no processamento de outras funções de um sistema de realidade aumentada (ex: sons, interações, etc), ou no processamento de algoritmos mais complexos que possam trazer ganhos qualitativos ao sistema sem afetar o desempenho.

$\mathrm{Na}$ área de hardwares e ferramentas de desenvolvimento, deve-se atentar ao aumento da participação de processadores cujos projetos permitem a junção da GPU com a CPU em um mesmo encapsulamento, como, por exemplo, as soluções AMD Fusion (AMD, 2011) e Intel AVX (INTEL, 2011). As GPUs também tem sido integradas em dispositivos móveis, tais como o Nvidia Tegra 2 (NVIDIA, 2011e), abrindo a possibilidade de processamento paralelo de algorit- 
mos. Para o maior aproveitamento destas abordagens, torna-se necessário o desenvolvimento de APIs e ferramentas que consigam aproveitar ainda mais os recursos da GPU, e ao mesmo tempo abstraindo esta complexidade para o programador. 


\section{REFERÊNCIAS}

ADOBE. Adobe and NVIDIA Announce GPU Acceleration for Flash Player. 2 de Junho de 2009. 2009. Disponível em: <http://www. adobe.com/ aboutadobe/pressroom/pressreleases/200906/060209AdobeandNvidia. html>. Acesso em: 28 de janeiro de 2011.

AJMERA, P. et al. Fast, parallel, gpu-based construction of space filling curves and octrees. In: Proceedings of the 2008 symposium on Interactive 3D graphics and games. New York, NY, USA: ACM, 2008. (I3D '08), p. 10:1-10:1.

ALLUSSE, Y. et al. Gpucv: an opensource gpu-accelerated framework for image processing and computer vision. In: Proceeding of the 16th ACM international conference on Multimedia. New York, NY, USA: ACM, 2008. (MM '08), p. 1089-1092.

AMD. The AMD Fusion Family of APUs. 2011. Disponível em: <http: //sites.amd.com/us/fusion/apu/Pages/fusion.aspx>. Acesso em: 23 de janeiro de 2012.

APODACA, A. A.; MANTLE, M. W. Renderman: Pursuing the future of graphics. IEEE Comput. Graph. Appl., IEEE Computer Society Press, v. 10, p. 44-49, 1990.

AZUMA, R. A survey of augmented reality. Presence: Teleoperators and Virtual Environments. vol. 6, v. 4, p. 355-385, 1997.

BIMBER, O.; RASKAR, R. Spatial Augmented Reality: Merging Real and Virtual Worlds. [S.I.]: A K Peters/CRC Press, 2005. ISBN 1568812302.

BOYD, C. Data-parallel computing. Queue, ACM, New York, NY, USA, v. 6, p. 30-39, 2008.

BUCK, I. et al. Brook for gpus: stream computing on graphics hardware. In: ACM SIGGRAPH 2004 Papers. New York, NY, USA: ACM, 2004. (SIGGRAPH '04), p. 777-786.

$\mathrm{CHE}, \mathrm{S}$. et al. A performance study of general-purpose applications on graphics processors using cuda. Journal of Parallel and Distributed Computing, v. 68, p. 1370-1380, 2008.

CHEN, L. et al. Using stereo camera to realize realistic video avatar in virtual environment. In: Proceedings of International Conference On Signal Processing. [S.I.: s.n.], 2002. 
CULLER, D. E.; GUPTA, A.; SINGH, J. P. Parallel Computer Architecture: A Hardware/Software Approach. San Francisco, CA, USA: Morgan Kaufmann Publishers Inc., 1997. ISBN 1558603433.

DOBB'S, D. CUDA, Supercomputing for the Masses: Part 21. 2010. Disponível em: <http://drdobbs.com/high-performance-computing/228300263>. Acesso em: 23 de janeiro de 2012.

. Running CUDA Code Natively on x86 Processors. 2011. Disponível em: <http: //drdobbs. com/high-performance-computing/231500166>. Acesso em: 23 de janeiro de 2012.

DUNCAN, R. A survey of parallel computer architectures. Computer, v. 23, p. 5-16, 1990.

ERICSSON, C. Real-time Collision Detection. [S.I.]: Morgan Kaufmann, 2005.

FATAHALIAN, K.; HOUSTON, M. A closer look at gpus. Commun. ACM, ACM, v. 51, p. 50-57, 2008.

FUNG, J.; MANN, S. Openvidia: parallel gpu computer vision. In: Proceedings of the 13th annual ACM international conference on Multimedia. New York, NY, USA: ACM, 2005. (MULTIMEDIA '05), p. 849-852.

. Using graphics devices in reverse: Gpu-based image processing and computer vision. In: Multimedia and Expo, 2008 IEEE International Conference on. [S.I.: s.n.], 2008. p. 9-12.

GIBSON, J.; MARQUES, O. Stereo depth with a unified architecture gpu. In: Computer Vision and Pattern Recognition Workshops, 2008. CVPRW '08. IEEE Computer Society Conference on. [S.I.: s.n.], 2008. p. 1-6.

GONZALES, R. C.; WOODS, R. E. Processamento de Imagens Digitais. [S.I.]: Edgard Blucher, 2000. ISBN 8521202644, 9788521202646.

GPGPU. GPGPU.org. 2002. Disponível em: <http://gpgpu.org/>. Acesso em: 23 de janeiro de 2012.

HIRSCHMULLER, H. Accurate and efficient stereo processing by semi-global matching and mutual information. In: Computer Vision and Pattern Recognition, 2005. CVPR 2005. IEEE Computer Society Conference on. [S.I.: s.n.], 2005. v. 2, p. 807-814.

HUMENBERGER, M. et al. A fast stereo matching algorithm suitable for embedded real-time systems. Comput. Vis. Image Underst., v. 114, p. 1180-1202, 2010.

INTEL. Intel AVX. 2011. Disponível em: <http://software.intel.com/ en-us/avx/>. Acesso em: 23 de janeiro de 2012. 
KIRNER, C.; SISCOUTTO, R. Realidade Virtual e Aumentada: Conceitos, Projeto e Aplicações. Porto Alegre: SBC - Sociedade Brasileira de Computação, 2007. ISBN 8576691086.

LUEBKE, D.; HUMPHREYS, G. How gpus work. Computer, v. 40, p. 96-100, 2007.

MADEIRA, D.; LEWINER, T. Gpu octrees and optimized search. In: VIII Brazilian Symposium on Games and Digital Entertainment. [S.I.: s.n.], 2009.

MICROSOFT. DirectCompute Lecture Series 101: Introduction to DirectCompute. 2010. Disponível em: <http://channel9.msdn.com/Blogs/gclassy/ DirectCompute-Lecture-Series-101-Introduction-to-DirectCompute>. Acesso em: 23 de janeiro de 2012.

. MSDN - HLSL. 2011. Disponível em: <http://msdn.microsoft. com/ en-us/library/bb509561 (v=vs . 85) . aspx>. Acesso em: 23 de janeiro de 2012.

MIDDLEBURY. vision.middlebury.edu. 2002. Disponível em: < http: //vision. middlebury. edu/stereo/>. Acesso em: 23 de janeiro de 2012.

MILGRAM, P.; KISHINO, F. A taxonomy of mixed reality visual displays. IEICE Transactions on Information Systems, E77-D, p. 1, 1994.

NAKAMURA, R. Vídeo-Avatar com Detecção de Colisão para Realidade Aumentada e Jogos. Tese (Doutorado) - Escola Politécnica, 2008. Disponível em: <http: //www.teses.usp.br/teses/disponiveis/3/3141/ tde-01102008-132754/pt-br . php>. Acesso em: 23 de janeiro de 2012.

NICKOLLS, J.; DALLY, W. The gpu computing era. Micro, IEEE, v. 30, p. 56-69, 2010.

NVIDIA. CUDA C Programming Guide 3.2. [S.I.], 2010. Disponível em: $<$ http://developer.download.nvidia.com/compute/cuda/3_2_prod/ toolkit/docs/CUDA_C_Programming_Guide.pdf>. Acesso em: 23 de janeiro de 2012.

CUDA C Programming Guide 4.0. [S.I.], 2011. Disponível em:

<http://developer. download.nvidia.com/compute/DevZone/docs/html/ C/doc/CUDA_C_Programming_Guide.pdf>. Acesso em: 23 de janeiro de 2012.

. CUDA In Action - Research \& Apps. 2011. Disponível em:

$<$ http://developer.nvidia.com/cuda-action-research-apps>. Acesso em: 23 de janeiro de 2012.

. Developer Zone - Cg Toolkit. 2011. Disponível em: <http: //developer .nvidia. com/cg-toolkit>. Acesso em: 23 de janeiro de 2012.

. Developer Zone - OpenCL. 2011. Disponível em: <http: //developer . nvidia. com/opencl>. Acesso em: 23 de janeiro de 2012. 
. NVIDIA Tegra 2. 2011. Disponível em: <http://wWw.nvidia.com/ object/tegra-2.html>. Acesso em: 23 de janeiro de 2012.

OPENCL. OpenCL - The open standard for parallel programming of heterogeneous systems. 2011. Disponível em: <http://www . khronos.org/ opencl/>. Acesso em: 23 de janeiro de 2012.

OPENCV. OpenCV Change Logs. 2010. Disponível em: <http://opencv. willowgarage.com/wiki/OpenCV\%20Change\%20Logs>. Acesso em: 28 de janeiro de 2011.

OPENGL. OpenGL Shading Language. 2011. Disponível em: <http: //www . opengl.org/documentation/glsl/>. Acesso em: 23 de janeiro de 2012.

OPENMP. OpenMP.org. 2012. Disponível em: <http://openmp.org/wp>. Acesso em 23 de janeiro de 2012.

OWENS, J. D. et al. A survey of general-purpose computation on graphics hardware. Computer Graphics Forum, v. 26, p. 80-113, 2007.

ROSENBERG, I. D. et al. Real-time stereo vision using semi-global matching on programmable graphics hardware. In: ACM SIGGRAPH 2006 Sketches. New York, NY, USA: ACM, 2006. (SIGGRAPH '06, v. 3).

SANDERS, J.; KANDROT, E. CUDA by Example: An Introduction to General-Purpose GPU Programming. [S.I.]: Addison-Wesley Professional, 2010. ISBN 0131387685.

SCHARSTEIN, D.; SZELISKI, R. A taxonomy and evaluation of dense two-frame stereo correspondence algorithms. Int. J. Comput. Vision, Kluwer Academic Publishers, Hingham, MA, USA, v. 47, p. 7-42, 2002.

SISCOUTTO, R. A. Proposta de Arquitetura para Teleconferência Baseada na Integração de Vídeo-Avatar Estereoscópico em Ambiente Virtual Tridimensional. Tese (Doutorado) — Escola Politécnica, 2003.

SKILLICORN, D. B.; TALIA, D. Models and languages for parallel computation. ACM Comput. Surv., ACM, v. 30, p. 123-169, 1998.

STONE, J. E.; GOHARA, D.; SHI, G. Opencl: A parallel programming standard for heterogeneous computing systems. IEEE Des. Test, IEEE Computer Society Press, v. 12, p. 66-73, 2010.

TOKUNAGA, D. M. Técnicas de Reconstrução e Renderização de Vídeo-Avatares para Educação e Jogos Eletrônicos. Tese (Mestrado) Escola Politécnica, 2010.

TSUDA, F.; NAKAMURA, R. Metodologia para conversão de algoritmos para cuda: Estudo de caso em sistema de vídeo-avatar com realidade aumentada. In: Anais do VIII Workshop de Realidade Virtual e Aumentada. [S.I.: s.n.], 2011. 
A technique for collision detection and $3 d$ interaction based on parallel gpu and cpu processing. In: Proceedings of the $X$ Brazilian Symposium on Games and Digital Entertainment. [S.I.: s.n.], 2011.

UMBAUGH, S. E. Computer Vision and Image Processing: A Practical Approach Using Cviptools with Cdrom. Upper Saddle River, NJ, USA: Prentice Hall PTR, 1997. ISBN 0132645998.

VELHO, L.; FRERY, A. C.; GOMES, J. Image Processing for Computer Graphics and Vision. [S.I.]: Springer Publishing Company, Incorporated, 2008. ISBN 1848001924, 9781848001923.

WU, E.; LIU, Y. Emerging technology about gpgpu. In: Circuits and Systems, 2008. APCCAS 2008. IEEE Asia Pacific Conference on. [S.I.: s.n.], 2008. p. 618-622.

YANG, R.; POLLEFEYS, M. A versatile stereo implementation on commodity graphics hardware. Real-Time Imaging, v. 11, p. 7-18, 2005.

YANG, Z.; ZHU, Y.; PU, Y. Parallel image processing based on cuda. In: Computer Science and Software Engineering, 2008 International Conference on. [S.I.: s.n.], 2008. v. 3, p. 198-201.

ZHANG, K. et al. Real-time accurate stereo with bitwise fast voting on cuda. In: Computer Vision Workshops (ICCV Workshops), 2009 IEEE 12th International Conference on. [S.I.: s.n.], 2009. p. 794-800.

ZHANG, N.; CHEN, Y. shan; WANG, J. li. Image parallel processing based on gpu. In: Advanced Computer Control (ICACC), 2010 2nd International Conference on. [S.I.: s.n.], 2010. v. 3, p. 367-370.

ZITOVA, B.; FLUSSER, J. Image registration methods: a survey. Image and Vision Computing, v. 21, p. 977-1000, 2003. 